MARINA SPARVOLI DE MEDEIROS

\title{
FABRICAÇÃO DE ELEMENTOS ÓPTICOS DIFRATIVOS DE MODULAÇÃO COMPLETA
}

\author{
Dissertação apresentada à Escola \\ Politécnica da Universidade de São \\ Paulo para obtenção do Título de \\ Mestre em Engenharia.
}


MARINA SPARVOLI DE MEDEIROS

\title{
FABRICAÇÃO DE ELEMENTOS ÓPTICOS DIFRATIVOS DE MODULAÇÃO COMPLETA
}

\author{
Dissertação apresentada à Escola \\ Politécnica da Universidade de São \\ Paulo para obtenção do Título de \\ Mestre em Engenharia. \\ Área de Concentração: \\ Engenharia Elétrica \\ Orientador: \\ Prof. Dr. Ronaldo D. Mansano
}


Este exemplar foi alterado e revisado em relação à versão original, sob a responsabilidade única do autor e com anuência de seu orientador.

São Paulo, 03 de Setembro de 2007

Assinatura do Autor

Assinatura do Orientador

Sparvoli, Marina

FABRICAÇÃO DE ELEMENTOS ÓPTICOS DIFRATIVOS DE MODULAÇÃO COMPLETA. São Paulo, 2007.

$102 \mathrm{p}$.

Dissertação (Mestrado) - Escola Politécnica da Universidade de São Paulo. Departamento de Engenharia de Sistemas Eletrônicos.

1. Elementos ópticos difrativos 2. Óptica difrativa

I. Universidade de São Paulo. Escola Politécnica. Departamento de Engenharia Eletrônica. 


\section{AGRADECIMENTOS}

Agradeço ao Prof. Dr. Ronaldo Domingues Mansano pela orientação deste trabalho e acima de tudo, pela paciência.

Á Prof ${ }^{\text {a }}$ Dra. Lucila Helena Deliesposte Cescato pelos conselhos dados na apresentação do Exame de Qualificação.

Ao Dr. Giuseppe A. Cirino pela consultoria e pelos muitos conselhos dados sempre quando houveram dúvidas e na apresentação do Exame de Qualificação.

Aos técnicos do LSI (Escola Politécnica da USP) Alexandre Marques Camponucci, Adir José Moreira e Nelson Ordonez pelo auxílio no desenvolvimento deste trabalho.

Aos professores Dr. José Fernando Diniz Chubaci e Mikiya Muramatsu do Intituto de Física da USP pela ajuda na caracterização óptica dos materiais utilizados neste projeto para o desenvolvimento dos dispositivos.

Ao Prof. Patrick Bernard Verdonck pela ajuda no início do projeto.

Ao Prof. Dr. Luis da Silva Zambom pela ajuda em geral na utilização da sala limpa.

Aos amigos do laboratório, em especial Ana Carolina Bueno, Roberto Leminski e Ana Paula Mousinho, pelo apoio, idéias, conselhos e discussões.

Obrigada a todos. 


\section{RESUMO}

Neste projeto foram desenvolvidos elementos ópticos difrativos fabricados em vidro óptico com modulação de fase, elementos fabricados em silício e em Diamond Like Carbon (carbono tipo diamante) com modulação completa de fase e amplitude. O vidro óptico começa a transmitir em $277 \mathrm{~nm}$ (ultravioleta) e vai até o infravermelho próximo (2200 nm) da mesma maneira que o Diamond Like Carbon (que começa a transmitir em 330 nm). Já o silício é um material que começa a transmitir no infravermelho próximo (em torno de $980 \mathrm{~nm}$ ) e vai até o infravermelho médio (16000 nm). Tanto para o Diamond Like Carbon como para o vidro óptico, optou-se por desenvolver dispositivos que operem para um comprimento de onda de 632,8 nm. Já os elementos ópticos difrativos baseados em silício foram fabricados para operar em 2 comprimentos de onda: $1550 \mathrm{~nm}$ e $10600 \mathrm{~nm}$.

Para os dispositivos fabricados, foram utilizadas etapas de limpeza de substrato, de deposição de filmes, de litografia e de corrosão úmida e por plasma. A etapa de corrosão por plasma foi o principal objeto de estudo do processo de fabricação com o intuito de otmilizá-la. Foram feitos estudos de taxa de corrosão dos materiais com diferentes composições gasosas com a finalidade de se encontrar os parâmetros mais adequados para otimizar a fabricação dos dispositivos. As melhores condições de processo para o vidro corroído com plasma de $\mathrm{CF}_{4}$ são pressão de 100 mTorr e potência de 400 W, para o Diamond Like Carbon corroído com plasma de $\mathrm{O}_{2}$, pressão de 25 mTorr e potência de $50 \mathrm{~W}$ e para o silício corroído com plasma de $\mathrm{SF}_{6}$ os parâmetros são pressão de 100 mTorr e potência de $150 \mathrm{~W}$.

Análises ópticas dos elementos, fabricados com esses processos foram realizadas. Na análise óptica dos dispositivos de vidro com dois e quatro níveis de modulação de fase ficou evidente que os elementos ópticos apresentaram bom desempenho devido à uniformidade da intensidade da luz projetada nas imagens e da baixa intensidade do ponto de ordem zero, além das imagens estarem bem focadas e definidas. Para os dispositivos fabricados em Diamond Like Carbon foram formadas imagens bem definidas e focadas. Em uma análise óptica da rugosidade RMS dos filmes finos de Diamond Like Carbon através da obtenção da Reflectância Total e da Reflectância Difusa, foi encontrado um valor de 18,8 nm, o qual se encontra bem abaixo do limite de $63 \mathrm{~nm}$, o que faz com que o dispositivo gere uma imagem otimizada. 


\begin{abstract}
In this project it has been manufactured diffractive optical elements in three materials, optical glass, Diamond Like Carbon (DLC) and silicon. These elements were applied in phase modulation devices. The extra advantage of silicon and DLC were the amplitude modulation in visible and ultra-violet spectra respectively. The optic glass starts to transmit at the wavelength $277 \mathrm{~nm}$ (UV light) and goes till the near infrared in the same way that the Diamond Like Carbon (that starts to transmit in $330 \mathrm{~nm}$ ). Silicon is a material that starts to transmit in the near infrared $(980 \mathrm{~nm})$ and goes till the middle infrared $(16000 \mathrm{~nm})$. Both, DLC and optic glass, was opted to developing devices that operate for a $632,8 \mathrm{~nm}$ wavelength. Diffractive Optical Elements silicon based had been manufactured to operate in two wavelengths: $1550 \mathrm{~nm}$ and $10600 \mathrm{~nm}$. For the manufactured diffractive optical elements, were used process stages of substrate cleanness, films deposition, lithography and hybrid wet and dry plasma etching. The plasma etching stage was the most studied manufacturing process, aiming of optimized it. For this, some studies of materials etching rate with different gases were made with the purpose to find the more adequate parameters of Radio Frequency power and pressure to reduce the process time to obtain the necessary thickness and low surface roughness. The best conditions of plasma etching process were 100 mTorr pressure and Radio Frequency power of $400 \mathrm{~W}$ for the glass, 25 mTorr pressure and Radio Frequency power $50 \mathrm{~W}$ for the Diamond Like Carbon and the parameters are $100 \mathrm{mTorr}$ pressure and Radio Frequency power $150 \mathrm{~W}$ for silicon. Optical analyses of the diffractive optical elements manufactured with these processes had been realized. In the optical analysis of the glass devices with two and four levels of phase modulation was evident that the optic elements had good performance due to uniformity of the projected light intensity in the images and low intensity of the zero order spot, as well the images are focused and defined. For elements manufactured in Diamond Like Carbon, defined and well-focused images had been formed. In an optic analysis of Diamond Like Carbon thin films RMS roughness through the Total Reflectance and the Diffuse Reflectance, was found a value of 18,8 nm roughness, which is below $63 \mathrm{~nm}$ limit, what do that the EOD generates an optimized image.
\end{abstract}




\section{SUMÁRIO}

\section{LISTA DE FIGURAS}

\section{LISTA DE TABELAS}

\section{LISTA DE ABREVIATURAS E SIGLAS}

1 INTRODUÇÃO 1

1.1. Apresentação do Trabalho 5

2 REVISÃO BIBLIOGRÁFICA $\quad 6$

2.1 Princípios de física óptica aplicados em elementos ópticos difrativos 6

2.2 Fabricação de EODs $\quad 14$

$\begin{array}{ll}2.3 \text { Replicagem de EODs } & 17\end{array}$

3 METODOLOGIA 20

3.1 Introdução 20

3.2 Métodos de limpeza das lâminas $\quad 20$

3.2.1 Limpeza de lâminas virgens de silício 20

3.2.2 Limpeza de lâminas virgens de vidro óptico 21

3.2.3 Remoção de fotorresiste $\quad 21$

3.2.4 Remoção de fotorresiste após a corrosão 21

3.2.5 Corrosão úmida de alumínio antes do processo de $\begin{array}{ll}\text { corrosão por plasma } & 21\end{array}$

3.2.6 Remoção de alumínio depois do processo de corrosão 22

3.3 Processos de deposição dos filmes de carbono tipo diamante (DLC) 22

3.3.1 Parâmetros utilizados para a deposição dos filmes de carbono 24

3.4 Evaporação de Alumínio $\quad 24$

3.5 Litografia $\quad 25$

$\begin{array}{ll}\text { 3.5.1 Litografia com fotorresiste OFPR } 8600 & 25\end{array}$

3.6 Equipamento de corrosão por plasma modo RIE

$\begin{array}{ll}\text { (Reactive Ion Etching) } & 27\end{array}$

$\begin{array}{ll}\text { 3.6.1 Processos de corrosão das lâminas de vidro } & 28\end{array}$

3.6.1.1 Parâmetros da corrosão por plasma para lâminas de vidro com máscara de fotorresiste ou alumínio 29

3.6.1.2 Parâmetros da corrosão com potências maiores de processo para lâminas protegidas por alumínio e corroídas com plasma de $\mathbf{C F}_{4}$ 
3.6.1.3 Corrosão por plasma para confecção de elementos

ópticos difrativos com 2 níveis de fase

3.6.1.4 Corrosão por plasma para confecção de elementos ópticos difrativos com 4 níveis de fase

3.6.2 Processos de corrosão de filme fino de DLC

3.6.2.1 Parâmetros da corrosão por plasma para

filmes finos de DLC sobre substrato de silício

3.6.2.2 Parâmetros da corrosão por plasma para

filmes finos de DLC sobre substrato

de vidro para fabricação de EODs

3.6.3 Processos de corrosão de lâminas de silício

3.6.3.1 Parâmetros da corrosão por plasma para

lâminas de silício

3.6.3.2 Parâmetros da corrosão por plasma para

lâminas de silício para fabricação de EODs

3.7 Elipsometria

3.8 Medições de rugosidade e altura de degrau por perfilometria

3.8.1 Medidas de altura do degrau pela técnica de

Perfilometria (amostras de vidro protegidas por fotorresiste)

3.8.1.1 Medidas pela técnica de Perfilometria antes

do processo de corrosão (amostras de vidro)

3.8.1.2 Medidas pela técnica de Perfilometria após

processo de corrosão (amostras de vidro)

3.8.1.3 Perfilometria após processo de corrosão e remoção do fotorresiste (amostras de vidro)

3.8.2 Medidas pela técnica de Perfilometria (amostras de vidro protegidas por alumínio)

3.8.3 Medidas pela técnica de Perfilometria (amostras

de DLC protegidas por fotorresiste)

3.8.4 Medidas pela técnica de Perfilometria

(amostras de silício protegidas por fotorresiste) 
3.13 Bancada de análise óptica

3.13.1 Analise óptica de elementos ópticos difrativos de vidro com 2 níveis de fase

3.13.2 Analise óptica de elementos ópticos difrativos de vidro com 4 níveis de fase

3.13.3 Analise óptica de elementos ópticos difrativos de DLC com 2 níveis de modulação de fase

4 RESULTADOS E DISCUSSÃO

4.1 Dispositivos difrativos binários fabricados em vidro óptico

4.1.2 Amostras protegidas por fotorresiste

4.1.2.1 Perfilometria antes do processo de corrosão

4.1.2.2 Perfilometria após processo de corrosão

4.1.2.3 Perfilometria após processo de corrosão e remoção do fotorresiste

4.1.3 Amostras protegidas por Alumínio

4.1.3.1 Perfilometria das amostras protegidas por alumínio

4.1.3.3 Análise da rugosidade por Microscopia de Força Atômica (AFM - Atomic Force Microscopy)

4.1.4 Estudo da corrosão por plasma de vidro com altas potências de $\mathbf{R F}$

4.1.4.1 Altura de degrau e rugosidades das amostras processadas com potência de $250 \mathrm{~W}, 350 \mathrm{~W}$ e $400 \mathrm{~W}$

\subsubsection{Microscopia de Força Atômica das amostras} de vidro processada com potências de 250, 350 e $400 \mathrm{~W}$

4.1.4.3 Microanálise das amostras de vidro corroídas por plasma - Porcentagem atômica das amostras processadas com $250 \mathrm{~W}, 350 \mathrm{~W}$ e $400 \mathrm{~W}$

4.1.5 EODs de dois níveis de fase obtidos através de corrosão de vidro óptico

4.1.5.1 Análise ópticas dos dispositivos ópticos difrativos de dois níveis de fase 
4.1.5.2 Análise da altura do degrau dos dispositivos fabricados

4.1.6 EODs de quatro níveis de fase obtidos através de corrosão

de vidro óptico

4.1.6.1 Análise óptica dos dispositivos ópticos difrativos de quatro níveis de fase

4.1.6.2 Análise óptica da superfície dos dispositivos

4.2 Dispositivos difrativos binários fabricados em DLC

4.2.1 Perfilometria e Elipsometria da amostra de filme fino

de DLC sobre substrato de silício

4.2.2 Perfilometria das amostras de filme fino sobre substrato de silício

4.2.2.1 Perfilometria antes do processo de corrosão

4.2.2.2 Perfilometria após processo de corrosão

4.2.2.3 Análise por Microscopia de Força Atômica (AFM Atomic Force Microscopy) das amostras de DLC

4.2.3 dispositivos de 2 níveis de fase obtidos pela corrosão de

filme fino de DLC

4.2.3.1 Análise óptica

4.2.3.2 Análise óptica da superfície dos dispositivos

4.3 Estudo de corrosão de silício para fabricação de dispositivos

difrativos binários

4.3.1 Perfilometria das amostras de silício

4.3.1.1 Medida da altura de degrau antes do processo de corrosão

4.3.1.2 Medidade de altura de degrau e rugosidades após processo de corrosão

4.3.1.3 Análise por Microscopia de Força Atômica (AFM Atomic Force Microscopy) das amostras de silício

4.3.2 Análise óptica da superfície dos dispositivos de 2 níveis de fase obtidos pela corrosão do silício

6 PROPOSTAS DE NOVOS TRABALHOS 


\section{LISTA DE FIGURAS}

Fig. 1 Família da óptica difrativa 1

Fig. 2 Funções básicas dos elementos ópticos difrativos 2

Fig. 3 Ilustração de um experimento de difração em uma abertura 6

Fig. 4 Ilustração do princípio de Huygens para a construção geométrica de $\begin{array}{ll}\text { uma frente de onda, a partir de uma frente de onda anterior } & 7\end{array}$

Fig. 5 Difração por uma fenda de área A 8

Fig. 6 Esquema de difração 9

Fig. 7 Elementos ópticos - a) lentes refrativas, b) espelhos, c) prisma, d) lente GRIN, e) elementos ópticos difrativos, f) elemento híbrido

Fig. 8 Um kinoform caracteriza uma superfície variante lisa (acima), enquanto um sistema óptico binário aproxima-se da superfície lisa através de uma série de etapas (abaixo)

Fig. 9 Esquema mostrando origem das matrizes de EODs, ferramentas de replicagem e a técnica de replicagem em si

Fig. 10 Ilustração esquemática da conversão de um elemento óptico refrativo (EOR) para um elemento óptico difrativo (EOD) (a) função de fase refrativa, (b) EOD resultante, (c) aproximação binária em oito níveis. Neste caso, são necessárias três etapas de fotolitografia e corrosão por plasma

Fig. 11 Sistema de magnetron sputtering reativo utilizado neste trabalho

Fig. 12 Sistema de magnetron sputtering reativo: (1) Campânula de aço inoxidável, (2) porta amostra, (3) alvo, (4) eletrodo, (5) válvula gaveta, (6) bomba turbo molecular, (7) sistema de RF composto de malha de acoplamento e gerador de RF

Fig. 13 máscaras utilizadas no processo a) padrão, b) óptica difrativa, c) $\pi / 2$ e d) $\pi$

Fig. 14 Reactive Ion Etching

Fig. 15 Representação esquemática do equipamento de corrosão: (1) eletrodo, (2) “crivo” que homogeneiza a entrada de gases, (3) entrada de gases

Fig. 16 Fabricação de elementos ópticos difrativos com 2 níveis de fase 30

Fig. 17 Sequência de fabricação de elementos ópticos difrativos com 4 níveis 31 
de fase

Fig. 18 Rugosidade máxima 35

Fig. 19 Medição da altura do degrau do resiste antes do processo de corrosão 36

Fig. 20 Medição da altura do degrau do fotorresiste corroído mais vidro corroído depois da corrosão 36

Fig. 21 Medição da altura do degrau do vidro corroído depois da corrosão e remoção do fotorresiste

Fig. 22 Sequência de obtenção de degrau para teste de rugosidade e taxa de corrosão

Fig. 23 Foto tirada do aparato utilizado na medição óptica dos EODs de vidro com dois níveis de fase

Fig. 24 Esquema do arranjo experimental utilizado para análise óptica de hologramas do tipo Fresnel com quatro níveis de modulação de fase. A distância d controla a magnificação da imagem.

Fig. 25 Aparato utilizado na medição óptica dos EODs de DLC com dois níveis de fase

Fig. 26 Taxa de corrosão do fotorresiste em função da variação do parâmetros de processo de corrosão por plasma

Fig. 27 Rugosidade normalizada em função da variação dos parâmetros de processo de corrosão por plasma do fotorresiste

Fig. 28 Taxa de corrosão do vidro em função da variação dos parâmetros de processo de corrosão por plasma

Fig. 29 Rugosidade normalizada em função da variação dos parâmetros de processo de corrosão por plasma do vidro

Fig. 30 Seletividade entre vidro e fotorresiste em função dos parâmetros de corrosão por plasma

Fig. 31 Taxa de corrosão do vidro em função da variação dos parâmetros de processo de corrosão por plasma

Fig. 32 Rugosidade normalizada em função da variação dos parâmetros de processo de corrosão por plasma do vidro

Fig. 33 Imagem amostra 50 mTorr e $50 \mathrm{~W}$

Fig. 34 Imagem amostra 50 mTorr e $100 \mathrm{~W}$

Fig. 35 Microscopia de Força Atômica para amostra processada com 53 
100mTorr e 50W

Fig. 36 Microscopia de Força Atômica para amostra processada com 100mTorr e $150 \mathrm{~W}$

Fig. 37 Microscopia de Força Atômica para amostra processada com 100mTorr e 200W

Fig. 38 Gráfico de taxa de corrosão em função de potência de RF para vidro óptico e sílica fundida

Fig. 39 Gráfico de taxa de corrosão em função de potência apenas para o vidro óptico

Fig. 40 Rugosidade normalizada em função da variação de potência no processo de corrosão por plasma do vidro com pressão constante de 100 mTorr

Fig. 41 Microscopia de Força Atômica das amostras processadas com a) amostra 250W, b) amostra $350 \mathrm{~W}$ e c) amostra $400 \mathrm{~W}$

Fig. 42 Espectro da amostra processada com $250 \mathrm{~W}$ com contagem dos elementos presentes para a) vidro e b) sílica fundida

Fig. 43 EODs “quadrado" corroídos por a) 5 minutos, b) 6 minutos, c) 6,5 minutos e d) 7 minutos

Fig. 44 EODs “cruz” corroídos por a) 5 minutos, b) 6 minutos, c) 6,5 minutos e d) 7 minutos

Fig. 45 Análise da intensidade de luz dos EODs “cruz" corroídos por a) 5 minutos, b) 6 minutos, c) 6,5 minutos e d) 7 minutos

Fig. 46 Análise de intensidade de luz 3D dos EODs “cruz” corroídos por a) 5 minutos, b) 6 minutos, c) 6,5 minutos e d) 7 minutos

Fig. 47 EOD de Fresnel Águia

Fig. 48 EOD de Fresnel Borboleta

Fig. 49 a) Estutura da borboleta e b) Rugosidade

Fig. 50 Curvas de transmitância do vidro virgem e do vidro corroído

Fig. 51 a) Reflectância difusa e total do vidro virgem, b) Reflectância difusa e total do vidro corroído e c) Reflectância difusa dividida pela total do vidro virgem e corroído para cálculo de rugosidade RMS

Fig. 52 Taxa de corrosão do fotorresiste em função dos parâmetros de processo da corrosão por plasma e média das rugosidades das 
amostras

Fig. 53 Rugosidade normalizada em função da variação dos parâmetros de processo de corrosão por plasma do fotorresiste

Fig. 54 Taxa de corrosão do DLC em função dos parâmetros de processo da corrosão por plasma e média das rugosidades das amostras

Fig. 55 Rugosidade normalizada em função da variação dos parâmetros de processo de corrosão por plasma do DLC

Fig. 56 AFM amostra 25 mTorr e 50W

Fig. 57 FM amostra 100 mTorr e 150W

Fig. 58 Imagem formada pelo dispositivo fabricado sobre filme fino de DLC a) “quadrado”, b) “cruz” e c) “LSI”

Fig. 59 Micrografia da estrutura do dispositivo “cruz”

Fig. 60 Curva de transmitância do filme fino de DLC sobre vidro óptico

Fig. 61 a) Reflectância difusa e total do DLC e b) Reflectância difusa dividida pela total do vidro virgem e corroído para cálculo de rugosidade RMS

Fig. 62 Taxa de corrosão do fotorresiste em função da variação dos parâmetros de processo de plasma

Fig. 63 Rugosidade normalizada em função da variação dos parâmetros de processo de corrosão por plasma do fotorresiste

Fig. 64 Taxa de corrosão do silício em função da variação dos parâmetros de processo de corrosão por plasma

Fig. 65 Rugosidade normalizada em função da variação dos parâmetros de processo de corrosão por plasma do silício

Fig. 66 Micrografia AFM das amostras de silício corroídas por plasma com os parâmetros a) 25 mTorr e 50W, b)100 mTorr e 50W e c)100 mTorr e 150W

Fig. 67 Estrutura do dispositivo Cruz

Fig. 68 Estrutura do dispositivo Quadrado

Fig. 69 Estrutura do dispositivo Círculo

Fig. 70 Estrutura da Rede Difrativa

Fig. 71 Micrografias do mesmo elemento óptico difrativo com detalhes em a) $50 \mu \mathrm{m}$ e b) $10 \mu \mathrm{m}$

Fig. 72 Curva de Transmitância do silício 


\section{LISTA DE TABELAS}

Tabela I - Métodos e características de alguns polímeros utilizados para replicagem 18

$\begin{array}{lll}\text { Tabela } & \text { II }- \text { Parâmetros da corrosão } & 29\end{array}$

Tabela $\quad$ III - Médias das rugosidades do vidro para trecho corroído e não $\quad 47$

Tabela $\quad$ IV - Médias das rugosidades do vidro protegido por alumínio $\quad 50$

Tabela $\quad \mathrm{V}-$ Resultados obtidos pela técnica de perfilometria 55

Tabela $\quad$ VI - Resultados obtidos pela microanálise de porcentagem atômica $\quad 59$

Tabela VII - Altura dos dispositivos obtidos por corrosão por plasma 64

Tabela VIII - Comparação entre vidro virgem e vidro corroído 69

$\begin{array}{lll}\text { Tabela } & \text { IX }- \text { Médias das rugosidades do fotorresiste } & 71\end{array}$

Tabela $\quad X-$ Médias das rugosidades do DLC 72

Tabela $\quad$ XI - Médias das rugosidades do Silício 80 


\section{LISTA DE ABREVIATURAS E SIGLAS}

EOD Elementos Ópticos Difrativos

DLC Diamond Like Carbon

MOEs Micro-Optical Elements

$\mathrm{d}_{\max } \quad$ Altura máxima

m Níveis de fase

M etapas de fotolitografia

PC policarbonato

PVC policloreto de vinila

PMMA polimetacrilato de metila

UV Ultra Violeta

DI Água deionizada

RIE Reactive Ion Etching

RF Rádio Frequëncia

n I índice de refração

d espessura

$\mathrm{R}_{\mathrm{A}} \quad$ Rugosidade média

RMS Rugosidade média quadrática

p.p., $\mathrm{R}_{\mathrm{t}} \quad$ Rugosidade máxima ou pico-a-pico

$\mathrm{h}_{\mathrm{r}} \quad$ Altura do fotorresiste

NIR Near Infra Red

$\mathrm{h}_{\mathrm{v}} \quad$ Altura do vidro corroído

RD reflectância Difusa

R0 reflectância total

$\lambda$ Comprimento de onda

$\Delta \quad$ Rugosidade RMS

SEM Scanning Electronic Microscopy

AFM Atomic Force Microscopy 


\section{INTRODUÇÃO}

O objetivo deste trabalho é a fabricação de elementos ópticos difrativos (EODs) com modulação de fase e EODs com modulação de amplitude e, paralelamente, a melhora dos processos envolvidos na fabricação dos dispositivos e integração das etapas. Estão sendo desenvolvidos elementos ópticos difrativos fabricados sobre substrato de vidro óptico, filmes finos de carbono como diamante (DLC - Diamond Like Carbon) e também a partir de substrato de silício. Os elementos ópticos difrativos pertencem a uma classe relativamente recente de sistemas ópticos que operam através do princípio de difração e aproveitam a luz difratada (Figura 1). Tais componentes são muito mais eficientes que os componentes ópticos clássicos e são usados para manipular a amplitude, a fase e a polarização de uma frente de onda. Estes elementos podem ser aplicados na prototipagem de dispositivos ópticos de baixo custo, cujo emprego pode ser visto em equipamentos utilizados no dia-a-dia, tais como sensores de posição e presença. É fato que a grande maioria dos instrumentos ópticos possuem elementos ópticos de transmissão e/ou reflexivos. Em certos casos é possível substituir estes dispositivos pelos elementos ópticos difrativos que são muito mais leves e ocupam um volume relativamente menor, além de eliminar quase todas as etapas empregadas em métodos tradicionais de fabricação de elementos ópticos, como abrasão e polimento [1-8].

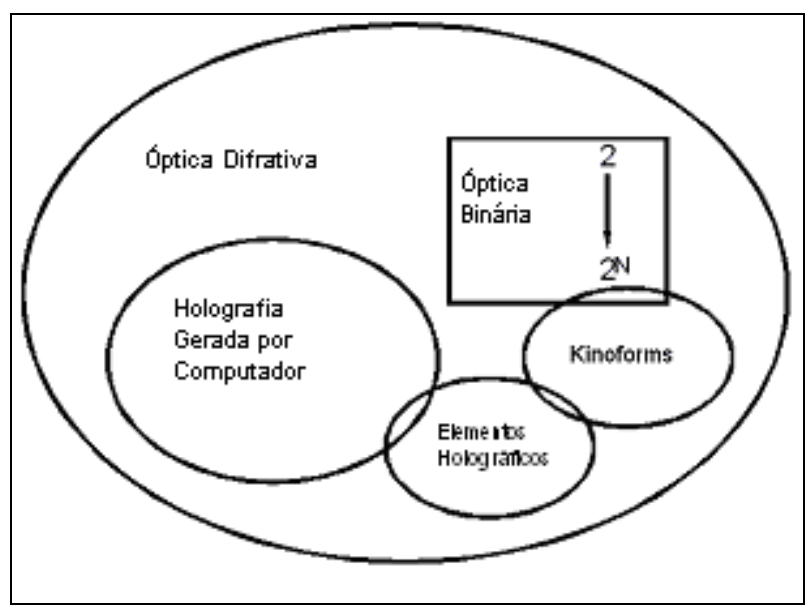

Fig.1 Família da óptica difrativa 
Os elementos ópticos tradicionais usam seu formato para "dobrar" a luz. A óptica difrativa trabalha pela quebra de ondas de luz incidentes em um vasto número de outras pequenas ondas, as quais são recombinadas para formar outras novas ondas que se propagam de maneira que se obtenha o resultado desejado. Os elementos ópticos difrativos são destinados à redefinir o papel dos sistemas ópticos em diversas áreas. EODs podem funcionar como redes, lentes ou qualquer outro tipo de elemento óptico (Figura 2). Grande abertura óptica, pouco peso, baixo custo e facilidade de produção em série são as características principais destes componentes. Podem oferecer propriedades ópticas únicas que não são possíveis com elementos ópticos convencionais. Podem ser fabricados com uma larga variedade de materiais como silício, sílica, polímeros, etc. Isto dá ao usuário uma grande flexibilidade de escolher o material para uma aplicação particular.

Estes componentes permitem o desenvolvimento de alguns produtos que não poderiam ser produzidos com as tecnologias ópticas precedentes (Figura 2).

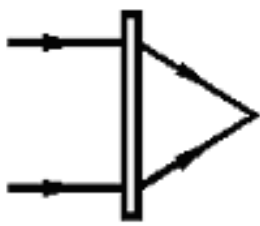

Lentes

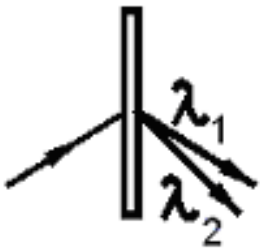

Dispersor

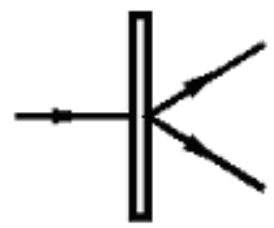

Beamsplitter

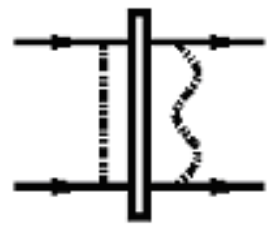

Gerador de onda Esférica

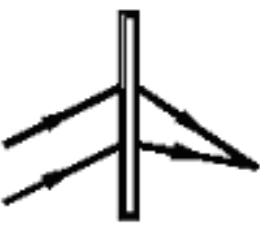

Powered Scanner

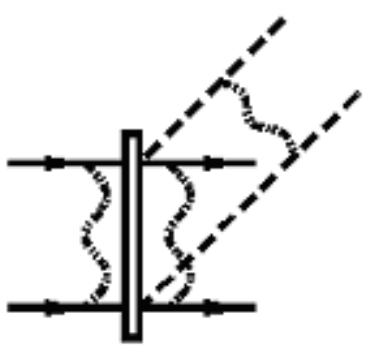

Wavefront

Sampler

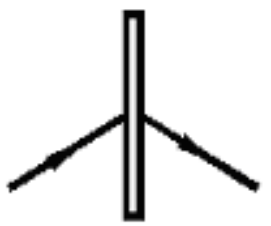

Defletor

de Feixe

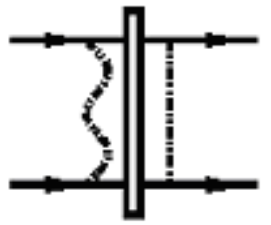

Corretor

Fig. 2 Funções básicas dos elementos ópticos difrativos [2] 
Os EODs têm as seguintes características:

- São sensíveis ao comprimento de onda. As características do comprimento focal e da aberração de um elemento difrativo variam com o comprimento de onda.

- Diversos elementos ópticos diferentes podem compartilhar da mesma estrutura sem interferir um com o outro. Assim, um único EOD pode ser usado como uma lente, um divisor de feixe e um filtro espectral simultaneamente.

- $\quad$ Os elementos difrativos são muito leves, porque são formados em películas finas de somente algumas micra.

- $\quad$ Podem gerar funções ópticas únicas que não são possíveis por elementos ópticos reflexivos ou refrativos convencionais, pois eles fornecem uma flexibilidade maior na configuração de sistema.

- $\quad$ Podem ser feitos para operar em uma faixa estreita de comprimento de onda.

- $\quad$ A fabricação e a replicagem são relativamente fáceis e baratas [3,4].

- $\quad$ Possuem baixo custo de manutenção [5].

EODs podem exibir aberrações cromáticas e/ou esféricas quando há uma mudança nos parâmetros e/ou no comprimento de onda do feixe de reconstrução ou do feixe de referência. As aberrações de ordem mais elevada tornam-se importantes para EODs de grandes aberturas para os quais as tolerâncias de alinhamento são muito baixas. A condição que eliminará todas as aberrações simultaneamente é duplicar um dos feixes de construção no processo de reconstrução. Isto é, entretanto, difícil de ser feito quando EODs são usados como componentes em instrumentos.

EODs podem desempenhar a maioria da funções fornecidas por um sistema óptico convencional, podendo ser aplicados nos seguintes dispositivo [6]:

- Filtros espectrais;

- Combinadores de feixes de luz;

- Sistema de exposição head-up para aviões e automóveis;

- Óculos de visão noturna;

- Comunicação óptica; 
- Discos compactos;

- Atenuador de difração de feixe de laser;

- Giroscópio óptico;

- Scanner Difrativo;

Também podem ser empregados em:

- Exposição Head-up montada em capacetes;

- Aplicações arquitetônicas;

- Sensores [8].

- Componentes híbridos difrativo-refrativo [7];

- Para dar forma à feixes de luz;

- $\mathrm{Na}$ arte;

- Para combinação coerente de feixes de laser;

- Para interconexões de computador;

- Para processamento de informação;

- Em geradores de padrão para teclado virtual á laser [9];

- Aplicações biomédicas e muitos outros dispositivos [10-33]. 


\subsection{Apresentação do Trabalho}

No Capítulo 2, é apresentada uma revisão bibliográfica da tecnologia de elementos ópticos difrativos, enfatizando a descrição das características físicas destes dispositivos, etapas de fabricação e replicagem, uma vez que a fabricação é o tópico mais importante a ser abordado pois se trata do objetivo deste estudo.

No Capítulo 3, são apresentados os materiais e métodos utilizados neste trabalho. Logo no início, é apresentado um esquema resumindo as etapas empregadas na fabricação de um elemento óptico difrativo. Neste capítulo tem-se a descrição dos métodos, materiais e equipamentos empregados na fabricação e caracterização física dos EODs, bem como na caracterização óptica dos padrões de difração gerados.

No Capítulo 4, são apresentados os resultados de caracterizações ópticas e físicas realizadas em elementos ópticos fabricados sobre substrato de vidro óptico B270 Schott, filme fino de DLC (diamond Like Carbon) sobre vidro óptico e EODs fabricados em silício.

No Capítulo 5, são apresentadas as conclusões do trabalho.

No Capítulo 6, são apresentadas propostas para novos trabalhos. 


\section{REVISÃO BIBLIOGRÁFICA}

\subsection{Princípios de física óptica aplicados em elementos ópticos difrativos}

$\mathrm{Na}$ óptica difrativa, os EODs operam de acordo com o princípio de HuygensFresnel. O princípio de Huygens é uma construção puramente geométrica que permite determinar a posição futura de uma frente de onda a partir de sua posição em um dado instante. Todos os pontos de uma frente de onda são considerados como fontes de ondas esféricas secundárias. A nova frente de onda, em um instante de tempo posterior, é a envolvente dessas ondas secundárias como se apresentam nesse instante. Deve-se considerar o fenômeno da difração da radiação eletromagnética, que é conseqüência da natureza ondulatória da luz. Ela se constitui da distorção causada numa onda eletromagnética que incide sobre um obstáculo de dimensões comparáveis ao seu comprimento de onda. Estes obstáculos podem ser aberturas num anteparo, objetos opacos tais como esferas, discos e outros. Em todos esses casos, o caminho seguido pelo raio não obedece às leis da óptica geométrica, sendo desviado sem haver mudanças no índice de refração do meio. Assim, temos a presença de radiação em locais nos quais ela não seria esperada, como nas regiões de sombra indicadas na Figura 3. A interação da radiação com as bordas do anteparo, ou do obstáculo, causa uma perturbação na radiação em propagação e a espalha por regiões onde ela não deveria normalmente ser detectada.

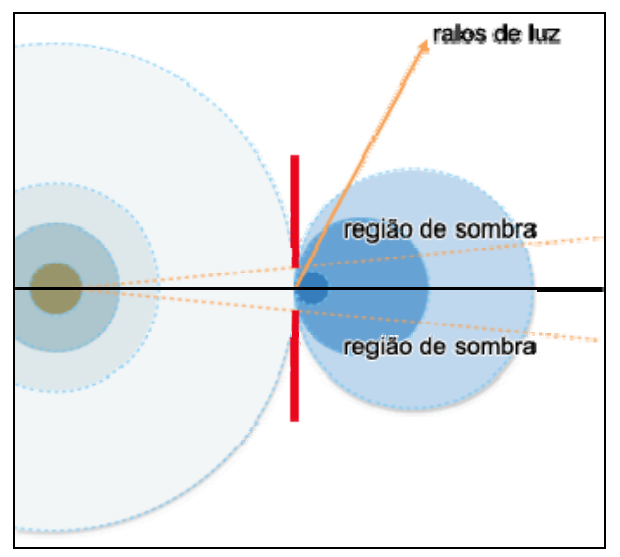

Fig.3 Ilustração de um experimento de difração em uma abertura 
Os aspectos essenciais da difração podem ser explicados qualitativamente pelo princípio de Huygens. Segundo ele, cada ponto na frente de onda age como uma fonte produzindo ondas secundárias que espalham em todas as direções. A função envoltória das ondas secundárias forma a nova frente de onda total. Na Figura 4 é ilustrado este fato. Com este princípio pode-se perceber que cada nova frente de onda no instante t' é formada pela interferência de infinitas fontes, as quais estão irradiando a partir da frente de onda no instante t. Isto pode ser traduzido em forma matemática dizendo-se que em cada ponto da nova frente de onda teremos um campo óptico que é igual à soma dos campos irradiados por todas as fontes secundárias. Nota-se que o fenômeno de difração baseia-se no de interferência. Como o número de fontes é infinito, as somas dos campos referentes a cada fonte secundária se transformará numa integral.

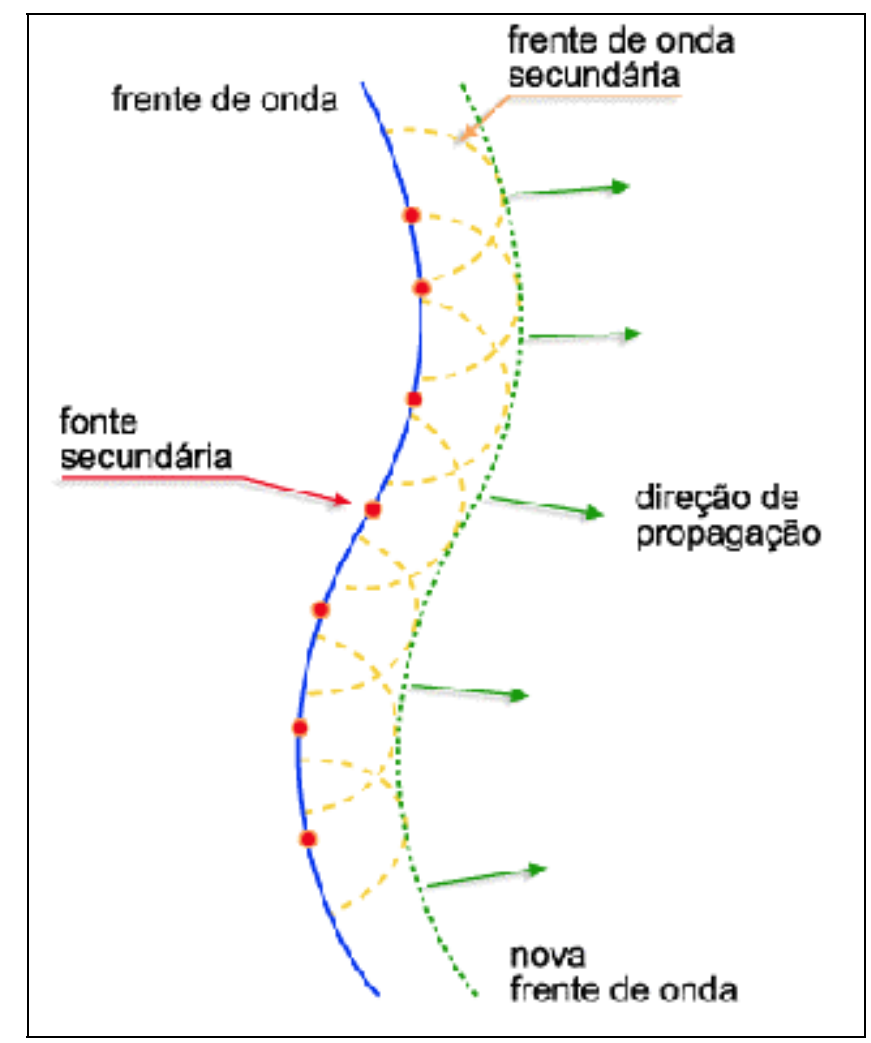

Fig.4 Ilustração do princípio de Huygens para a construção geométrica de uma frente de onda, a partir de uma frente de onda anterior

O princípio de Huygens pode ser enunciado matematicamente pela soma (integral) das várias ondas secundárias geradas numa área iluminada, como por exemplo uma 
fenda. A geometria para esta situação está esquematizada na Figura 5. A equação resultante de várias ondas secundárias no ponto $\mathrm{P}$ é dado pela eq. (1):

$$
U(P)=\iint_{A} U_{A} \frac{\exp \left\{i\left(k r_{2}-\omega t\right)\right\}}{r_{2}} d A
$$

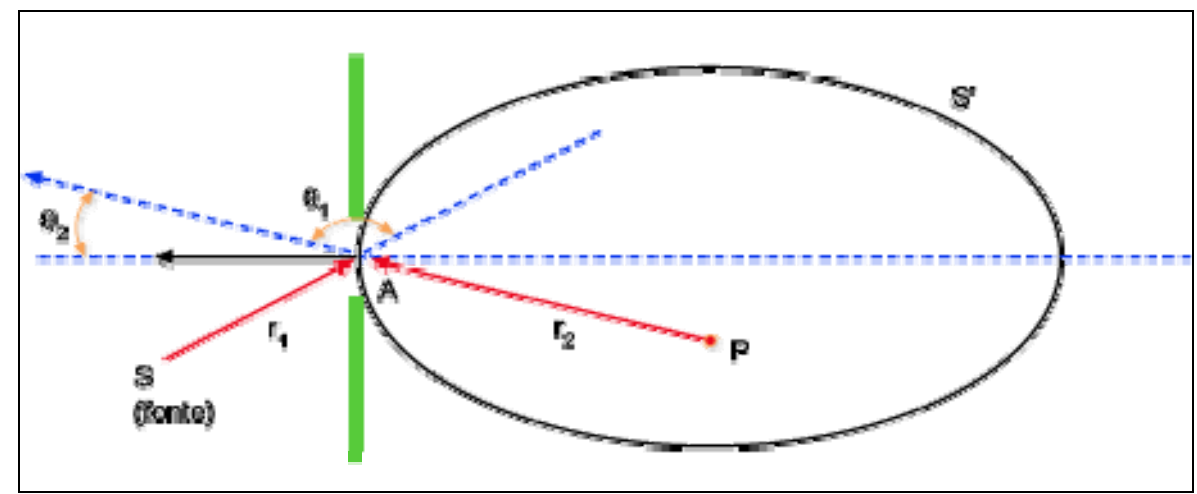

Fig.5 Difração por uma fenda de área $\mathrm{A}$

onde $\mathrm{U}_{\mathrm{A}}$ é a amplitude da onda primária que se origina na fonte $\mathrm{S}$ situada a uma distância $\mathrm{r}_{1}$ e ilumina a fenda. A partir dela, cada elemento dA da abertura gera uma onda esférica secundária que interfere no ponto $\mathrm{P}$, situado a uma distância $\mathrm{r}_{2}$, com outras ondas esféricas geradas em diferentes elementos da abertura [37].

Augustin Jean Fresnel adicionou às idéias intuitivas de Huygens o princípio de Thomas Young de interferência. Ao fazer isso, Fresnel supôs que sob determinadas circunstâncias as amplitudes e as fases das frentes de onda secundárias de Huygens poderiam interferir umas com as outras.

A amplitude e a fase de uma onda são uma parte manifestada de seu comportamento oscilatório. A amplitude é um número ou uma função escalar que descreve a extensão máxima da vibração do campo elétrico [40,41]. A fase é o comprimento do trajeto óptico de um raio, ou a fração de um ciclo oscilatório medido de uma referência específica ou origem [39]. 
O princípio de Huygens-Fresnel é um princípio de superposição usando frentes de ondas esféricas como as funções da base na superposição. $O$ princípio de superposição da frente de onda indica que as perturbações resultantes em uma frente de onda são as somas algébricas das ondas individuais que compreendem a frente de onda. A superposição é usada também para somar algebricamente amplitudes $[42,43]$.

Gustav Kirchhoff desenvolveu uma teoria matemática do princípio de HuygensFresnel, que se transformou posteriormente na teoria de difração escalar da onda de Fresnel-Kirchhoff. Arnold Johannes Wilhelm Sommerfeld desenvolveu mais tarde a teoria de difração escalar de Rayleigh-Sommerfeld [38].

Fresnel usou corretamente o princípio de Huygens para explicar a difração. Naquela época supunha-se que a luz consistia de ondas mecânicas, produzidas em um éter onipresente. Maxwell demonstrou que a natureza das ondas luminosas não era mecânica, mas eletromagnética. Einstein chegou a concepção moderna dessas ondas, eliminando a necessidade de se postular um éter. Atualmente é considerado que a construção de Huygens é uma interpretação de que cada ponto de uma frente de onda irradia uma pequena onda esférica [44].

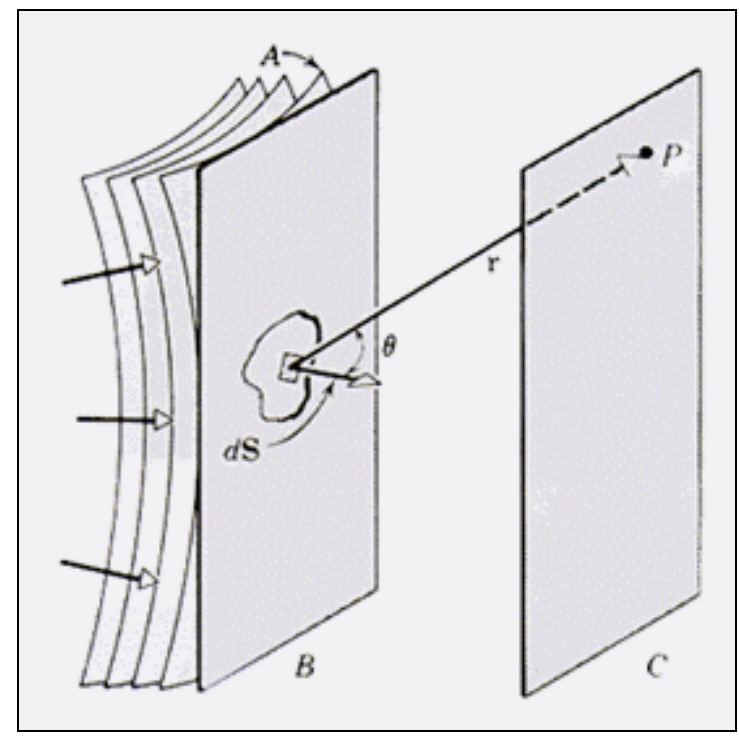

Fig.6 Esquema de difração 
Na Figura 6 é ilustrado um caso geral de difração. A superfície A é uma frente de onda que incide em um anteparo opaco $\mathbf{B}$, contento uma abertura de forma arbitrária; há, ainda, um anteparo $\mathbf{C}$, que recebe a luz que atravessa o orifício. Pode-se avaliar a distribuição de intensidade luminosa produzido em $\mathbf{C}$, subdividindo-se a frente de onda em áreas elementares dS, cada uma das quais se torna uma fonte de ondas secundárias de Huygens em expansão. Obtém-se a intensidade luminosa em um ponto $\mathbf{P}$, arbitrário, somando-se as perturbações ondulatórias causadas pelas ondas secundárias que aí chegam, vindas de todos esses irradiadores elementares.

As perturbações ondulatórias que atingem o ponto $\mathbf{P}$, diferem entre si em amplitude e fase porque (a) os irradiadores elementares estão a diversas distâncias de $\mathbf{P}$, (b) a luz sai dos irradiadores formando os mais variados ângulos com a normal à frente de onda e (c) alguns irradiadores são bloqueados pelo anteparo B e outros não. Cálculos de difração - simples em princípio - podem tornar-se difíceis na prática. Os cálculos tem que ser repetidos para todos os pontos do anteparo $\mathbf{C}$ em que se quiser conhecer a intensidade da luz. Adota-se exatamente este processo para avaliar a distribuição de intensidade produzida por uma fenda dupla.

Pode-se dividir o estudo do fenômeno de difração em duas classes gerais. $\mathrm{Na}$ primeira, chamada difração de Fresnel, a fonte luminosa está a uma distância finita do obstáculo difrator, tem feixes de luz não paralelos e a figura de difração resultante é estudada em um anteparo próximo ao obstáculo difrator [34,35,46,47].

Na segunda classe, chamada difração de Fraunhofer, a frente de onda incidente é direcionada por uma lente de modo que os feixes de luz fiquem paralelos. Atrás do obstáculo difrator é colocada outra lente e a figura de difração resultante é examinada em um anteparo colocado no ponto focal da lente $[36,45]$.

Um tipo de EOD, chamado de gerador de teste padrão, é baseado em uma rede de difração. Uma aplicação particularmente útil de geradores do teste padrão é o interconector óptico. Projetando a eficiência de difração de um elemento óptico difrativo em suas várias ordens, a luz provinda de várias fontes, tais como lasers de 
diodo, pode ser dirigida para vários detetores. Estas interconecções podem ser usadas como base para elementos aritméticos em um computador óptico.

Instrumento útil para separação de comprimentos de onda de luz é a rede de difração, que é um dispositivo com um grande número de linhas, ou fenda, igualmente espaçados numa superfície plana [48]. Esta rede pode ser feita pelo corte de ranhuras paralelas, igualmente espaçadas, numa placa de vidro ou de metal, mediante uma máquina fresadora de precisão. Numa rede de reflexão, a luz se reflete nas cristas entre as ranhuras. Um disco CD/DVD tem algumas propriedades de uma rede de reflexão. Na rede de transmissão, a luz passa pelos intervalos transparentes entre as ranhuras.

Ao imaginar uma onda plana de luz que incide normalmente numa rede de transmissão, admite-se que a largura de cada fenda na rede seja muito pequena, de modo que cada fenda forme um feixe amplamente difratado. A figura de interferência da rede num anteparo distante se deve a um grande número de fontes luminosas igualmente espaçadas. Os máximos de interferência estarão nos ângulos $\theta$ dados pela eq. (2):

$$
d \operatorname{sen} \theta=m \lambda
$$

onde o número m é a ordem dos máximos de interferência. A posição de um máximo de interferência não depende do número de fontes, mas, quanto maior for este número, mais nítido e afilado será este máximo.

O poder de resolução da rede de difração se define como $\lambda /|\Delta \lambda|$, onde $|\Delta \lambda|$ é a menor diferença entre dois comprimentos de onda vizinhos que pode ser resolvido e $\lambda$ é o comprimento de onda aproximado das raias vizinhas. O poder de resolução é proporcional ao número de linhas da rede que estiverem iluminadas, pois quanto mais numerosas forem as fendas iluminadas, mais nítidos serão os máximos de interferência [49].

Quando se fala sobre controlar a luz através da difração, surgem uma série de termos: sistema óptico binário, kinoforms, elementos ópticos holográficos gerados por 
computador e muitos outros [50-52]. O termo geral que abrange todos estes conceitos é sistema óptico difrativo, e para fins de discussão, os componentes ópticos descritos aqui serão chamado elementos ópticos difrativos (DOEs - diffractive optic elements ou em português, EODs) (Figura 7).

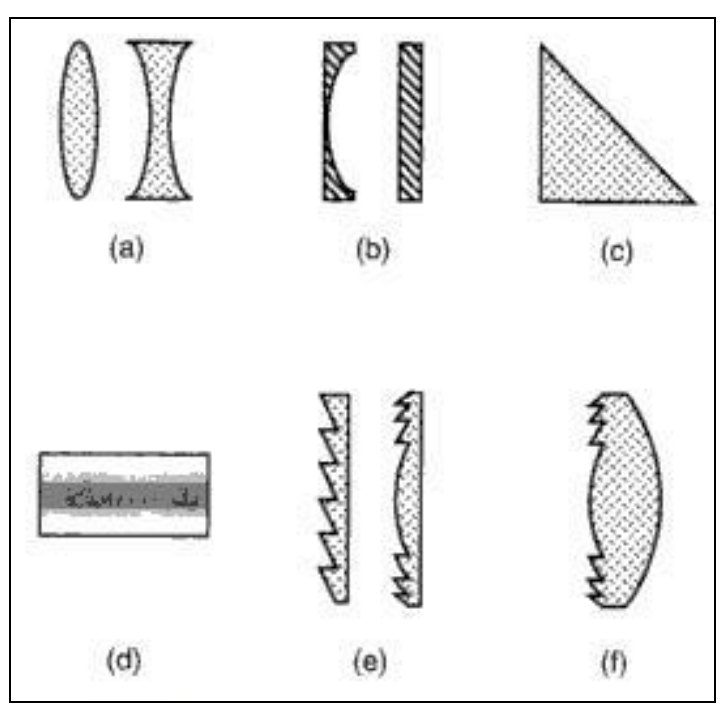

Fig.7 Elementos ópticos - a) lentes refrativas, b) espelhos, c) prisma, d) lente GRIN, e) elementos ópticos difrativos, f) elemento híbrido

Um EOD é um componente que modifica frentes de onda segmentando e dirige os segmentos com o uso da interferência e do controle de fase. Um kinoform é um EOD cujas superfícies de controle de fase estejam variando de maneira "contínua" (Figura 8). Um sistema óptico binário é o EOD mais simples que caracteriza somente duas superfícies fase-controladas, as quais introduzem algo entre 0 e $\lambda / 2$ da diferença de fase para a frente de onda incidente. Quando há $\mathrm{N}$ máscaras, um elemento óptico binário multi-nível pode ser gerado, geralmente tendo por resultado níveis de fase $2^{\mathrm{N}}$. Um elemento óptico holográfico é um EOD gerado pela interferência de duas frentes de onda para produzir um dispositivo que seja usado como um componente óptico. A única distinção entre este elemento e um holograma é que um holograma pretende geralmente criar uma imagem volumétrica de uma cena. 


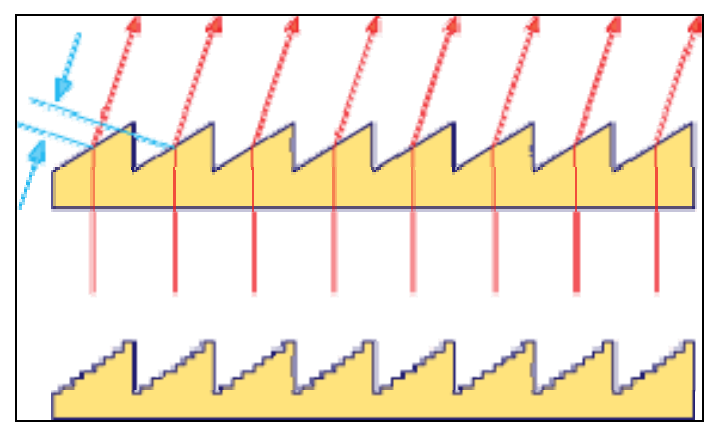

Fig.8 Um kinoform caracteriza uma superfície variante lisa (acima), enquanto um sistema óptico binário aproxima-se da superfície lisa através de uma série de etapas (abaixo)

Antes de se fazer uma breve revisão dos tipos diferentes de EOD, pode ser útil enfatizar alguns conceitos que podem ajudar a compreender como os elementos difrativos trabalham. A propagação da luz através de muitos componentes ópticos pode ser compreendida de uma maneira mais fácil como pacotes de raios que são transmitidos através de um sistema óptico para formar imagens ou para produzir padrões de luz. Para compreender EODs, no entanto, é melhor pensar em termos de frentes de ondas. Perpendicularmente ao sentido da propagação do raio de luz associado, uma frente de onda é uma superfície contínua na qual o campo elétrico tem a mesma fase e, geralmente, a mesma amplitude. Por exemplo, raios de luz provenientes de uma fonte localizada no infinito e que estão paralelos uns aos outros, e a frente de onda correspondente é um campo elétrico plano perpendicular aos raios de luz, também conhecido como onda plana. Quando esta onda plana é focalizada por uma lente positiva, a onda plana é convertida em ondas esféricas centradas no ponto focal. 


\subsection{Fabricação de EODs}

Existem numerosas tecnologias para a fabricação de MOEs (micro-optical elements) e EODs, mas a produção comercial é dominada apenas por duas maneiras básicas:

1. Processos litográficos para fabricação de óptica difrativa binária.

Litografia comercial (Figura 9) para semicondutores com máscara de exposição e processos de corrosão que são utilizados para fabricar microestruturas ópticas em sílica fundida ou substrato de silício, permitindo que múltiplos elementos sejam fabricados simultaneamente resultando na diminuição de custos. Esta é atualmente a principal tecnologia de fabricação de elementos ópticos difrativos. Uma tecnologia similar, o refluxo de fotorresiste e transferência por corrosão para o substrato, é a tecnologia dominante para produção de MOEs de altíssima qualidade.

2. Processos de impressão direta baseados em e-beam litography (litografia por feixe de elétrons) (Figura 9). Tais tecnologias produzem peças originais de ótima qualidade, com qualquer fotorresiste, ou transferencia por corrosão para o substrato. Além do mais, são processos livres de máscara, o que torna o tempo de gravação no protótipo mais rápido do que em outros processos, mas com custo elevado [53,54]. 


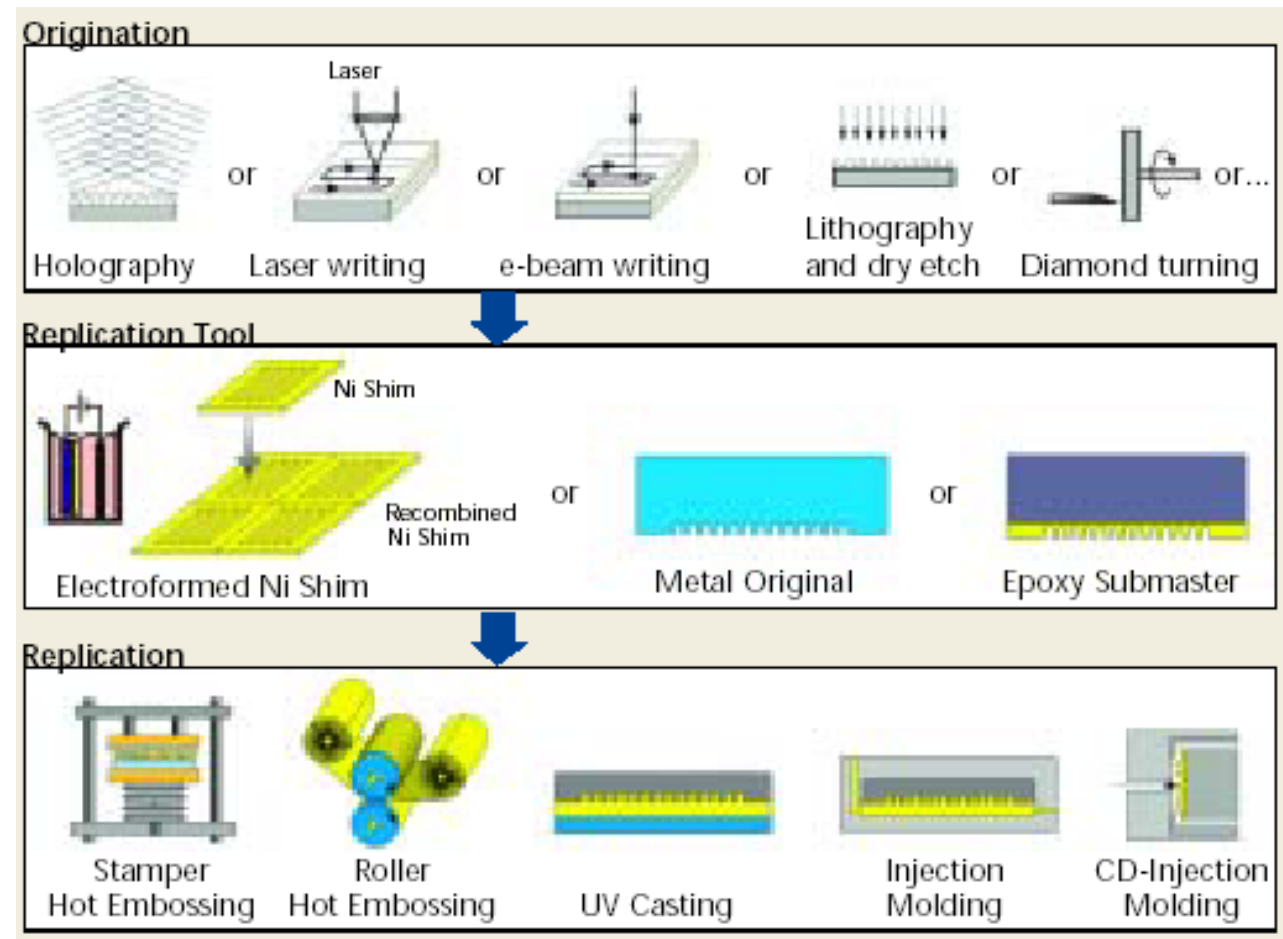

Fig. 9 Esquema mostrando origem das matrizes de EODs, ferramentas de replicagem e a técnica de replicagem em si

Neste trabalho, deseja-se fabricar de elementos ópticos difrativos de modulação através de processos de litografia e corrosão. A modulação de fase se dá através do número de níveis que o elemento óptico difrativo possui e a modulação de amplitude se dá através da espessura. Os relevos impõem uma modulação na fase da luz incidente, resultando numa distribuição luminosa desejada em algum plano posterior ao EOD (plano de reconstrução). A forma desta frente de onda pode ser alterada de modo que sua propagação possa ter a direção modificada, convergir para um foco ou exibir qualquer comportamento escolhido [55-60]. A espessura máxima do relevo deve corresponder ao percurso óptico de apenas meio comprimento de onda binário.

Na Figura 10 é mostrado um exemplo de elemento difrativo, numa abordagem de óptica binária, contendo oito níveis de discretização de fase. Por ser necessário apenas introduzir um pequeno retardo na fase em cada ponto da frente de onda, estes elementos são mais leves que os correspondentes elementos refrativos. Considera-se que o dispositivo deve operar com luz laser vermelha $(\lambda=632,8 \mathrm{~nm})$ que é o mesmo do laser de HeNe utilizado neste projeto para a caracterização e teste dos dispositivos 
obtidos, e que o relevo da Figura $10 \mathrm{~b}$ foi fabricado num substrato de vidro $(\mathrm{n}=1,51)$. Desta forma, a altura máxima de relevo é eq. (3):

$$
\mathrm{d}_{\max }=632,8 / 2(1,51-1)=0,65 \mu \mathrm{m}
$$

$\mathrm{O}$ número de máscaras de fotolitografia, $\mathrm{M}$, necessários para discretizar um relevo contínuo em m níveis de fase, deve obedecer a seguinte lei eq. (4):

$$
\mathrm{m}=2^{\mathrm{M}}
$$

Sendo assim, são necessárias $M=3$ etapas de fotolitografia para discretizar o relevo contínuo em $\mathrm{m}=8$ níveis de fase, como é mostrado na Figura 10c. Para tanto, tem-se eq. (5):

$$
\mathrm{d}_{\mathrm{M}}=\mathrm{d}_{\max } / 2^{\mathrm{M}}=1,3 / 8=0,16 \mu \mathrm{m}
$$

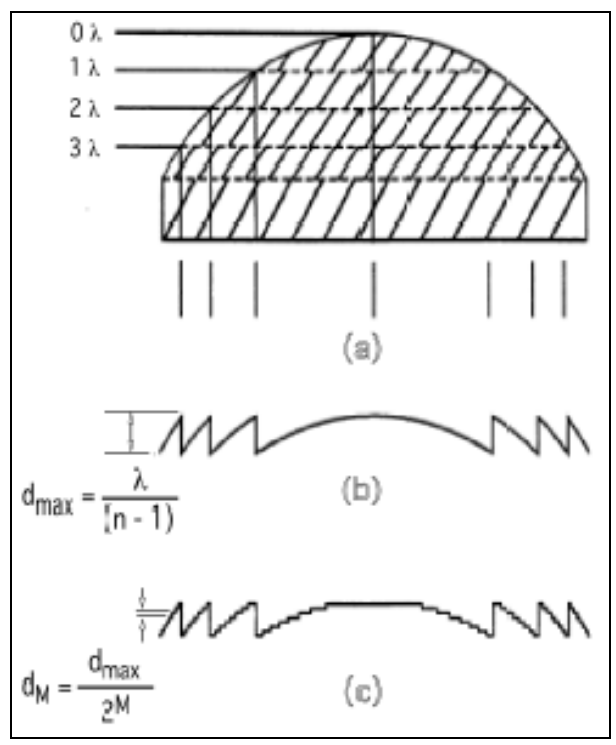

Fig.10 Ilustração esquemática da conversão de um elemento óptico refrativo (EOR) para um elemento óptico difrativo (EOD) (a) função de fase refrativa, (b) EOD resultante, (c) aproximação binária em oito níveis. Neste caso, são necessárias três etapas de fotolitografia e corrosão por plasma

\subsection{Replicagem de EODs}


EOD's binários são fabricados geralmente em substratos de sílica fundida ou silício. A redução de custo no volume de produção é possível com a produção em escala de wafers contendo múltiplos elementos a serem fabricados simultaneamente. Os maiores wafers podem ter até $30 \mathrm{~cm}$ de diâmetro. O desafio das tecnologias de replicagem é garantir estruturas microscópicas com precisão na escala nanômetrica com produção de milhões de replicas uniformes. Os métodos principais de replicagem de EOD's são eletrodeposição, moldagem por injeção, prensagem à quente e aplicação por centrifugação e cura (Figura 9). Os critérios chave de seleção entre os métodos do replicagem são as características macroscópicas das réplicas, tais como a planaridade, a exatidão dimensional, propriedades mecânicas e o preço final do dispositivo [61]. O desenvolvimento comercial da tecnologia de replicagem para superfícies micro ópticas pode ser dividida em quatro etapas básicas [53]:

(1) Projeto: Otimização da estrutura superfície microestruturada ou nanoestruturada.

(2) Origem: Fabricação da estrutura básica da superfície.

(3) Ferramenta: Fabricação da ferramenta de replicagem, tipicamente em um molde de níquel.

(4) Produção (replicagem): produção em massa, tipicamente pelos métodos mais comuns já citados.

Os materiais mais usados para replicagem são polímeros termo-plásticos (que são moldáveis quando aquecidos [62]) tais como o policarbonato (PC), o policloreto de vinila (PVC), o polimetacrilato de metila (PMMA), resinas fotossensíveis do tipo Novolak e resinas curadas por radiação UV (NOA 61, por exemplo). Na Tabela I são mostradas algumas propriedades ópticas e mecânicas de polímeros empregados com maior frequência . 
Tabela I - Métodos e características de polímeros utilizados para replicagem [63]

\begin{tabular}{|c|c|c|c|c|c|}
\hline Material & Método de Replicagem & $\begin{array}{c}\text { Índice de refração } \\
(633 \mathrm{~nm})\end{array}$ & $\begin{array}{c}\text { Faixa de } \\
\text { Transmitância }(\mathrm{nm})\end{array}$ & $\begin{array}{l}\text { Transição } \\
\text { vítrea (“'C) }\end{array}$ & Fabricante \\
\hline PC & $\begin{array}{c}\text { Moldagem por injeção, } \\
\text { Prensagem a quente }\end{array}$ & 1,58 & $380-1600$ & 145 & $\begin{array}{c}\text { Rohm, } \\
\text { GE, Bayer }\end{array}$ \\
\hline PMMA & $\begin{array}{c}\text { Moldagem por injeção, } \\
\text { Prensagem a quente, } \\
\text { Deposição e cura }\end{array}$ & 1,49 & $400-1100$ & $94-108$ & $\begin{array}{l}\text { Rohm, } \\
\text { Degussa }\end{array}$ \\
\hline PVC & $\begin{array}{c}\text { Moldagem por injeção, } \\
\text { Prensagem a quente por } \\
\text { rolo }\end{array}$ & 1,54 & $400-2200$ & $75-105$ & $\begin{array}{c}\text { BF } \\
\text { goodrich }\end{array}$ \\
\hline NOA61 & Deposição e cura UV & 1,56 & $350-2000$ & - & Norland \\
\hline
\end{tabular}

A seguir são apresentadas as descrições dos principais processos de replicagem:

Eletrodeposição: A resolução e fidelidade do processo de eletrodeposição é dada tipicamente em escala nanométrica. A vasta maioria das matrizes de microestruturas é eletrodepositada em níquel, devido ao baixo nível de estresse mecânico da camada metálica eletrodepositada. A eletrodeposição de prata [58] é mais extensamente utilizada na indústria de prensagem de hologramas. Espessuras típicas para a matriz metálica encontram-se entre 50 e $100 \mu \mathrm{m}$ [64 -71].

Prensagem a quente: Esta técnica é bastante atrativa pois, a partir de um equipamento relativamente simples, é capaz de replicar estruturas com bastante fidelidade, em áreas de até $10 \times 10 \mathrm{~cm}^{2}$. Esta técnica consiste em submeter o polímero (tipicamente um filme de policarbonato) sob pressão a uma temperatura levemente acima da Tg que é a temperatura de transição vítrea (tipicamente maior que $50^{\circ} \mathrm{C}$ ). O equipamento pode ser do tipo estampa ou do tipo cilindro rolante. É largamente empregada em estruturas holográficas para segurança. A prensagem por estampa fornece excelente resolução para estruturas com dimensões horizontais submicrométricas [72].

Moldagem por injeção: Nesta técnica injeta-se um material plástico fundido numa câmara sob temperatura controlada, onde está o micro relevo que se quer replicar . O polímero é esfriado e solidifica-se, quando é então separado do molde [73, 74]. A 
grande maioria de produtos de consumo tais como lentes de Fresnel para projetores e câmeras e discos compactos (CDs) para a reprodução de áudio são fabricados a partir de moldagem por injeção.

Aplicação por centrifugação e cura. Esta técnica consiste na aplicação de uma resina (PMMA ou policarbonato, por exemplo) num substrato rígido com o microrrelevo, tais como níquel, alumínio ou silício. Em seguida o sistema é submetido a ciclos térmicos de modo que a temperatura da resina polimérica atinja a temperatura de transição vítrea, Tg. Em seguida o sistema é esfriado até a temperatura ambiente quando é feita a separação do molde e da réplica. A centrifugação e cura é particularmente atrativa para fabricar microestruturas de alta razão de aspecto e elementos híbridos. Uma desvantagem é o tempo gasto no ciclo térmico (várias horas), o qual torna-se proibitivo para certas aplicações. No entanto com novas tecnologias de cura de resinas através de exposição ao UV, este processo é bastante rápido [71]. 


\section{METODOLOGIA}

\subsection{Introdução}

Tem-se neste capítulo a descrição dos métodos, materiais e equipamentos empregados na fabricação e caracterização física dos elementos ópticos difrativos, bem como na caracterização óptica dos padrões de difração gerados. Para o desenvolvimento deste trabalho foram utilizados três tipos de substrato: lâminas de silício com $75 \mathrm{~mm}$ de diâmetro, $360 \mu \mathrm{m}$ de espessura tipo p, com boro como dopante, lâminas de vidro óptico B270 da Schott com $1 \mathrm{~mm}$ de espessura e diâmetro de $75 \mathrm{~mm}$ e lâminas de sílica fundida (ambas as faces polidas0 com $360 \mu \mathrm{m}$ de espessura e diâmetro de $75 \mathrm{~mm}$ da Valley Design. Todos substratos apresentam rugosidade RMS inferior à $\lambda / 10$ para a faixa do visível. Antes do início do processo os 3 tipos de substratos foram submetidos a etapas de limpeza para remoção de contaminações que possam comprometer os resultados do trabalho.

\subsection{Métodos de limpeza das lâminas}

A importância da limpeza das lâminas no processo de microfabricação é essencial para alcançar os resultados desejados do dispositivo.

\subsubsection{Limpeza de lâminas virgens de silício}

Receita de limpeza utilizada para remoção de gorduras e óxido nativo [75].

a) lavagem por 5 minutos em água deionizada (resistividade de $18 \mathrm{M} \Omega . \mathrm{cm}$ ).

b) $4 \mathrm{H}_{2} \mathrm{SO}_{4}+1 \mathrm{H}_{2} \mathrm{O}_{2}\left(10\right.$ minutos à $\left.115^{\circ} \mathrm{C}\right)$.

c) Água D.I. - lavagem (5 min.).

d) $20 \mathrm{H}_{2} \mathrm{O}+1 \mathrm{HF}$ (temperatura ambiente até a lâmina sair seca da solução). 


\subsubsection{Limpeza de lâminas virgens de vidro óptico e de sílica fundida}

Receita de limpeza para remoção de contaminações com metais [75] e orgânicos.

a) Lavagem por 5 minutos em água deionizada (resistividade de $18 \mathrm{M} \Omega . \mathrm{cm}$ ).

b) $5 \mathrm{H}_{2} \mathrm{O}_{2}+1 \mathrm{NH}_{4} \mathrm{OH}+4 \mathrm{H}_{2} \mathrm{O}$ por 10 minutos à $80{ }^{\circ} \mathrm{C}$.

c) Água D.I. - lavagem (5 min.).

d) Secagem com nitrogênio.

\subsubsection{Remoção de fotorresiste}

Para a remoção do fotorresiste, foram realizadas as seguintes etapas:

a)Acetona por 10 minutos à $70^{\circ} \mathrm{C}$.

b) Álcool isopropílico por 10 minutos à $70{ }^{\circ} \mathrm{C}$.

c) Secagem com nitrogênio.

\subsubsection{Remoção de fotorresiste após a corrosão}

Foi utilizada a seguinte receita:

a) $3 \mathrm{H}_{2} \mathrm{SO}_{4}+1 \mathrm{H}_{2} \mathrm{O}_{2}\left(2\right.$ minutos à $\left.115^{\circ} \mathrm{C}\right)$.

b) Água D.I. - lavagem (2 min.).

c) $1 \mathrm{H}_{2} \mathrm{O}_{2}+1 \mathrm{NH}_{4} \mathrm{OH}+4 \mathrm{H}_{2} \mathrm{O}$ por 2 minutos.

d) Água D.I. - lavagem (2 min.).

e) Secagem com nitrogênio.

\subsubsection{Corrosão úmida de alumínio antes do processo de corrosão por plasma}

O alumínio foi removido da seguinte maneira para definição da máscara:

a) $175 \mathrm{H}_{3} \mathrm{PO}_{4}+70 \mathrm{H}_{2} \mathrm{O}+15 \mathrm{HNO}_{3}$ (taxa de corrosão de $200 \mathrm{~nm}$ por minuto à $40{ }^{\circ} \mathrm{C}$ ).

b) Água D.I. - lavagem (5 minutos).

c) Secagem com nitrogênio. 


\subsubsection{Remoção de alumínio depois do processo de corrosão}

Foi utilizada a seguinte receita:

a) Água D.I. - lavagem (5 min.).

b) $4 \mathrm{H}_{2} \mathrm{SO}_{4}+1 \mathrm{H}_{2} \mathrm{O}_{2}\left(10\right.$ minutos à $\left.115^{\circ} \mathrm{C}\right)$.

c) Água D.I. - lavagem (5 min.).

d) $1 \mathrm{H}_{2} \mathrm{O}_{2}+1 \mathrm{NH}_{4} \mathrm{OH}+5 \mathrm{H}_{2} \mathrm{O}$ por 10 minutos à $80^{\circ} \mathrm{C}$.

e) Água D.I. - lavagem (2 min.).

f) Secagem com nitrogênio.

\subsection{Processos de deposição dos filmes de carbono tipo diamante (DLC - Diamond Like Carbon)}

Os filmes foram produzidos em um sistema de RF magnetron sputtering reativo (Figura 11) projetado e montado no Laboratório de Sistemas Integráveis do departamento de Engenharia de Sistemas Eletrônicos da Escola Politécnica da Universidade de São Paulo (PSI - EPUSP), um desenho esquemático do equipamento é apresentado na Figura 12. Para as deposições foi utilizado um alvo de grafite com $150 \mathrm{~mm}$ de diâmetro e pureza de 99,9999 \%. A amostra a ser depositada é colocada a $100 \mathrm{~mm}$ de altura em relação ao alvo. Com o sistema de vácuo composto de uma bomba turbo-molecular e uma bomba rotativa mecânica, a pressão de fundo é de $9 \times 10^{-7}$ Torr e a pressão de processo é de $5 \times 10^{-3}$ Torr. A temperatura da amostra não é controlada, mas é medida por meio de um termopar tipo $\mathrm{K}$ e chega no máximo a $90{ }^{\circ} \mathrm{C}$. Durante a deposição a vazão total dos gases de processo é de 70 sccm. 


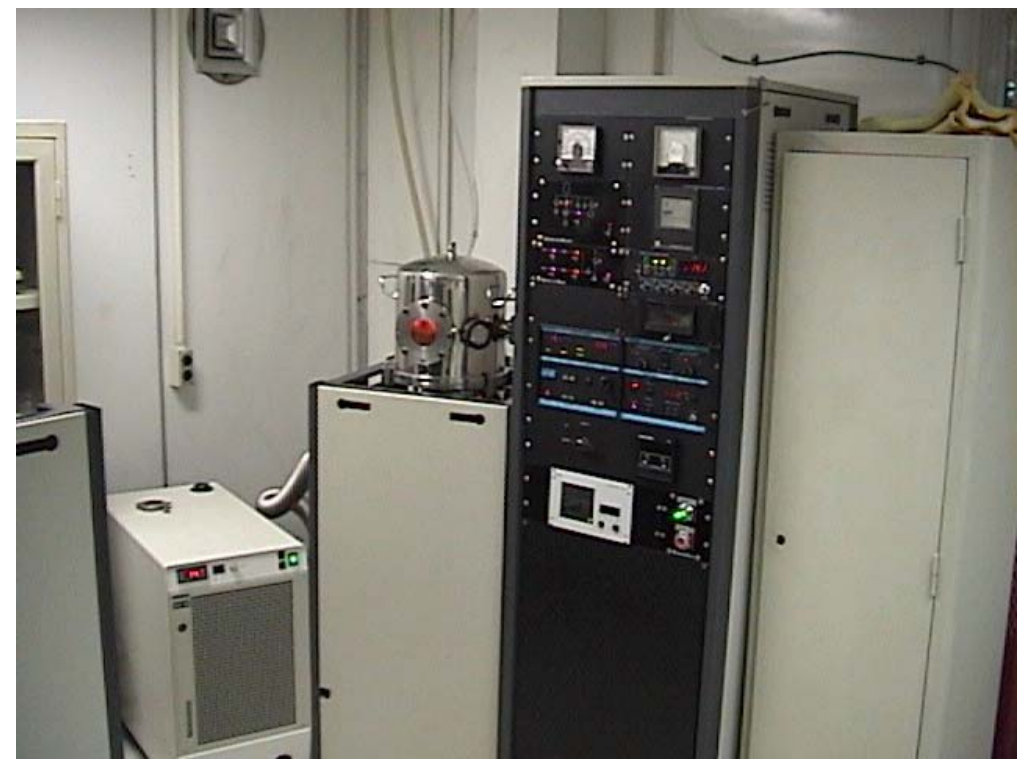

Fig. 11 Sistema de magnetron sputtering reativo utilizado neste trabalho

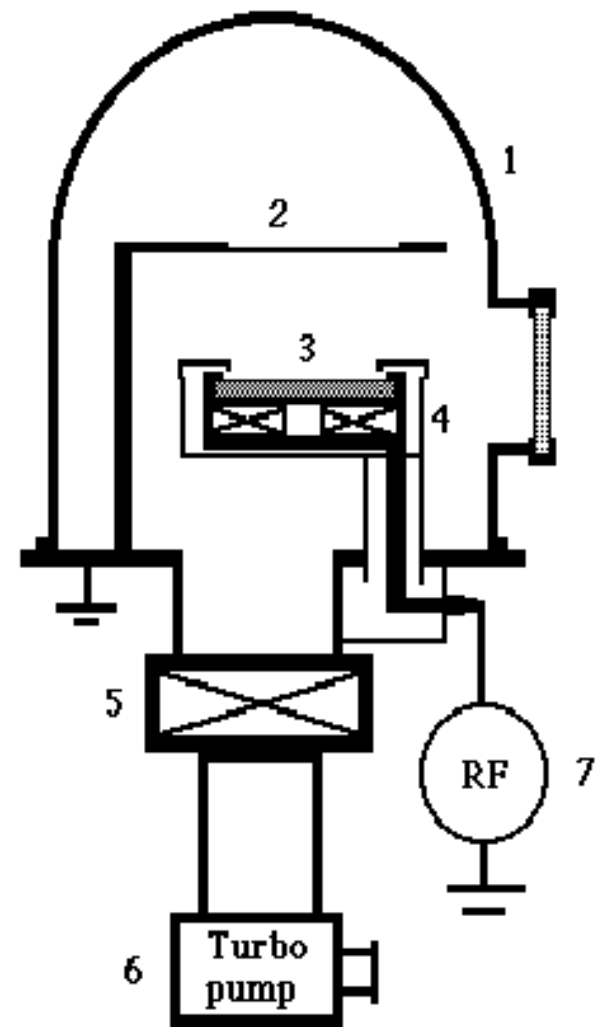

Fig.12 Desenho esquemático do sistema de magnetron sputtering reativo: (1) Campânula de aço inoxidável, (2) porta amostra, (3) alvo, (4) eletrodo, (5) válvula gaveta, (6) bomba turbo molecular, (7) sistema de RF composto de malha de acoplamento e gerador de RF 


\subsubsection{Parâmetros utilizados para a deposição dos filmes de carbono}

Nestes processos foram depositados filmes finos de DLC sobre lâminas de silício e vidro.

Processo 1: Deposição com metano puro $\left(\mathrm{CH}_{4}\right)$ para estudo de índice de refração e taxa de deposição.

Substrato: silício.

Pressão de fundo de $1,2 \times 10^{-6}$ Torr.

Vazão $\mathrm{CH}_{4}=70 \mathrm{sccm}$.

Pressão de processo $=5 \mathrm{~m}$ Torr.

Potencia RF $(13,56 \mathrm{MHz})=250 \mathrm{~W}$.

Tempos $=2$ horas e 20 minutos (1 lâmina), 1 hora e 40 minutos (1 lâmina), 2 horas ( 2 lâminas).

Processo 2: Deposição com metano puro $\left(\mathrm{CH}_{4}\right)$ para fabricação de EODs com dois níveis de fase.

Substrato: vidro.

Pressão de fundo de $1,2 \times 10^{-6}$ Torr.

Vazão $\mathrm{CH}_{4}=70 \mathrm{sccm}$.

Pressão de processo $=5 \mathrm{~m}$ Torr.

Potencia RF $(13,56 \mathrm{MHz})=250 \mathrm{~W}$.

Tempo $=1$ hora e 30 minutos.

\subsection{Evaporação de Alumínio}

A evaporação de uma máscara de alumínio sobre o substrato de vidro tem como finalidade promover a formação de estruturas durante o processo de corrosão.

Primeiramente, é feita a pesagem da quantidade de necessária de alumínio para se obter $200 \mathrm{~nm}$ de espessura do filme de metal evaporado. A quantidade é obtida pela seguinte equação eq. (6):

$$
M=4 \pi h^{2} e \rho
$$


Onde:

$\mathrm{M}=$ massa de material a evaporar necessária.

$\rho=$ densidade do material $\left(\rho_{\mathrm{Al}}=2,7 \mathrm{~g} / \mathrm{cm}^{3}\right)$.

$\mathrm{e}=$ espessura desejada $(200 \mathrm{~nm})$.

$\mathrm{h}=$ altura da lâmina medida em relação ao filamento (no caso, $13 \mathrm{~cm}$ ).

Após feito os cálculos, o metal é colocado no filamento da evaporadora, é feito o pré vácuo e em seguida o alto vácuo. A evaporação do metal se dá com uma corrente que passa pelo filamento em torno de 20 a $40 \mathrm{~A}$.

\subsection{Litografia}

As fotoalinhadora empregadas foram uma Veb Elektromat (Call Zeiss Jena) para amostras de 3" e uma Electronic Vision AL 420 para amostras de 4", ambas com resolução máxima de $2 \mu \mathrm{m}$.

\subsubsection{Litografia com fotorresiste OFPR 8600}

Foi feito o seguinte processo:

- Aplicação de álcool isopropílico $20 \mathrm{~s}$ à $2500 \mathrm{rpm}$ no spinner.

- Aplicação do promotor de aderência HMDS 20 s à 2500rpm no spinner.

- Aplicação do fotorresiste OFPR 8600 Tokyo Ohka $20 \mathrm{~s}$ à 2500rpm no spinner.

- Pré cura 3 minutos à $90^{\circ} \mathrm{C}$.

- Exposiçao UV por 35s seguida de revelação (solução com 1 parte de $\mathrm{KOH}$ $2,5 \%$ e 2 partes de água D.I.) por 30 s.

- Pós cura por 20 minutos à $135^{\circ} \mathrm{C}$.

Foram utilizados 4 tipos de máscara no processo de litografia (Figura 13). A máscara padrão utilizada tinha como finalidade gerar degraus após a corrosão para ser medida a profundidade de corrosão, a taxa de corrosão e a rugosidade tanto da parte corroída quanto da parte não corroída. A máscara óptica difrativa tinha como finalidade gerar 22 elementos ópticos difrativos e, a partir deles, se fazer uma análise do desempenho 
destes. As máscara $\pi / 2$ e $\pi$ utilizadas em seqüência tinham como finalidade a produção de elementos ópticos difrativos com quatro níveis de fase.
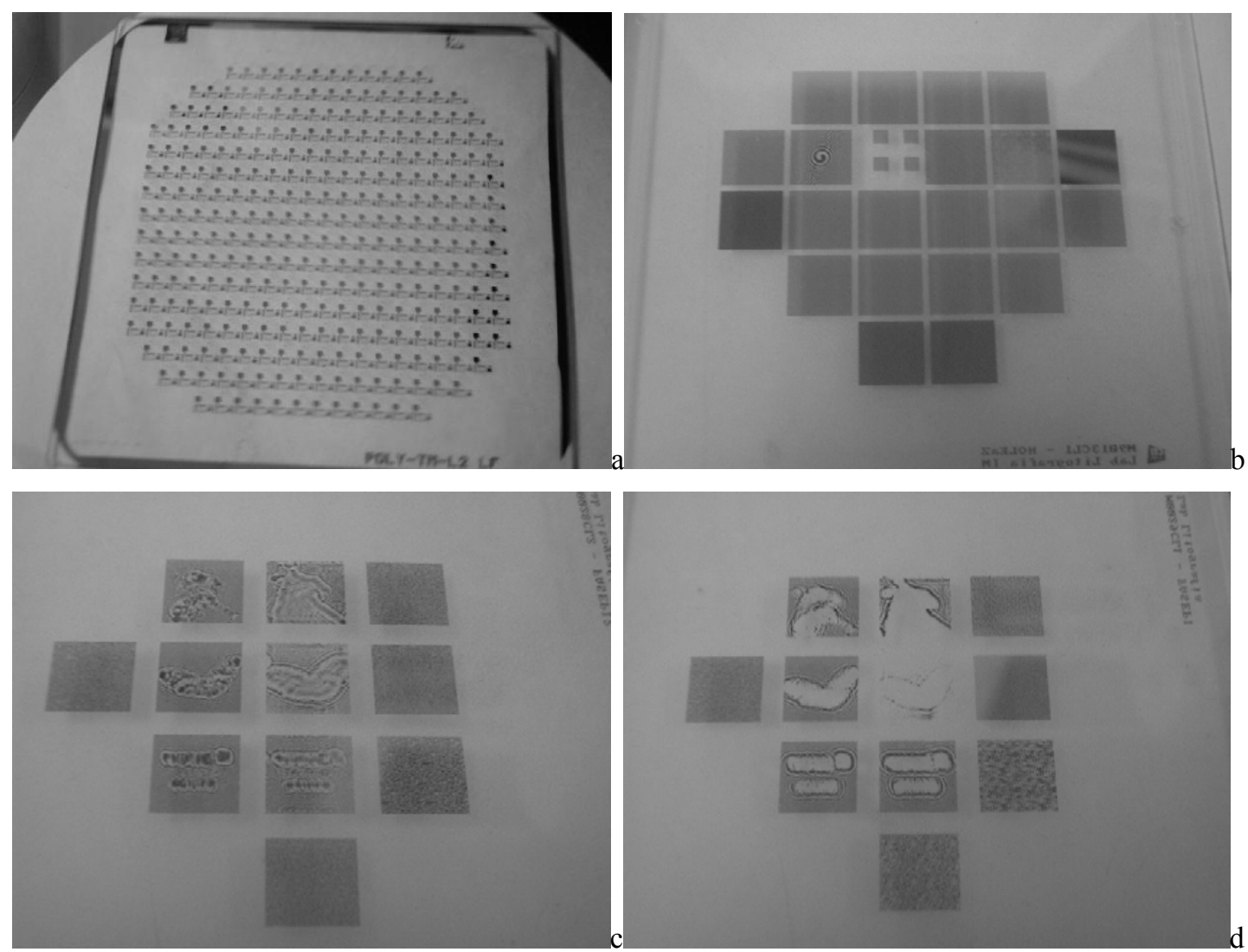

Fig. 13 máscaras utilizadas no processo a) padrão, b) óptica difrativa, c) $\pi / 2$ e d) $\pi$ (o padrão das últimas duas máscaras foi projetado pelo grupo de óptica difrativa da EESC) 


\subsection{Equipamento de corrosão por plasma modo RIE (Reactive Ion Etching)}

O equipamento de corrosão utilizado é um reator de placas paralelas denominado RIE (Reactive Ion Etching) com eletrodos assimétricos. Na figura 14 é apresentada a foto do sistema de plasma.

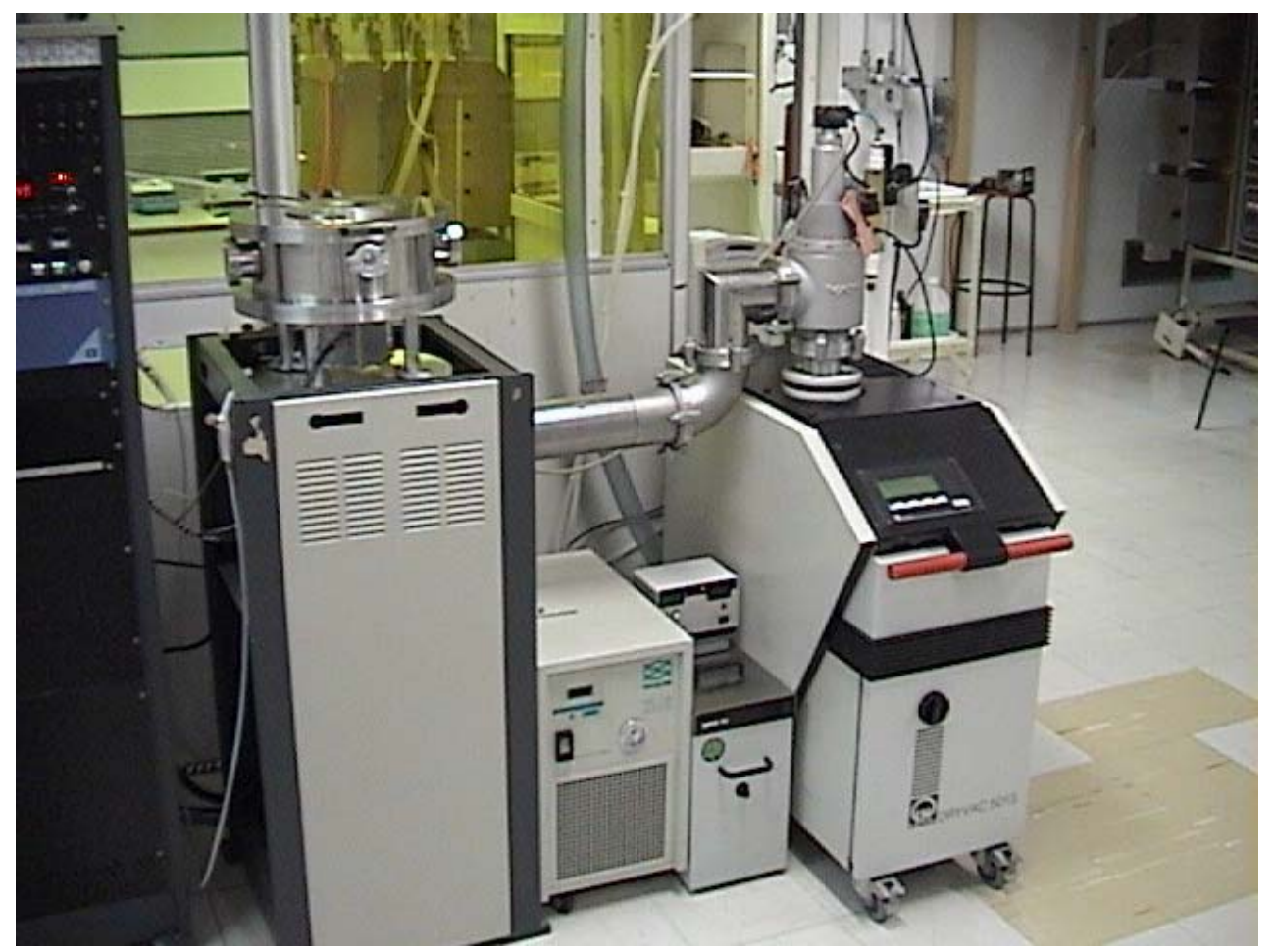

Fig. 14 Reator de corrosão por plasma utilizado (RIE)

A câmara de processo é fabricada em aço inoxidável 316L com $310 \mathrm{~mm}$ de diâmetro interno, com $85 \mathrm{~mm}$ de espaçamento entre os eletrodos. O eletrodo inferior (cátodo) é feito de cobre, podendo ser revestido de vários outros materiais, sendo, neste trabalho, usado apenas o alumínio. Ele tem $150 \mathrm{~mm}$ de diâmetro e possui um sistema de refrigeração autônomo, o qual possibilita o controle de temperatura entre $-10^{\circ} \mathrm{C}$ e $+40^{\circ} \mathrm{C}$, utilizando óleo siliconado como líquido refrigerante. O gás de processo é admitido via a tampa superior, a qual possui um distribuidor, em forma de "crivo", de $150 \mathrm{~mm}$ de diâmetro, com furos de $0,8 \mathrm{~mm}$ de diâmetro e espaçamento de $10 \mathrm{~mm}$ entre si, dispostos cartezianamente (Figura 15). 
O sistema de bombeamento consiste em um conjunto bomba mecânica $\left(80 \mathrm{~m}^{3} / \mathrm{h}\right)+$ bomba "roots" $\left(500 \mathrm{~m}^{3} / \mathrm{h}\right)$. A descarga é excitada por um conjunto gerador de RF (modelo RFX-600) + malha acopladora (modelo ATX-600). Este conjunto pode fornecer à descarga até $600 \mathrm{~W}$ de potência de RF à 13,56 MHz.

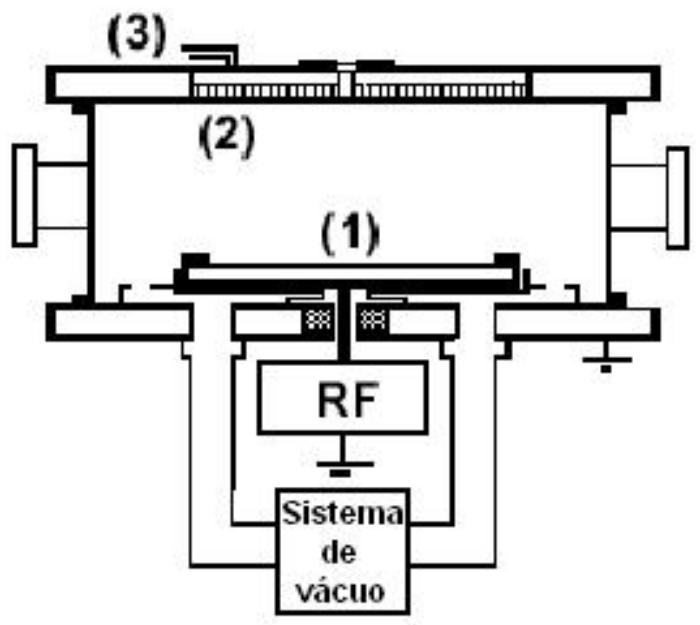

Fig.15 Desenho esquemático do equipamento de corrosão por plasma: (1) eletrodo, (2) "crivo" que homogeniza a entrada de gases, (3) entrada de gases

\subsubsection{Processos de corrosão das lâminas de vidro}

Para que fosse possível obter a taxa de corrosão por plasma do vidro óptico, foi necessário realizar a medição da espessura da camada de vidro óptico corroída durante o processo, para isso foram feitas corrosões de amostras protegidas pelo fotorresiste (16 amostras) e pelo alumínio (16 amostras) e para isso foi utilizado um sistema de corrosão por plasma, modo RIE (Reactive Ion Etching) de lâmina única. Este processo foi feito corroendo-se a superfície de uma pequena área de cada $1 / 4$ de lâmina. Durante o processo tomou-se o cuidado de ser colocado $3 / 4$ de uma lâmina "blank" juntamente com o 1/4 da lâmina onde serão feitas as medidas para que se desse uma corrosão homogênea. Os parâmetros de processo são apresentados em seguida. 


\subsubsection{Parâmetros da corrosão por plasma para lâminas de vidro com máscara de fotorresiste ou alumínio}

Os processos foram realizados com plasma com $\mathrm{CF}_{4}$ puro com vazão de $48 \mathrm{sccm}$. A corrosão foi feita por um tempo de 3 minutos para 16 amostras protegidas por máscara de fotorresiste e 15 minutos para 16 amostras protegidas por máscara de alumínio variando-se os parâmetros pressão (50, 100, 150 e 200 mTorr) e potência de RF (50 W, $100 \mathrm{~W}, 150 \mathrm{~W}$ e $200 \mathrm{~W})$. A temperatura utilizada no sistema de refrigeração foi de $5^{\circ} \mathrm{C}$.

\subsubsection{Parâmetros da corrosão com potências maiores de processo para lâminas protegidas por alumínio e corroídas com plasma de $\mathbf{C F}_{4}$}

Após ter sido feita a litografia com máscara padrão (utilizada para se gerar degraus), a corrosão do alumínio e a remoção do fotorresiste que protegia este, foi realizada a corrosão por plasma. No processo foi feito plasma de $\mathrm{CF}_{4}$ puro com vazão de 96 sccm. A corrosão foi feita para 4 amostras onde haviam uma parte de lâmina de sílica fundida e uma parte de lâmina de vidro óptico. Neste processo, era desejado fazer um estudo das taxas de corrosões e rugosidade para diferentes tipos de materiais variando-se o parâmetro potência (Tabela II). A pressão foi mantida em 100 mTorr e a temperatura utilizada no sistema de refrigeração foi de $20^{\circ} \mathrm{C}$.

Tabela II - Parâmetros da corrosão

\begin{tabular}{|c|c|c|}
\hline $\begin{array}{c}\text { Amostra } \\
\text { (Potência) }\end{array}$ & $\begin{array}{c}\text { Pressão } \\
\text { (m Torr) }\end{array}$ & $\begin{array}{c}\text { Tempo } \\
\text { (minutos) }\end{array}$ \\
\hline $\mathbf{2 5 0}$ W & 100 & 9 \\
\hline 300 W & 100 & 9 \\
\hline 350 W & 100 & 2 \\
\hline $\mathbf{4 0 0}$ W & 100 & 3 \\
\hline
\end{tabular}




\subsubsection{Corrosão por plasma para confecção de elementos ópticos difrativos com} 2 níveis de fase

Após ter sido feita a litografia com a máscara óptica difrativa (com 22 elementos ópticos difrativos), corrosão úmida do alumínio e remoção do fotorresiste, foi feita a corrosão por plasma. No processo foi feito plasma de $\mathrm{CF}_{4}$ puro com vazão de 48 sccm. A corrosão foi feita com pressão constante de 100 mTorr, potência de $400 \mathrm{~W}$ e a temperatura utilizada no sistema de refrigeração era de $5^{\circ} \mathrm{C}$. A seqüência do processo de fabricação é apresentada na Figura 16.

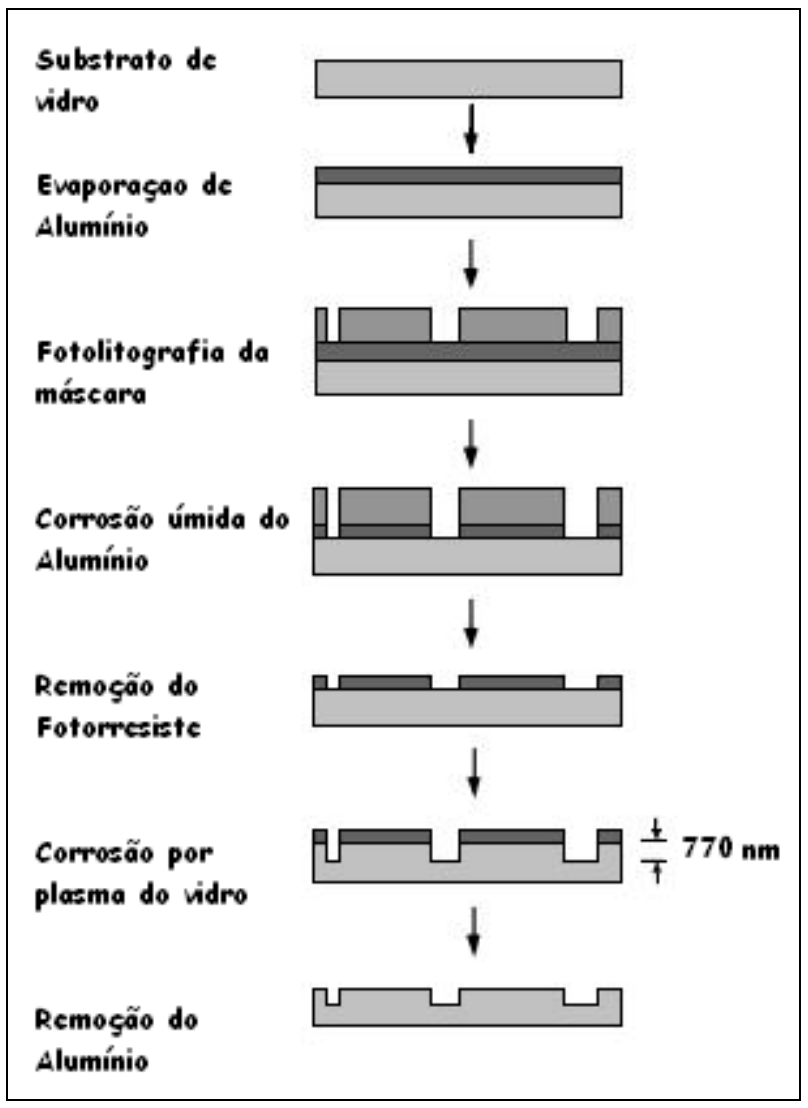

Fig.16 Seqüência de fabricação de elementos ópticos difrativos com 2 níveis de fase 


\subsubsection{Corrosão por plasma para confecção de elementos ópticos difrativos com} 4 níveis de fase

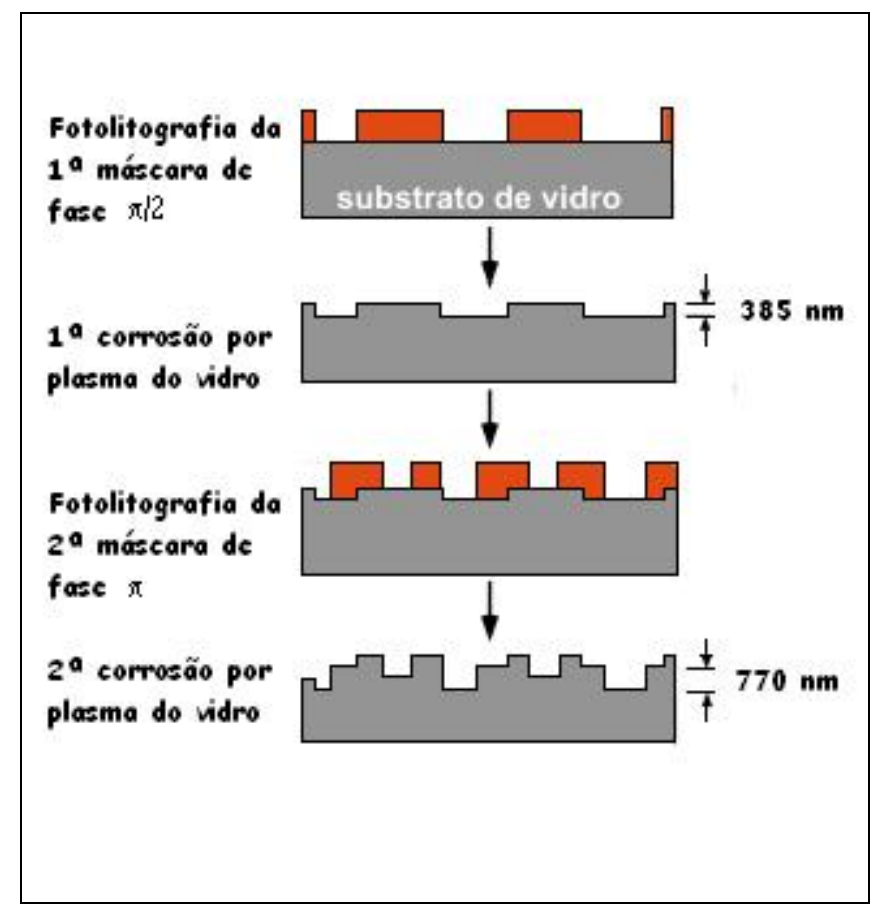

Fig.17 Seqüência de fabricação de elementos ópticos difrativos com 4 níveis de fase

Para se obter os 2 primeiros níveis, após ter sido feita a litografia com máscara $\pi / 2$, corrosão do alumínio e remoção do fotorrsiste, foi feita a corrosão por plasma. No processo foi feito plasma de $\mathrm{CF}_{4}$ puro com vazão de $48 \mathrm{sccm}$. A corrosão foi feita com pressão constante de 100 mTorr, potência de $400 \mathrm{~W}$ e a temperatura utilizada no sistema de refrigeração era de $5{ }^{\circ} \mathrm{C}$. Com a finalidade de se obter o dispositivo final com 4 níveis de fase e que operará com laser de $\mathrm{HeNe}(\lambda=632,8 \mathrm{~nm})$, novamente foi feita a litografia com máscara $\pi$, corrosão do alumínio com posterior remoção do fotorresiste e finalmente corrosão do vidro com os mesmos parâmetros da primeira corrosão (Figura 17). 


\subsubsection{Processos de corrosão de filme fino de DLC}

\subsubsection{Parâmetros da corrosão por plasma para filmes finos de DLC sobre substrato de silício}

No processo foi feito plasma com $\mathrm{O}_{2}$ puro com vazão de $20 \mathrm{sccm}$. A corrosão foi feita para 9 amostras variando-se os parâmetros pressão (25, 50 e 100 mTorr) e potência $(50,100$ e $150 \mathrm{~W})$. Para as amostras cujos processos foram realizados com potência de $150 \mathrm{~W}$, o tempo foi de 1 minuto de corrosão. Para as amostras restantes, o tempo de processo foi de 2 minutos. A temperatura utilizada no sistema de refrigeração era de $5{ }^{\circ} \mathrm{C}$. Foi utilizada máscara de alumínio para a gravação dos padrões sobre o DLC e sobre tal máscara foi mantido o fotorresiste para também ser calculada a rugosidade e taxa de corrosão deste sofrida durante o processo.

\subsubsection{Parâmetros da corrosão por plasma para filmes finos de DLC sobre substrato de vidro para fabricação de EODs}

Para fabricação dos elementos ópticos difrativos de dois níveis com modulação de fase, foi feito um processo de corrosão com plasma de $\mathrm{O}_{2}$ (vazão de $20 \mathrm{sccm}$ ) e parâmetros potência de $50 \mathrm{~W}$ e pressão 25 mTorr. A temperatura utilizada no sistema de refrigeração era de $5{ }^{\circ} \mathrm{C}$ e foi utilizada apenas uma máscara de fotorresiste para gravação dos padrões dos elementos ópticos difrativos.

\subsubsection{Processos de corrosão de lâminas de silício}

\subsubsection{Parâmetros da corrosão por plasma para lâminas de silício}

No processo foi feito plasma com gás de $\mathrm{SF}_{6}$ com vazão de $20 \mathrm{sccm}$. A corrosão foi feita para 9 amostras por 2 minutos variando-se os parâmetros pressão $(25,50$ e 100 mTorr) e potência $(50,100$ e $150 \mathrm{~W})$. A temperatura utilizada no sistema de refrigeração foi de $10{ }^{\circ} \mathrm{C}$. Foi utilizada máscara de alumínio para a gravação dos 
padrões sobre o silício e sobre tal máscara foi mantido o fotorresiste para também ser calculada a rugosidade e taxa de corrosão sofrida durante o processo.

\subsubsection{Parâmetros da corrosão por plasma para lâminas de silício para fabricação de EODs}

Para fabricação dos elementos ópticos difrativos de dois níveis com modulação de fase, foi feito um processo de corrosão com plasma de $\mathrm{SF}_{6}$ (vazão de $20 \mathrm{sccm}$ ) e parâmetros potência de $50 \mathrm{~W}$ e pressão de $25 \mathrm{mTorr}$.

\subsection{Elipsometria}

Foi utilizado o elipsometro da Rudolph Research modelo AUTO-EL-NIR3, para medir o índice de refração dos materiais (vidro óptico, DLC e silício) utilizados na fabricação dos EOD's.

A elipsometria é um método óptico não destrutivo que permite medir o índice de refração (n) e o coeficiente de extinção de um substrato e também a espessura (d) de filmes finos transparentes sobre um substrato altamente absorvente, cujos valores de n e coeficiente de extinção sejam conhecidos.

O equipamento utilizado possui como fonte uma lâmpada halógena com filtros interferênciais $(405,632,8$ e $830 \mathrm{~nm})$, que passa através de um polarizador circular (para obter um feixe de polarização circular e de intensidade máxima). Essa polarização circular é, em seguida, transformada em polarização linear por um polarizador. Finalmente, a luz chega sobre a amostra. Após reflexão, a luz passa por um analisador, e depois através de um filtro selecionando apenas o comprimento de onda desejado, isso para evitar qualquer perturbação da luz ambiente. Enfim, a luz chega sobre o fotodetetor.

O método consiste em avaliar as mudanças no estado de polarização da luz causada pela reflexão numa superfície [76]. 


\subsection{Medições de rugosidade e altura de degrau por perfilometria}

Para medir a rugosidade e a altura do degrau das lâminas de teste e mesmo dos elementos ópticos difrativos fabricados, foi utilizado um perfilômetro da Sloan, modelo DEKTAK 3030.

A rugosidade costuma ser uma propriedade das superfícies com uma pequena dificuldade de definição de seu conceito. Ao observar-se tal propriedade, é possível enterder-se do que se trata imediatamente, mas nem sempre é possível explicá-la satisfatoriamente [77]. Existe mais trivialidade em se medir a espessura ou o degrau de um filme. Foram desenvolvidos inúmeros aparelhos para realizar medições de rugosidade como microscópios ópticos, microscópios eletrônicos, perfilometros mecânicos, perfilometros ópticos, micro-interferometros e rugosimetros baseados no espalhamento da luz $[78,79]$. No entanto, cada um destes equipamentos apresenta suas vantagens, desvantagens e limitações.

Utilizam-se vários modelos para caracterizar a rugosidade de uma superfície. As 3 grandezas mais utilizadas são a rugosidade média $\left(\mathrm{R}_{\mathrm{A}}\right)$, a rugosidade RMS e a rugosidade pico-a-pico Rt. Tem-se:

1) Rugosidade média ou $R_{A}$ eq. (7):

$$
R_{A}=\left(\frac{1}{N} \sum_{i=1}^{N}\left|Z_{i}\right|\right)
$$

2) Rugosidade RMS ou Avg eq. (8):

$$
R_{R M S}=\left(\frac{1}{N} \sum_{i=1}^{N} Z_{i}^{2}\right)^{1 / 2}
$$

3) Rugosidade máxima ou pico-a-pico (p.p.) eq. (9):

É dada pela diferença entre o pico mais alto e a depressão mais baixa no comprimento considerado. Pode ser um bom indicador da ocorrência de falhas no processo de fabricação [78].

$$
R_{t}=Z_{\max }-z_{\min }
$$


onde $z_{\max }$ é o valor mais positivo de todos $z_{i}$ e $z_{\min }$ é o valor mais negativo (Figura $18)$.

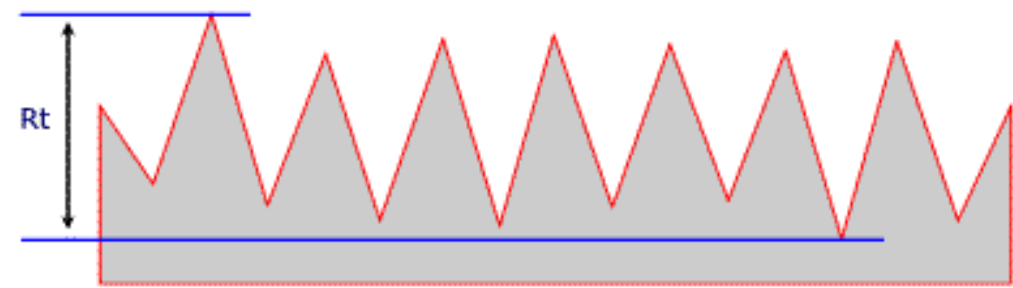

Fig. 18 Rugosidade máxima

A rugosidade pico-a-pico é a mais imprecisa, já que necessita apenas de dois pontos para ser obtida. Quanto mais pontos utilizados no cálculo da rugosidade, mais precisa esta será e, portanto, as rugosidades $\mathrm{R}_{\mathrm{A}}$ e RMS apresentam maior precisão [79].

\subsubsection{Medidas de altura do degrau pela técnica de Perfilometria (amostras de vidro protegidas por fotorresiste)}

Nesta medição foi obtida a altura do fotorresiste depositado, quanto o fotorresiste foi corroído através do processo RIE (reactive ion etching) e qual espessura do vidro foi corroída. De início, as lâminas foram limpas e sobre elas foi depositado aproximadamente $1,3 \mu \mathrm{m}$ de fotorresiste e a litografia foi feita com uma máscara padrão. Quatro destas lâminas foram cortadas em 4 partes que foram submetidas ao processo de corrosão modo RIE. As amostras obtidas produziram diferentes resultados quanto á altura do degrau, rugosidade e taxa de corrosão, já que os parâmetros pressão e potência RF do processo de corrosão foram variados. Teve-se o cuidado de separar-se uma das lâminas para poder se medir a altura do fotorresiste. Após o processo de corrosão, foi feita a medição por perfilometria com a finalidade de se obter a rugosidade do vidro e o degrau resultante formado pelo vidro corroído juntamente com o fotorresiste corroído. E, por fim, todo o fotorresiste foi removido e pode-se obter também por perfilometria, a espessura do vidro corroído e novamente uma medida da rugosidade do vidro corroído e também do vidro não corroído protegido pelo fotorresiste. 
3.8.1.1 Medidas pela técnica de Perfilometria antes do processo de corrosão (amostras de vidro)

Esta medida foi realizada antes de se fazer o processo de corrosão e, através do perfilometro foi obtido o valor médio $h_{r}$ que é a altura do fotorresiste depositado (Figura 19).

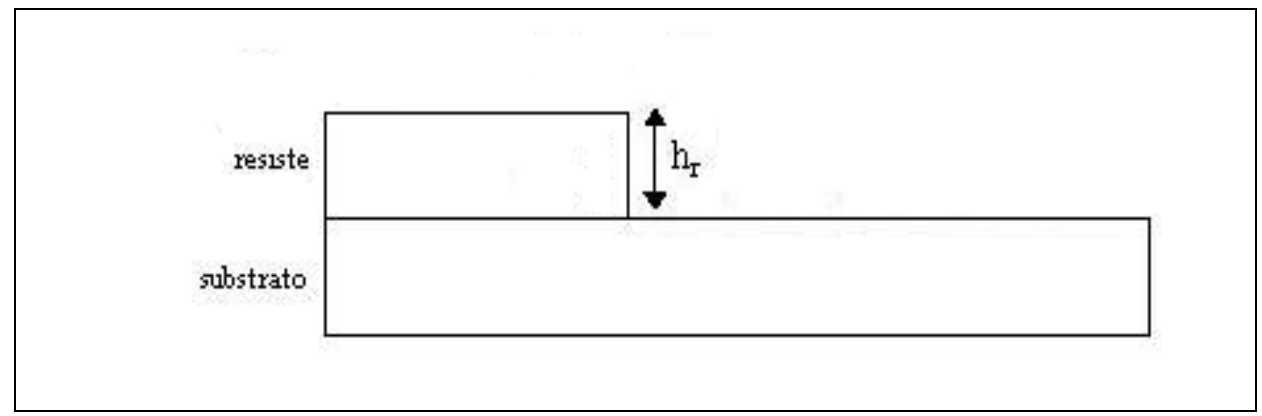

Fig.19 Medição da altura do degrau do resiste antes do processo de corrosão

\subsubsection{Medidas pela técnica de Perfilometria após processo de corrosão (amostras de vidro)}

Após o processo de corrosão, foi possível pela técnica de perfilometria obter os valores médios de $\mathrm{h}_{\mathrm{rc}+\mathrm{v}}$ (para as amostras protegidas por fotorresiste) que seriam a soma de $h_{r c}$ e $h_{v}($ Figura 20).

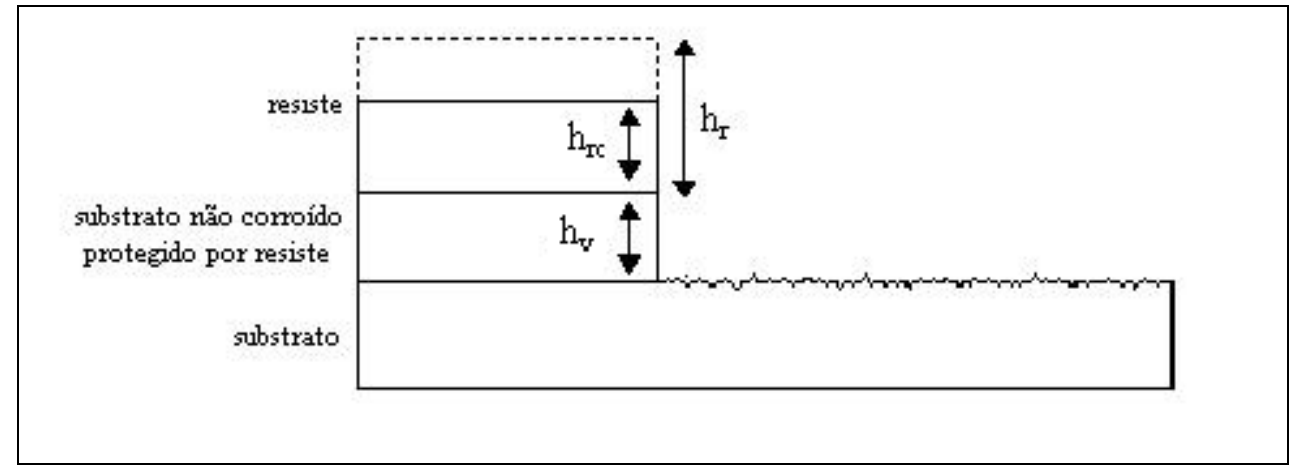

Fig. 20 Medição da altura do degrau do fotorresiste corroído mais vidro corroído depois da corrosão 


\subsubsection{Perfilometria após processo de corrosão e remoção do fotorresiste (amostras de vidro)}

Após a remoção de todo o fotorresiste o valor da altura $h_{v}$ do vidro corroído de fato pode ser medida (Figura 21).

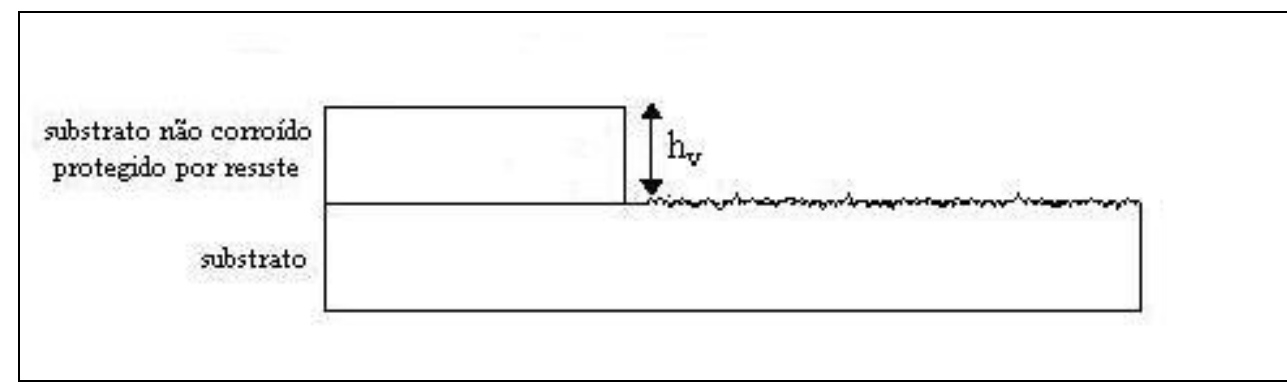

Fig. 21 Medição da altura do degrau do vidro corroído depois da corrosão e remoção do fotorresiste

\subsubsection{Medidas pela técnica de Perfilometria (amostras de vidro protegidas por alumínio)}

Esta medição foi feita após o processo de corrosão e remoção do alumínio com a finalidade de se obter a altura do vidro corroído $h_{v}$, as rugosidades pico-a-pico, RMS e $R_{A}$ do trecho corroído para obter-se uma comparação destes valores com os resultados do processo de corrosão do vidro protegido por máscara de fotorresiste (Figura 22).

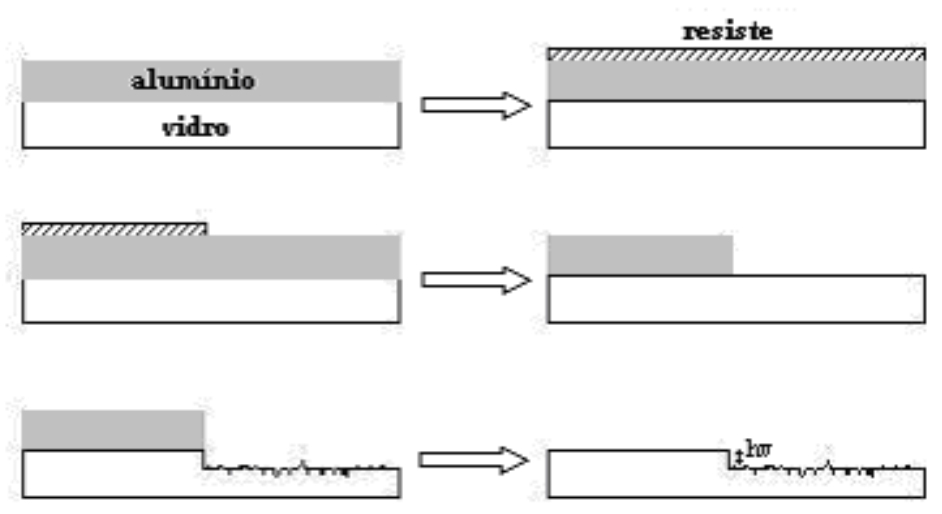

Fig. 22 Seqüência de obtenção de degrau para teste de rugosidade e taxa de corrosão 


\subsubsection{Medidas pela técnica de Perfilometria (amostras de DLC protegidas por fotorresiste)}

Após o processo de corrosão foi medida a altura das camadas de DLC e fotorresiste juntamente. Em seguida, foi removido o fotorresiste e medida a espessura do DLC.

\subsubsection{Medidas pela técnica de Perfilometria (amostras de silício protegidas por fotorresiste)}

A altura do degrau do silício corroído somente pôde ser averiguada após a remoção da máscara de fotorresiste. Antes de tal remoção, foi primeiramente medida a altura do degrau do fotorresiste mais o silício corroído após o processo de corrosão por plasma, com a finalidade de também se obter a taxa de corrosão do fotorresiste.

\subsection{Espectrofotometria UV-Vis-NIR}

Foi utilizado o equipamento Varian, modelo Cary 500 (disponível no Instituto de Física da USP), para medir a transmitância da radiação incidente em vários comprimentos de onda $(200<\lambda<3300 \mathrm{~nm})$ dos materiais. Através do mesmo equipamento acoplado à uma esfera integradora, também pôde-se medir a reflectância total e a difusa do DLC e do vidro para se calcular a rugosidade.

\subsection{Microscopia Eletrônica de Varredura (SEM)}

Foi utilizado um microscópio NOVA NanoSEM 400 da FEI para a obtenção de micrografias das amostras.

\subsection{Microscopia de Força Atômica}

Foi utilizado um microscópio da Digital Instruments modelo NanoScope III, scanner tipo E, (Contact Mode), para quantificação da rugosidade superficial e visualização da morfologia e topografia das estruturas. 


\subsection{Microanálise}

Foi utilizado um Microscópio Eletrônico de Varredura 6460LV da Jeol com EDS (Energy Dispersive Spectrometer) localizado no Instituto de Física da USP e a coleta de dados se deu da seguinte maneira: quando o feixe de elétrons atinge a amostra, seus átomos são excitados e, ao voltarem para o estado fundamental, emitem fótons com energias características do átomo. Os fótons são assim identificados em termos de sua energia e coletados pelo detector de raios-X localizado dentro da câmara de vácuo. Desta forma o conjunto hardware e software do sistema adquire e gera o espectro relativo ao número de contagens em função da energia, em $\mathrm{keV}$, identificando os elementos químicos presentes na amostra. Os átomos a partir do boro são identificáveis, uma vez que o detector possui filtro de NORVAR ao invés de berílio. Além dos espectros, o sistema realiza análise de pontos, linhas e regiões definidas sobre a imagem da amostra.

\subsection{Bancada de análise óptica}

Para análise óptica dos dispositivos, foram utilizadas as seguintes infra-estruturas:

\subsubsection{Analise óptica de elementos ópticos difrativos de vidro com 2 níveis de} fase

Para a análise do funcionamento dos EODs, foram escolhidos dois dispositivos: um que forma uma imagem de um quadrado e outra que uma cruz. Para obter os resultados desta análise, foi montado um aparato constituído de um laser de $\mathrm{HeNe}$ com $\lambda=632,8 \mathrm{~nm}$, um pinhole (abertura $100 \mu \mathrm{m}), 3$ lentes $(\mathrm{D}=30 \mathrm{~mm})$, um polarizador e um anteparo onde a imagem foi formada para ser capturada por uma câmera ccd (Figura 23). 


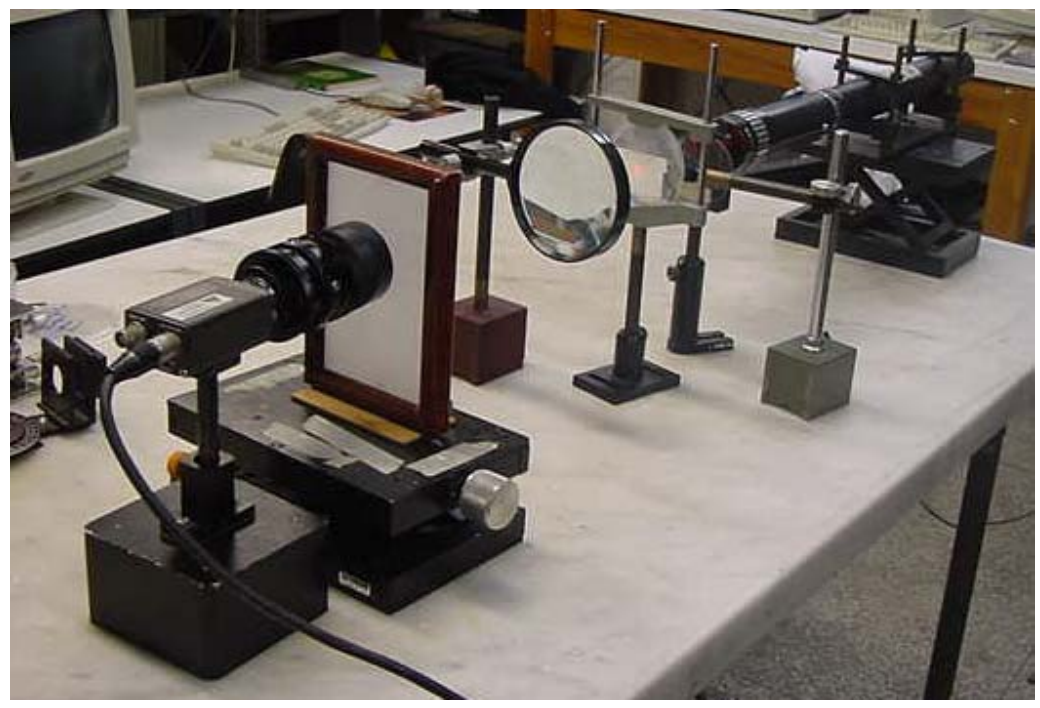

Fig. 23 Foto do aparato utilizado na medição óptica dos EODs com 2 níveis de fase

\subsubsection{Analise óptica de elementos ópticos difrativos de vidro com 4 níveis de} fase

Para a análise do funcionamento dos elementos ópticos difrativos, foram escolhidos dois dispositivos: um que forma uma imagem de uma borboleta e um que forma a imagem de uma águia. Para obter os resultados desta análise, foi montado um aparato constituído de um laser de $\mathrm{HeNe}$ com comprimento de onda de 632,8 nm, um pinhole (abertura $100 \mu \mathrm{m}), 3$ lentes $(\mathrm{D}=30 \mathrm{~mm}$ ), um polarizador e um anteparo onde a imagem foi formada para ser capturada por uma câmera ccd (Figura 24).

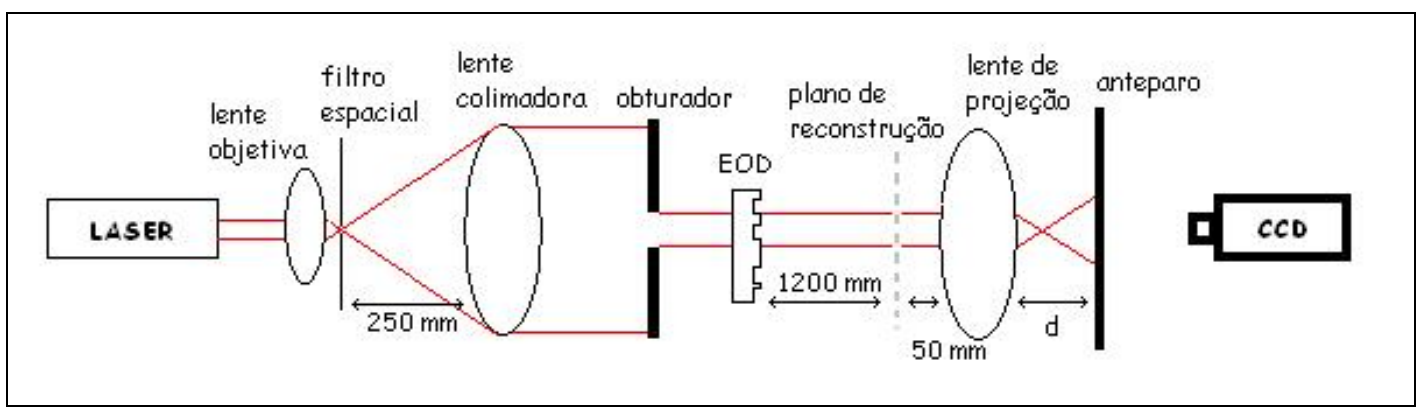

Fig. 24 Esquema do arranjo experimental utilizado para análise óptica de hologramas do tipo Fresnel com quatro níveis de modulação de fase. A distância d controla a magnificação da imagem. 
3.13.3 Analise óptica de elementos ópticos difrativos de DLC com 2 níveis de modulação de fase

Para obter os resultados desta análise, foi montado um aparato constituído de um laser de $\mathrm{HeNe}$ com comprimento de onda de $632,8 \mathrm{~nm}$ e um anteparo onde a imagem foi formada para ser capturada por uma câmera ccd (Figura 25).

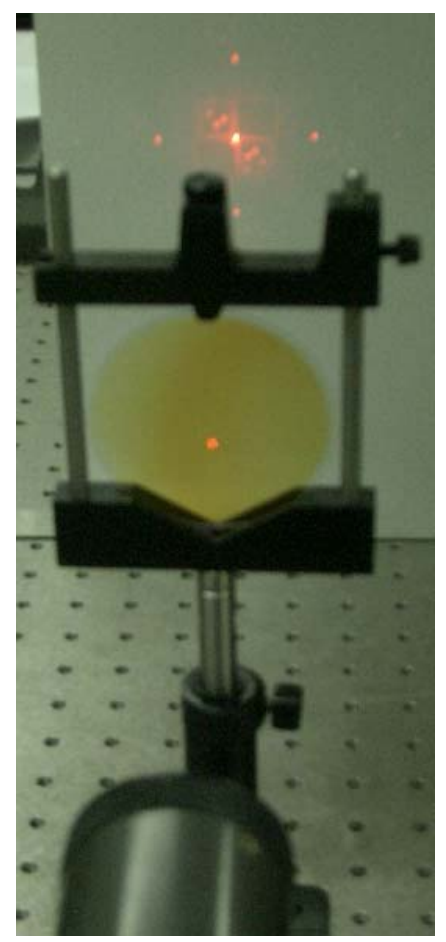

Fig 25 Aparato utilizado na medição óptica dos EODs de DLC com dois níveis de fase 


\section{RESULTADOS E DISCUSSÃO}

\subsection{Dispositivos difrativos binários fabricados em vidro óptico}

Foi feito um estudo de processos de litografia e corrosão do vidro óptico B270 da Schott, com a finalidade de se obter processos que apresentem menores rugosidades (RMS, $\mathrm{R}_{\mathrm{A}}$ e pico-a-pico) com a maior taxa de corrosão possível, o que possibilita a fabricação de um elemento difrativo em menor tempo, diminuindo assim gastos e, devido à baixa rugosidade da superfície do dispositivo final, formação de uma imagem de alta resolução e livre de ruídos causado por speckle inerente. Para tanto, foram feitos processos variando-se potência, pressão, temperatura do eletrodo do equipamento RIE e até mesmo concentração de gases utilizados no plasma.

A partir de dispositivos fabricados sobre o vidro óptico, foram também feitas análises ópticas com a finalidade de se estudar a resolução das imagens formadas.

\subsubsection{Elipsometria}

Foi obtido o índice de refração do substrato (n) medido com um comprimento de onda $\lambda=632,8 \mathrm{~nm}$. Este índice foi medido em 10 lâminas e em cada uma delas foram analisados 50 pontos, dos quais foi tirada uma média e um desvio padrão. $O$ resultado é muito importante para as futuras etapas pois é com base nele que pode-se calcular a espessura necessária para se fabricar um dispositivo otimizado.

Verificou-se que não houve uma grande variação nos valores médios de índice de refração das lâminas, cuja média é 1,4041 $( \pm 0,0084)$, indicando que as amostras apresentam índices de refração aproximados. A lâmina mais discrepante com relação ao conjunto é a 9 que possui o mais alto índice de refração máximo $(1,5351)$ e o mais baixo n mínimo (1,3838), mas no geral, isto não afetou sua média.

Foi medido também o coeficiente de absorção do substrato (Ks) utilizando-se de um 
comprimento de onda $\lambda=632,8 \mathrm{~nm}$ cuja média para as 10 amostras foi de 0,0168 $( \pm 0,0066)$.

\subsubsection{Amostras protegidas por fotorresiste}

\subsubsection{Perfilometria antes do processo de corrosão}

Esta medida foi realizada antes de ser realizado o processo de corrosão e obteve-se o valor médio $\mathrm{h}_{\mathrm{r}}=1319,8 \mathrm{~nm}( \pm 15,3 \mathrm{~nm})$ que é a altura do fotorresiste depositado.

\subsubsection{Perfilometria após processo de corrosão}

Após o processo de corrosão e antes da remoção total do fotorresiste, foram feitas medidas por perfilometria. Foi visto claramente que o processo de corrosão por plasma atacou intensamente o fotorresiste que protegia o padrão a ser implementado no substrato de vidro. Justamente por este motivo, foi necessário substituir o fotorresiste por alumínio em um processo posterior, apesar de ser necessário incluir mais uma etapa no processo de fabricação do dispositivo. Nas próximas etapas de corrosão somente se fará o uso de alumínio, abandonando-se completamente os processos com o uso máscara de fotorresiste. 


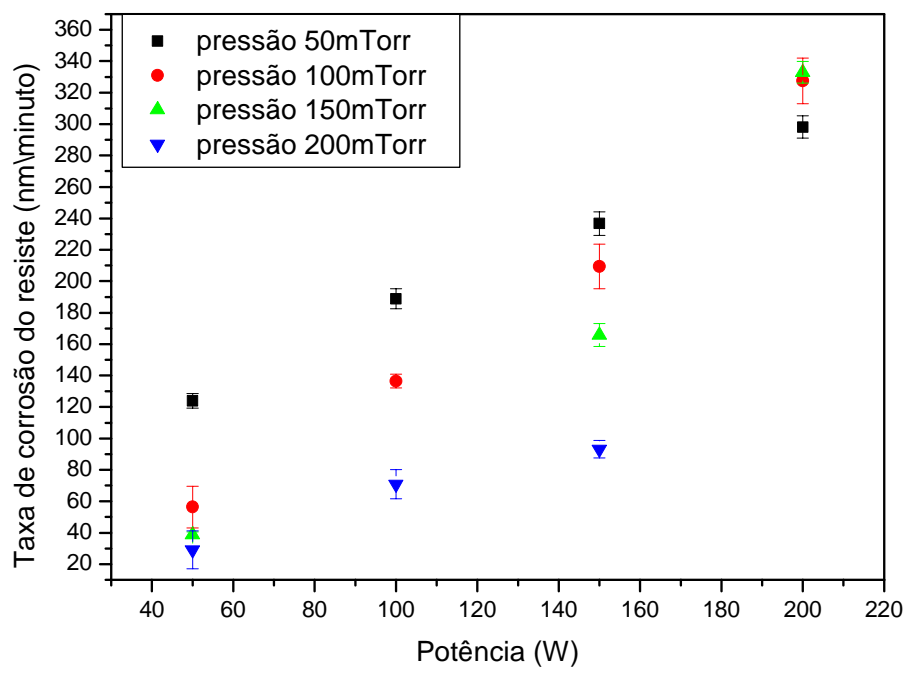

Fig. 26 Taxa de corrosão do fotorresiste em função da variação dos parâmetros de plasma no processo de corrosão

Na Figura 26 é apresentado o gráfico de taxa de corrosão do fotorresiste em função da potência de RF, para diferentes pressões de processo. Observa-se um aumento acentuado da taxa de corrosão com o aumento da potência para todas pressões utilizadas. Isto é causado em baixas pressões pelo aumento do ataque iônico (visto o caráter linear da curva), enquanto que em altas pressões é causado devido ao aumento de radicais (visto o caráter parabólico das curvas). As curvas pertencentes às pressões intermediárias de 100 mTorr e 150 mTorr apresentaram um crescimento com o aumento da potência mais acentuado em relação às outras curvas. Já a curva pertencente à pressão de 200 mTorr apresentou um crescimento (da taxa de corrosão do fotorresiste com o aumento da potência) menor ao ser comparado com o crescimento das outras curvas. A taxa de corrosão deste processo com uso de máscara de fotorresiste está demasiadamente alta, indicando que o fotorresiste não foi apropriado para o processo.

Os valores da rugosidade pico-a-pico, RMS e $\mathrm{R}_{\mathrm{A}}$ foram constantes (respectivamente em torno de $26,7 \mathrm{~nm}$ e 5,5 $\mathrm{nm}$ e 3,6 nm) para as 16 amostras com fotorresiste, apesar da amostra cujo processo foi feito com potência de $100 \mathrm{~W}$ e pressão 50 mTorr apresentar alguns valores fora da média (valores da rugosidade pico-a-pico e RMS 
foram respectivamente $41,9 \mathrm{~nm}$ e $12,5 \mathrm{~nm}$ ). A polimerização durante o processo de corrosão por plasma é um parâmetro influente pois concorre com a corrosão do material e além de ser um obstáculo à corrosão, ele aumenta a rugosidade da superfície.

A melhor observação da rugosidade em função da profundidade corroída é dada pela rugosidade normalizada que é obtida dividindo-se a rugosidade RMS pela altura do degrau obtido.

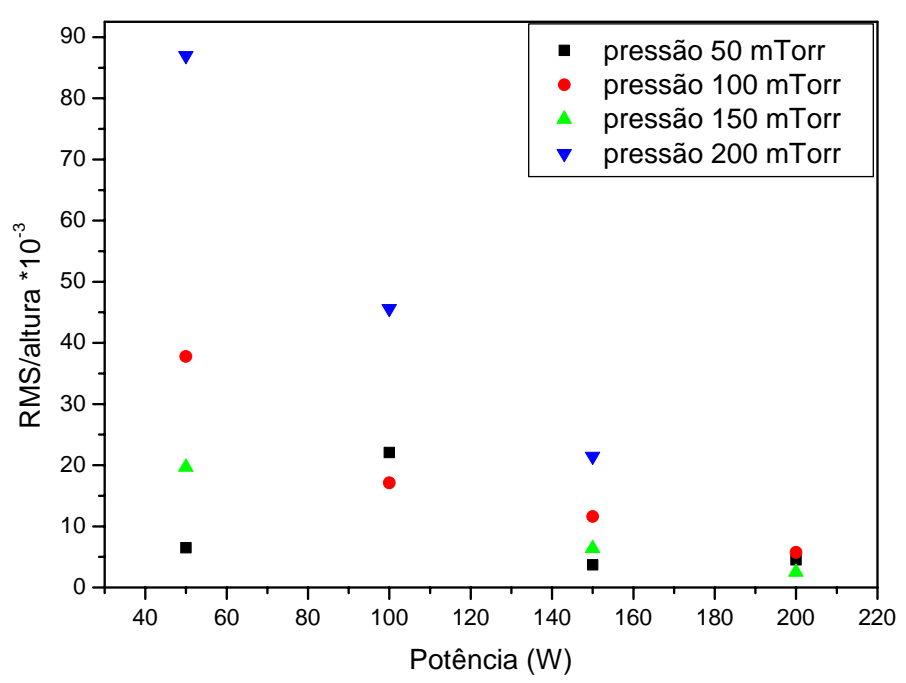

Fig. 27 Rugosidade normalizada em função da variação dos parâmetros de processo de corrosão por plasma do fotorresiste

Pela rugosidade normalizada apresentada na Figura 27 observa-se que quanto maior a potência, menor seu valor. A pressão também influencia a inclinação de cada curva. As curvas apresentam um comportamento inverso ao das curvas apresentadas para a taxa de corrosão em função de potência: ao invés de crescer com a variação de potência, elas declinam. Isto indica que a altura corroída cresce com o aumento de potência, no entanto as rugosidades RMS permanecem semelhantes para diferentes pressões e potências, portanto, para maiores profundidades corroídas, a rugosidade normalizada é maior. 


\subsubsection{Perfilometria após processo de corrosão e remoção do fotorresiste}

Após ter sido medido os valores de altura do fotorresiste juntamente com o vidro corroído e rugosidade do trecho corroído da amostra ainda com fotorresiste, foi feita a remoção de todo este e o valor da altura $h_{v}$ do vidro corroído de fato pode ser calculada.

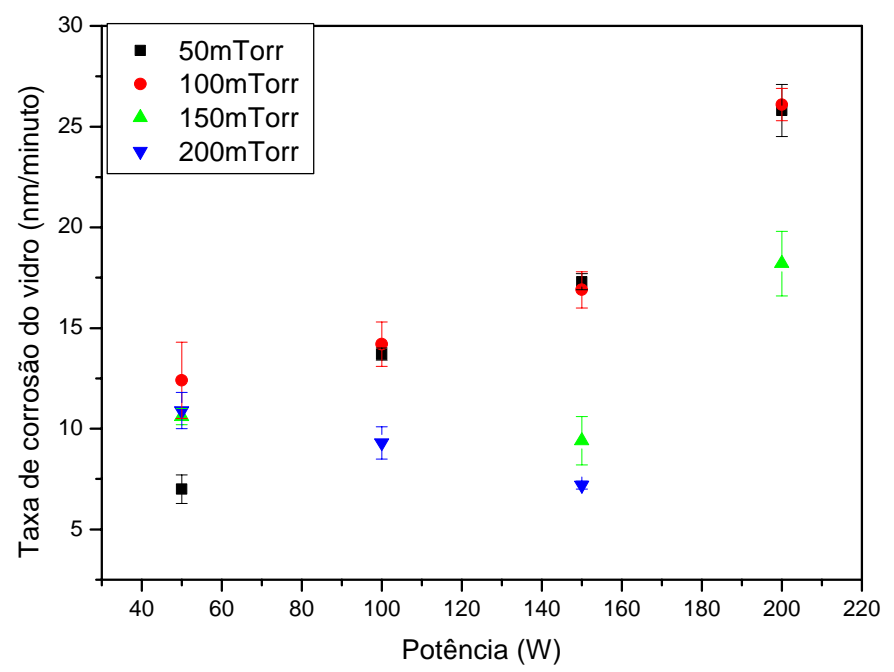

Fig. 28 Taxa de corrosão do vidro em função da variação dos parâmetros de processo de corrosão por plasma

Na Figura 28 é apresentado o gráfico de taxa de corrosão do vidro em função dos parâmetros do processo de plasma. As curvas para as 2 pressões mais baixas crescem quase que na mesma proporção, apesar da inclinação da curva pertencente à pressão de 100 mTorr ser mais suave. Em oposição é visto que a curva para a maior pressão apresenta declínio, mostrando assim que a taxa de corrosão não aumenta com o aumento da pressão, mas depende de outro fator que é a potência. Portanto, observase que existe um ponto onde a taxa de corrosão é otimizada e este ocorre com pressão de 100 mTorr e potência de $200 \mathrm{~W}$ (apesar de não possuir o maior valor, o ponto ocorrido com pressão de 50 mTorr e potência $200 \mathrm{~W}$ possui um valor muito próximo do ponto otimizado). 
Após ter sido feita a corrosão e a medição da altura do fotorresiste corroído juntamente com o vidro corroído, o fotorresiste foi removido com acetona e alcóol isopropílico.

Tabela III - Médias das rugosidades do vidro para trecho corroído e não corroído

\begin{tabular}{|c|c|c|c|}
\hline \multirow{2}{*}{ Trecho } & \multicolumn{3}{|c|}{ Rugosidade Média (nm) } \\
\cline { 2 - 4 } & pico-a-pico & RMS & $\mathrm{R}_{\mathrm{A}}$ \\
\hline Corroído & 16,5 & 2,4 & 2,8 \\
\hline Não corroído & 17,2 & 2,9 & 3 \\
\hline
\end{tabular}

Com base na média dos resultados das rugosidades pico-a-pico para o trecho corroído e não corroído das amostras, nota-se que o valor do primeiro é inferior ao segundo. Uma possível hipótese é que no processo da corrosão, o substrato tenha perdido as características de rugosidade originais do material com o ataque à superfície do vidro gerado pelo plasma

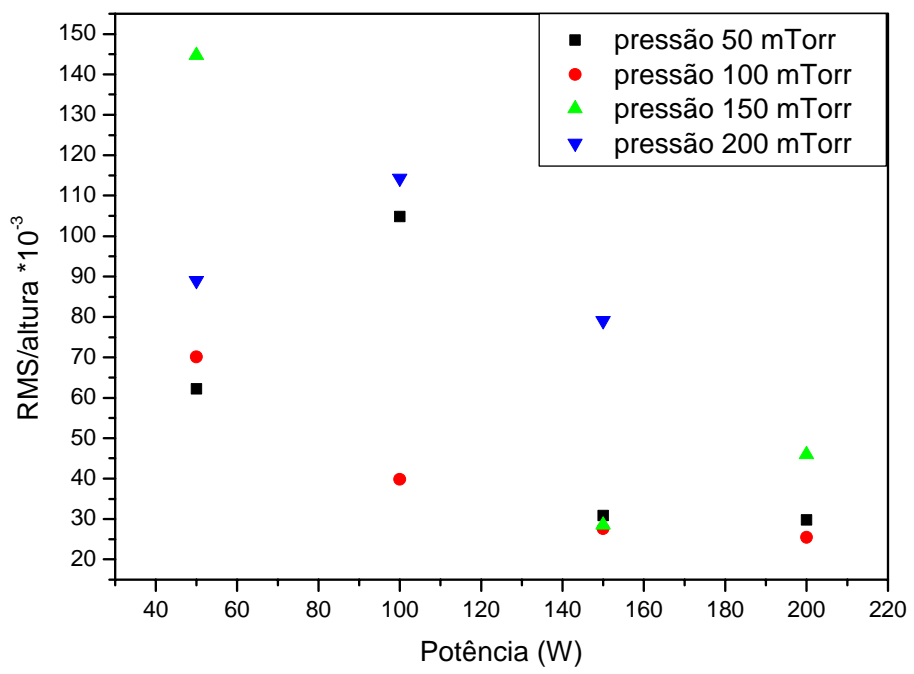

Fig. 29 Rugosidade normalizada em função da variação dos parâmetros de processo de corrosão por plasma do vidro

Na Figura 29, são apresentados valores de rugosidade normalizada do vidro que têm um comportamento diferente dos valores do fotorresiste. Para a potência de $100 \mathrm{~W}$, existe uma variação nas curvas, elas não seguem o mesmo padrão, indicando que houve um ou mais fatores que possam ter sido a causa. Um dos principais problemas pode ter sido o fato do vidro ser composto por óxidos que provocaram o 
micromascaramento, causando assim, uma variação na rugosidade normalizada. Outro problema pode ter sido a máscara de fotorresiste que sofreu sputtering e com isso, tal material foi redepositado sobre a superfície do vidro, o que causou mais rugosidade e menos corrosão.

É observado que os valores de seletividade são relativamente baixos, indicando que houve demasiado ataque ao fotorresiste durante o processo de corrosão por plasma. $\mathrm{O}$ valor ideal para a seletividade do vidro em relação ao fotorresiste seria entre 5 e 10 e os resultados inferiores à 0,4 só provam que o fotorresiste não é a máscara de proteção ideal para ser utilizada no processo, levando-se em conta que se forem feitos processos mais longos, ela poderá ser corroída totalmente, inutilizando o dispositivo a ser implementado no vidro.

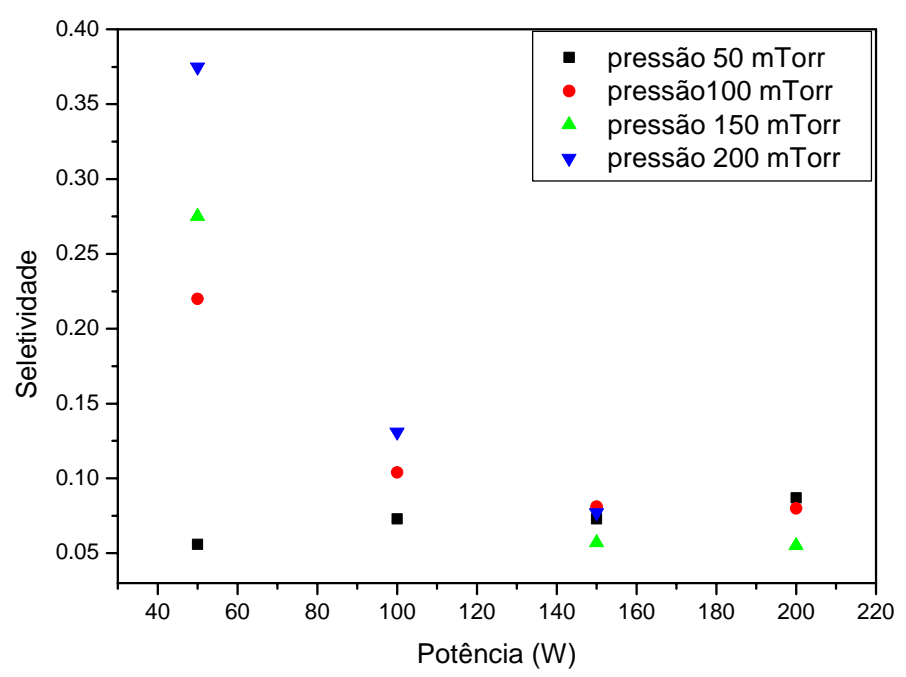

Fig. 30 Seletividade entre vidro e fotorresiste em função dos parâmetros de corrosão por plasma

As curvas para seletividade (Figura 30) entre vidro e fotorresiste decaem quase que exponencialmente, com exceção da curva pertencente à pressão de 50 mTorr que é quase constante, apesar de apresentar uma leve tendência ao crescimento. A curva com maior inclinação pertence à maior pressão e as curvas intermediárias apresentam praticamente o mesmo comportamento. 
Com base nos resultados referentes ao índice de refração obtidos pela técnica de elipsometria, temos que (Eq.10):

$$
\mathrm{d}_{\max }=632,8 / 2(1,41-1)=0,77 \mu \mathrm{m}
$$

A partir deste valor e tendo os resultados das taxas de corrosão do vidro para cada processo, pode-se estimar em minutos o tempo necessário para se obter a amplitude $d_{\text {max }}$ em cada processo de corrosão do vidro protegido por fotorresiste. Neste estudo, o processo ideal é aquele cuja pressão é de 100 mTorr e potência $200 \mathrm{~W}$, para o qual o tempo calculado é 29,5 minutos. Levando em conta a seletividade, este tempo de processo ainda é muito alto e a máscara pode ser totalmente corroída, inutilizando o dispositivo.

\subsubsection{Amostras protegidas por Alumínio}

\subsubsection{Perfilometria das amostras protegidas por alumínio}

Como o processo anterior não apresentou bons resultados com relação à corrosão do fotorresiste, foi feita a segunda série de experimentos utilizando uma máscara de alumínio, já que tal material não sofre corrosão durante o processo de plasma. Após o processo e remoção do alumínio, foi medida a altura e a rugosidade do trecho corroído do vidro pela técnica de perfilometria.

Um dos objetivos deste trabalho é corrigir a problemática do processo de corrosão por plasma do vidro com relação à reprodutibilidade do processo e a rugosidade relativamente alta nos dispositivos. O processo inicial já feito em um trabalho anterior neste laboratório [69] era com plasma de $\mathrm{CF}_{4}+\mathrm{H}_{2}$ utilizando filmes de fotorresiste como máscara. Como o plasma de $\mathrm{CF}_{4}+\mathrm{H}_{2}$ promove demasiada polimerização (processo que é concorrente da corrosão) e não resultou em bons resultados, neste trabalho utilizou-se plasma de $\mathrm{CF}_{4}$ puro com a finalidade de se diminuir a rugosidade no dispositivo final.

Pelo $\mathrm{h}_{\mathrm{v}}$ (altura corroída em 15 minutos) e $\mathrm{Tx}_{\mathrm{v}}$ (taxa de corrosão do vidro) é visto que o processo pode ser controlado e portanto é possível corroer-se uma altura o mais 
perto possível do desejado na lâmina inteira. Em todos os casos de amostra, a rugosidade RMS foi inferior a 1/10 do comprimento de onda $632,8 \mathrm{~nm}$ do laser de $\mathrm{HeNe}$, indicando que a rugosidade da superfície estava com um valor muito baixo. Apesar dos bons resultados, é fato que a taxa de corrosão do vidro é menor com o uso de máscara de alumínio do que no processo de corrosão com o uso de máscara de fotorresiste.

Nota-se que apesar do tempo de corrosão ter sido 5 vezes maior do que no processo feito anteriormente com fotorresiste, os valores das 3 rugosidades para todas amostras (amostras protegidas por máscara de fotorresiste e amostras protegidas por máscara de alumínio) estão bem próximos, com exceção da amostra cujo processo de corrosão foi feito com potência RF de $200 \mathrm{~W}$ e pressão de 150 mTorr que apresentou valores muito elevados tanto para rugosidade pico-a-pico quanto para as rugosidades RMS e $R_{A}(65 \mathrm{~nm}, 13 \mathrm{~nm}$ e $11 \mathrm{~nm}$ respectivamente).

\begin{tabular}{|c|c|c|}
\hline \multicolumn{3}{|c|}{$\begin{array}{c}\text { Tabela IV - Médias das rugosidades do } \\
\text { vidro protegido por alumínio }\end{array}$} \\
\hline p.p.(nm) & $\mathbf{R M S ( n m )}$ & $\mathbf{R}_{\mathbf{A}}(\mathbf{n m})$ \\
\hline 17 & 3,2 & 2,8 \\
\hline
\end{tabular}

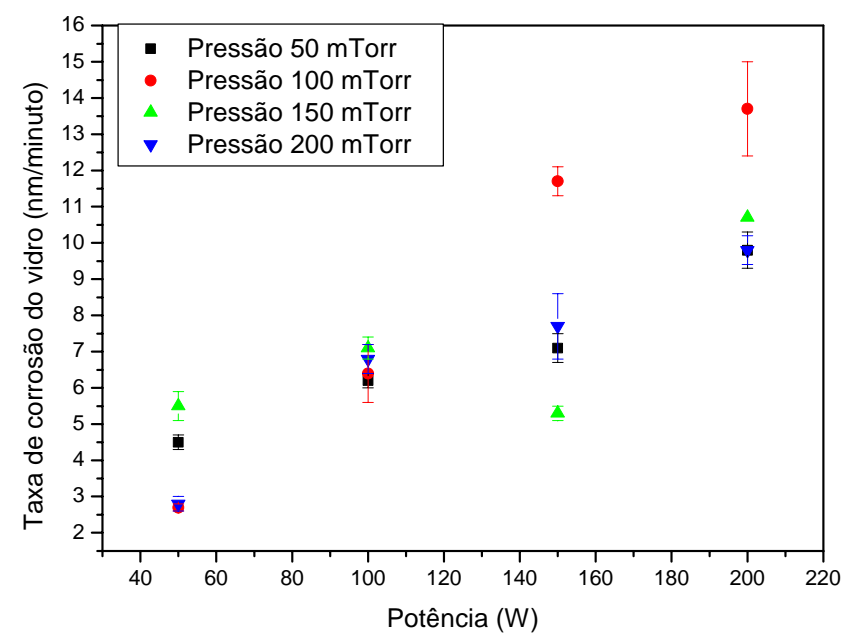

Fig. 31 Taxa de corrosão do vidro em função da variação dos parâmetros de processo de corrosão por plasma

No gráfico da Figura 31 são apresentadas as curvas da taxa de corrosão em função da potência do processo, a curva que apresenta uma inclinação mais acentuada é a pertencente à pressão de 100 mTorr e é nela que se encontra o ponto ótimo do processo (onde existe maior taxa de corrosão) para uma potência de RF de $200 \mathrm{~W}$. 


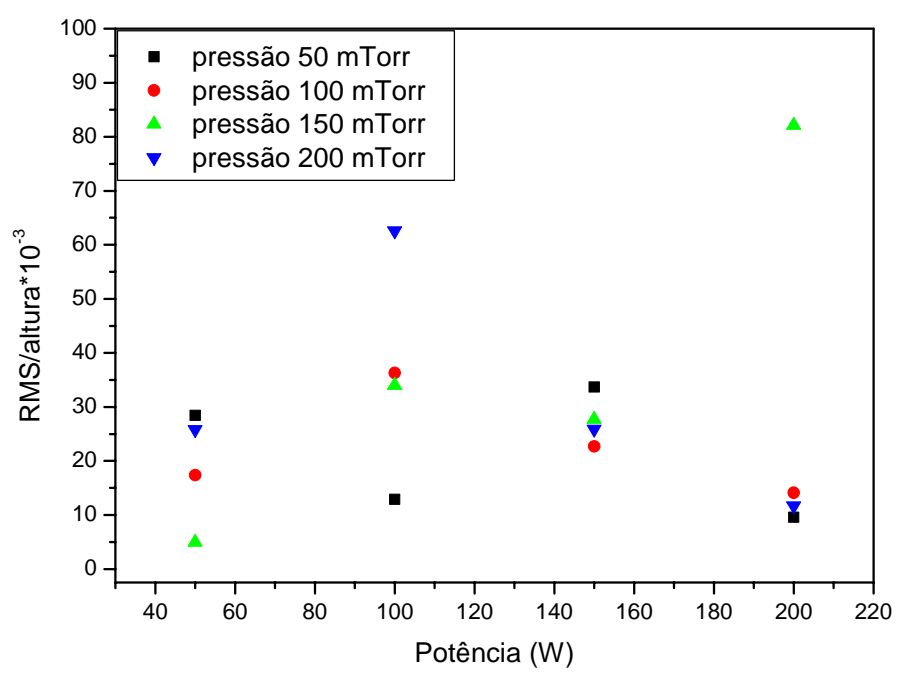

Fig. 32 Rugosidade normalizada em função da variação dos parâmetros de processo de corrosão por plasma do vidro

As curvas de rugosidade normalizada para o substrato de vidro protegido por alumínio se comportaram da mesma maneira que as do substrato de vidro protegido por apenas fotorresiste, ou seja, apresentaram pontos discrepantes para a potência de $100 \mathrm{~W}$. Como neste caso o fotorresiste que foi utilizado na fotolitografia para gravar o padrão sobre o alumínio foi removido antes do processo de corrosão, o problema que pode ter ocorrido foi devido aos óxidos presentes na composição do vidro. É observado que apesar do comportamento ter sido parecido, as rugosidades RMS normalizadas para o vidro protegido por alumínio são menores que os valores para o vidro protegido por fotorresiste (Figuras 32 e 29), indicando que pelo fato da presença de fotorresiste durante a corrosão, haja mesmo redeposição deste material, aumentando a rugosidade.

Pode-se estimar em minutos o tempo necessário para se obter a amplitude $d_{\max } \quad 0,77$ $\mu \mathrm{m}$ em cada processo de corrosão do vidro protegido por alumínio. O menor tempo estimado de processo (56,2 minutos) foi obtido para amostra cuja pressão de processo foi $100 \mathrm{mTorr}$ e potência $200 \mathrm{~W}$. 
Com relação aos tempos de corrosão para se obter uma espessura de $0,77 \mu \mathrm{m}$, é visível que houve um aumento nos valores calculados para este processo utilizando máscara de alumínio com relação ao processo utilizando fotorresiste e isto já era esperado, baseando-se nos resultados de taxa de corrosão do vidro.

\subsubsection{Análise por Microscopia Eletrônica de Varredura}

Foram obtidas micrografias da rugosidade da superfície do substrato de vidro após corrosão através da técnica de microscopia eletrônica de varredura (SEM - Scanning Electronic Microscopy) para se fazer uma análise qualitativa dos efeitos de pressão e potência no processo. Nas micrografias são mostradas as superfícies das amostras cujos parâmetros de corrosão foram pressão constante de 50mTorr e potência de 50W e 100W respectivamente nas Figura 33 e 34.

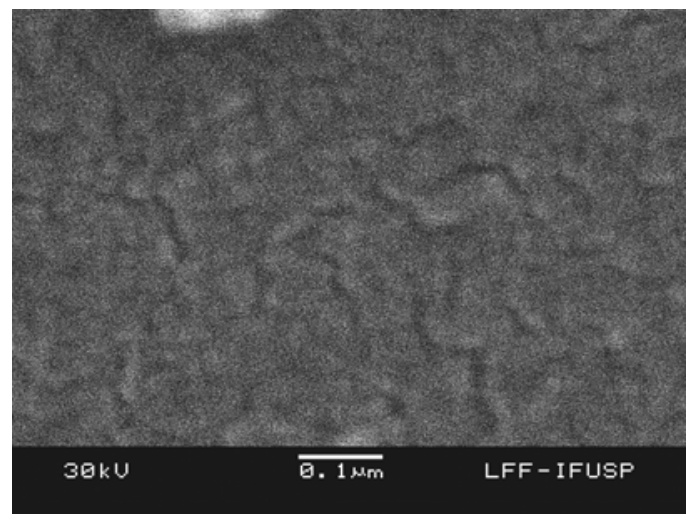

Fig.33 Imagem amostra 50mTorr e 50W

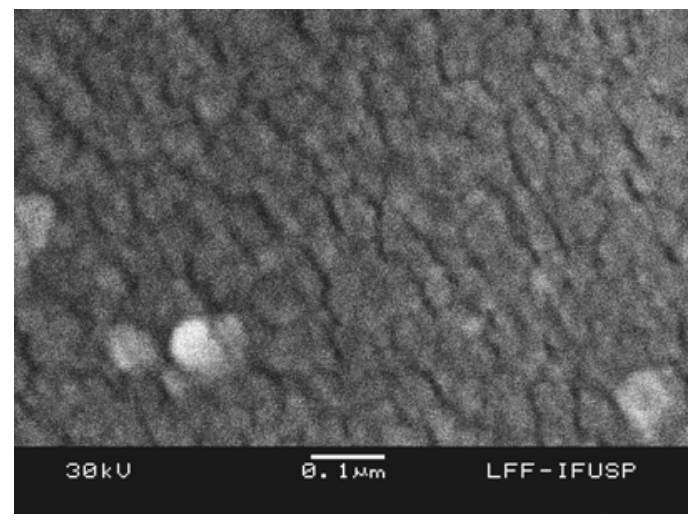

Fig.34 Imagem amostra 50mTorr e 100W

\subsubsection{Análise da rugosidade por Microscopia de Força Atômica (AFM - Atomic Force Microscopy)}

Foi feita análise por Microscopia de Força Atômica de três amostras com pressão constante de 100 mTorr e potências RF de 50W, 150W e 200W como parâmetros do processo de corrosão com a finalidade de se obter resultados quantitativos de rugosidade. 


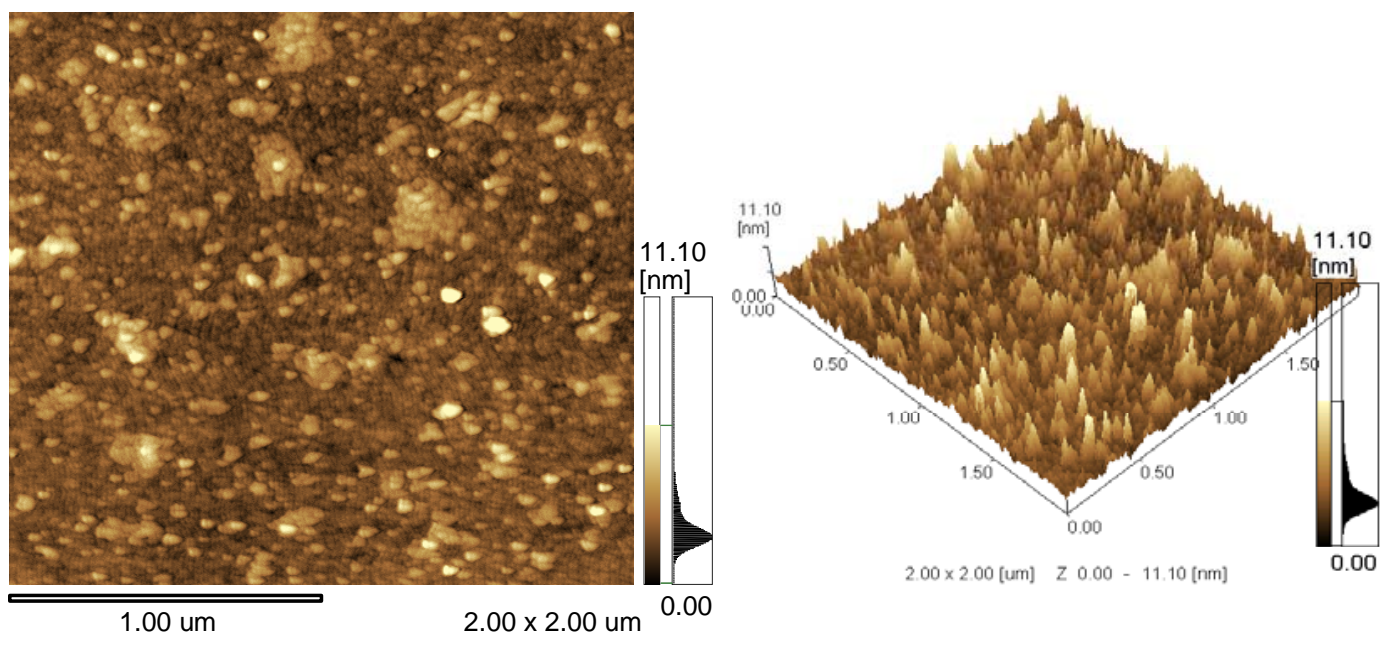

Fig. 35 Microscopia de Força Atômica para amostra processada com 100 mTorr e $50 \mathrm{~W}$

Apesar da amostra cujo processo de corrosão com pressão de 100 mTorr e potência de 50W apresentar um valor muito baixo de rugosidade RMS (1,447 nm), na Figura 35 é mostrada uma visão em duas dimensões e em três dimensões de uma pequena superfície de área $4 \mu \mathrm{m}^{2}$ com diversos picos demasiadamente íngremes e que não se encontram distribuídos uniformemente.

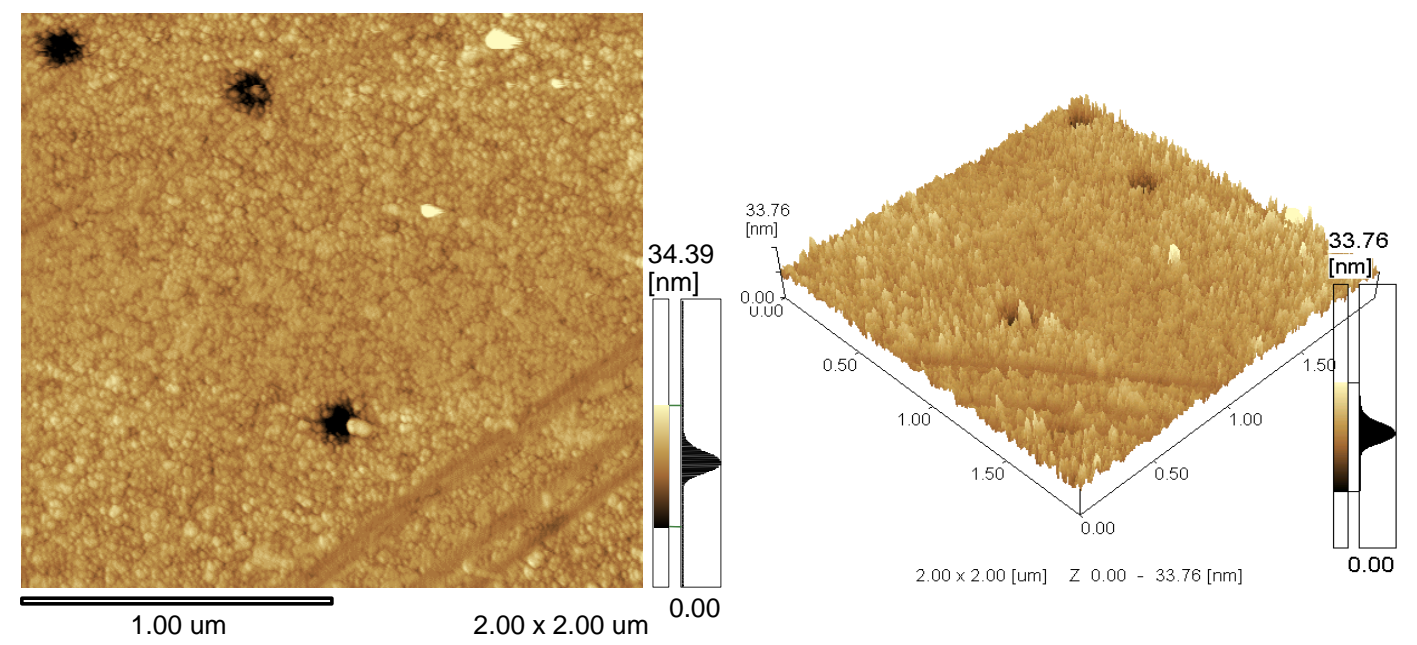

Fig. 36 Microscopia de Força Atômica para amostra processada com 100mTorr e $150 \mathrm{~W}$

As menores rugosidades (Figura 36) são apresentadas pela amostra processada com pressão 100 mTorr e potência $150 \mathrm{~W}$ que apresenta uma distribuição mais uniforme 
de picos menos íngremes e com pontas mais arredondadas. Embora a rugosidade RMS (3,542 $\mathrm{nm})$ seja maior do que a amostras anterior, seria muito mais confiável produzir um dispositivo com os parâmetros de corrosão desta amostra do que fabricar um elemento óptico difrativo com os parâmetros apresentados anteriormente (pressão 100 mTorr e potência $50 \mathrm{~W}$ ).

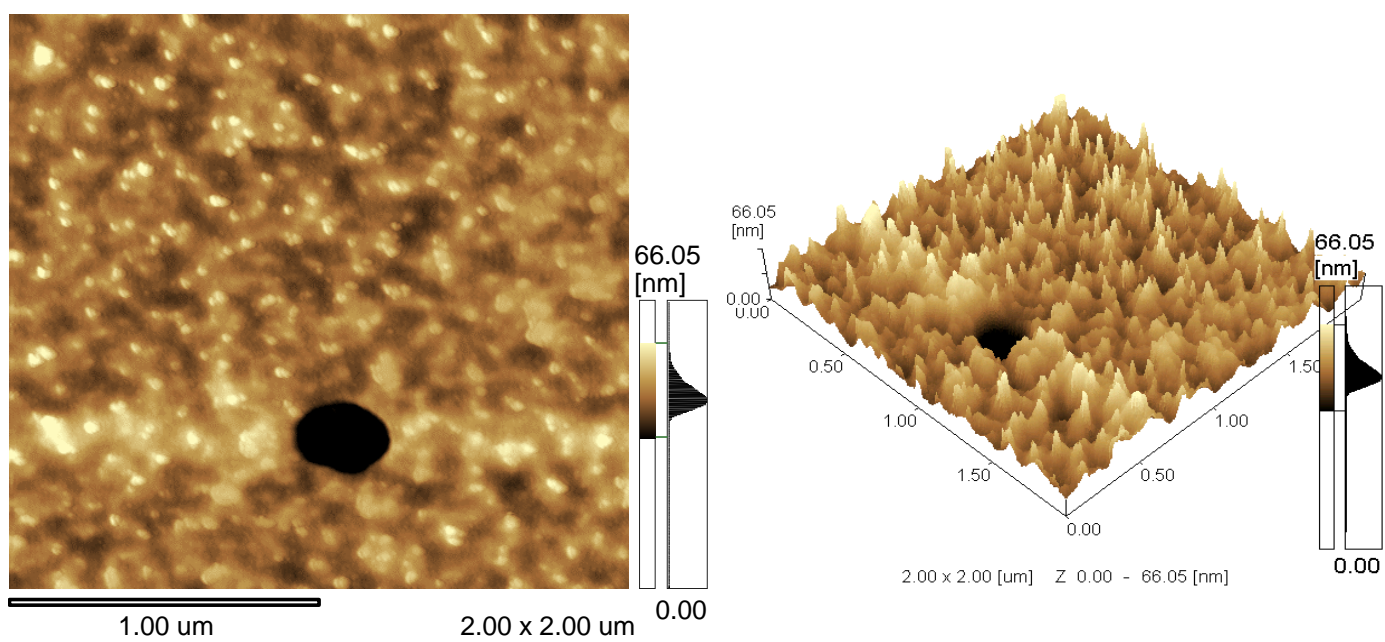

Fig. 37 Microscopia de Força Atômica para amostra processada com 100 mTorr e 200W

Os piores resultados foram observados para a imagem apresentada na Figura 37 pertencente a amostra que foi submetida ao processo de corrosão com pressão 100 mTorr e potência $200 \mathrm{~W}$. Além da rugosidade RMS (14,026 nm) ser muito maior do que a apresentada nas outras duas amostras, existem picos muito íngremes distribuídos irregularmente ao longo da superfície, de tal maneira que podem ser considerados como defeitos da estrutura.

\subsubsection{Estudo da corrosão por plasma de vidro com altas potências de RF}

\subsubsection{Altura de degrau e rugosidades das amostras processadas com potência de $250 \mathrm{~W}, 350 \mathrm{~W}$ e $400 \mathrm{~W}$}

Este estudo de corrosão por plasma teve como objetivo verificar as taxas de corrosão de diferentes materiais empregados em dispositivos ópticos difrativos. Foram também utilizadas potências de processo maiores $(250 \mathrm{~W}, 300 \mathrm{~W}, 350 \mathrm{~W}$ e $400 \mathrm{~W})$ do 
que as utilizadas anteriormente com a finalidade de se obter taxas de corrosões maiores e portanto diminuir o tempo de processo para se alcançar a espessura desejada. A pressão dos processos foi mantida constante em 100 mTorr. Os resultados obtidos são apresentados na Tabela V.

Tabela V - Resultados obtidos pela técnica de perfilometria

\begin{tabular}{|c|c|c|c|c|c|c|c|c|}
\hline \begin{tabular}{|l|} 
Amostra \\
\end{tabular} & Material & $\begin{array}{c}\text { Tempo } \\
\text { (minuto) }\end{array}$ & h (nm) & $\begin{array}{l}\text { p.p. } \\
\text { (nm) }\end{array}$ & RMS(nm) & $\mathbf{R}_{\mathrm{A}}(\mathrm{nm})$ & $\begin{array}{c}\text { RMS }_{\text {normalizada }} \\
\left({ }^{*} 10^{-3}\right)\end{array}$ & $\begin{array}{c}\mathrm{Tx}_{\mathrm{v}} \\
(\mathrm{nm} / \mathrm{min})\end{array}$ \\
\hline \multirow[b]{2}{*}{$250(\mathrm{~W})$} & Vidro & 9 & 389 & 35,6 & 1,6 & 15,8 & 4,1 & 43,2 \\
\hline & $\begin{array}{c}\text { Sílica } \\
\text { fundida }\end{array}$ & 9 & 1088,2 & 23,3 & 2,3 & 2,9 & 2,1 & 120,9 \\
\hline \multirow[b]{2}{*}{$350(W)$} & Vidro & 9 & - & - & - & - & - & - \\
\hline & $\begin{array}{l}\text { Sílica } \\
\text { fundida }\end{array}$ & 9 & 2636,1 & 144,3 & 5,4 & 24,8 & 2 & 292,9 \\
\hline \multirow[b]{2}{*}{$400(W)$} & Vidro & 3 & 503,5 & 40 & 5,4 & 6,7 & 10,7 & 167,8 \\
\hline & $\begin{array}{l}\text { Sílica } \\
\text { fundida }\end{array}$ & 3 & 932,7 & 26,7 & 3,5 & 4,6 & 3,8 & 310,9 \\
\hline
\end{tabular}

Na Tabela V observa-se que existe uma grande diferença no valor das taxas de corrosão de um material para outro, principalmente para a potência de processo 400 W que foi a mais alta utilizada. Isto de fato é comprovado na literatura [80 - 83] e é observado que quanto mais contaminações existentes no material, menor a taxa de corrosão. $\mathrm{O}$ vidro utilizado neste trabalho é composto de vários outros elemento além de $\mathrm{SiO}_{2}$, tais como $\mathrm{Na}_{2} \mathrm{O}+\mathrm{K}_{2} \mathrm{O}, \mathrm{CaO}, \mathrm{BaO}, \mathrm{ZnO}, \mathrm{TiO}_{2}$ e $\mathrm{Sb}_{2} \mathrm{O}_{3}$.

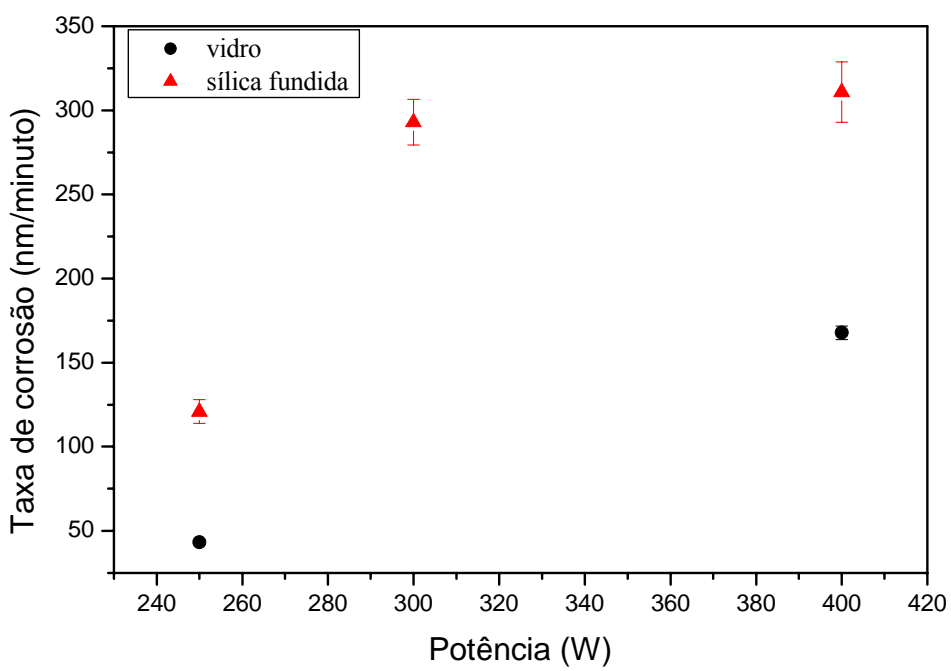

Fig. 38 Gráfico de taxa de corrosão em função de potência de RF para vidro óptico e sílica fundida 
Na Figura 38 são apresentas as curvas de taxa de corrosão em função de potência para 2 diferentes tipos de materiais. O vidro óptico é o que apresenta menores valores para taxa de corrosão, já que contém em sua composição diversos contaminantes que durante o processo de corrosão por plasma formam componentes não voláteis, os quais impedem que o vidro seja corroído.

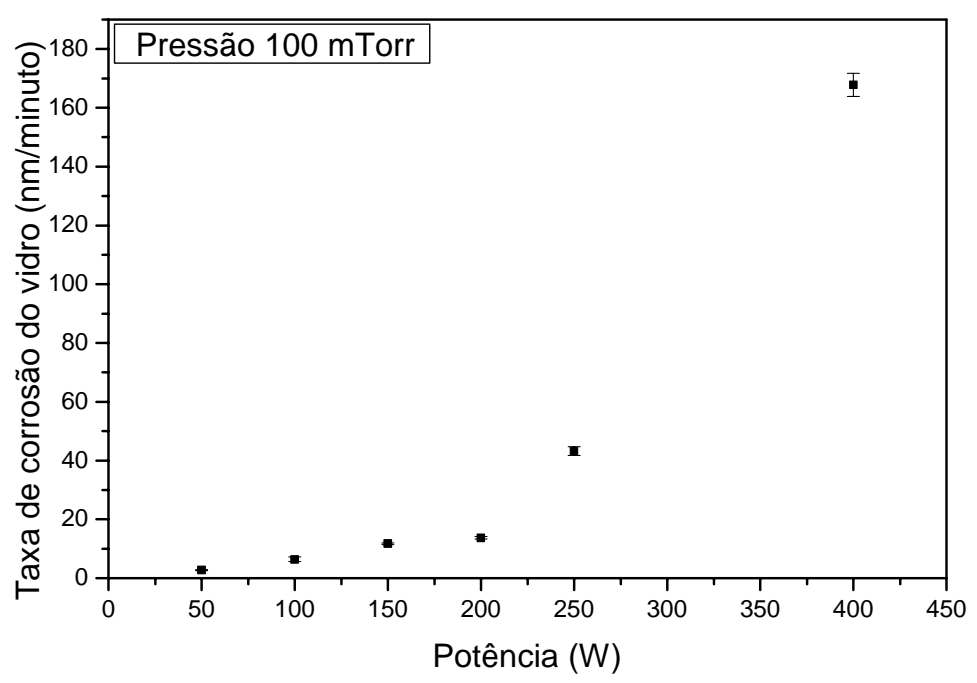

Fig. 39 Gráfico de taxa de corrosão em função de potência para o vidro óptico

Na Figura 39 são apresentadas as taxas de corrosão para o vidro óptico em função da potência. Pode ser observado que quanto mais alta a potência, maior a taxa de corrosão do vidro e a partir de $200 \mathrm{~W}$ a taxa de corrosão cresce abruptamente. Os resultados podem ser confirmados quando comparados com os reportados na literatura [84]. 


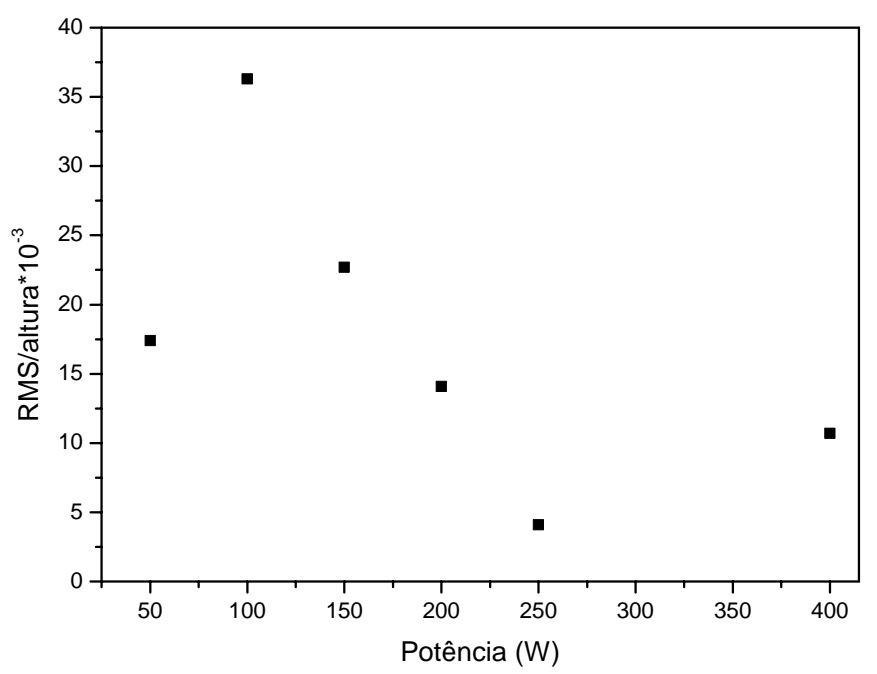

Fig. 40 Rugosidade normalizada em função da variação de potência no processo de corrosão por plasma do vidro com pressão constante de 100 mTorr

A curva de rugosidade normalizada (Figura 40) apresentou um comportamento linear e decrescente, exceto para os dois pontos cujas potências RF foram de $50 \mathrm{~W}$ e 400 W. Na menor potência houve baixa taxa de corrosão e, como a rugosidade RMS possuia valores parecidos com os demais pontos, resultou-se que a rugosidade normalizada ficou abaixo do esperado e fora da curva. Isto ocorreu devido à baixa energia, o que diminuiu o ataque iônico à superfície e promoveu a formação de menos radicais, evitando uma corrosão mais profunda. Para a maior potência utilizada, ocorreu uma taxa de corrosão mais elevada, no entanto também ocorreu maior rugosidade RMS devido ao micromascaramento através dos elementos não voláteis, portando a rugosidade normalizada apresentou um valor fora da curva. 


\subsubsection{Microscopia de Força Atômica das amostras de vidro processada com} potências de 250, 350 e $400 \mathrm{~W}$
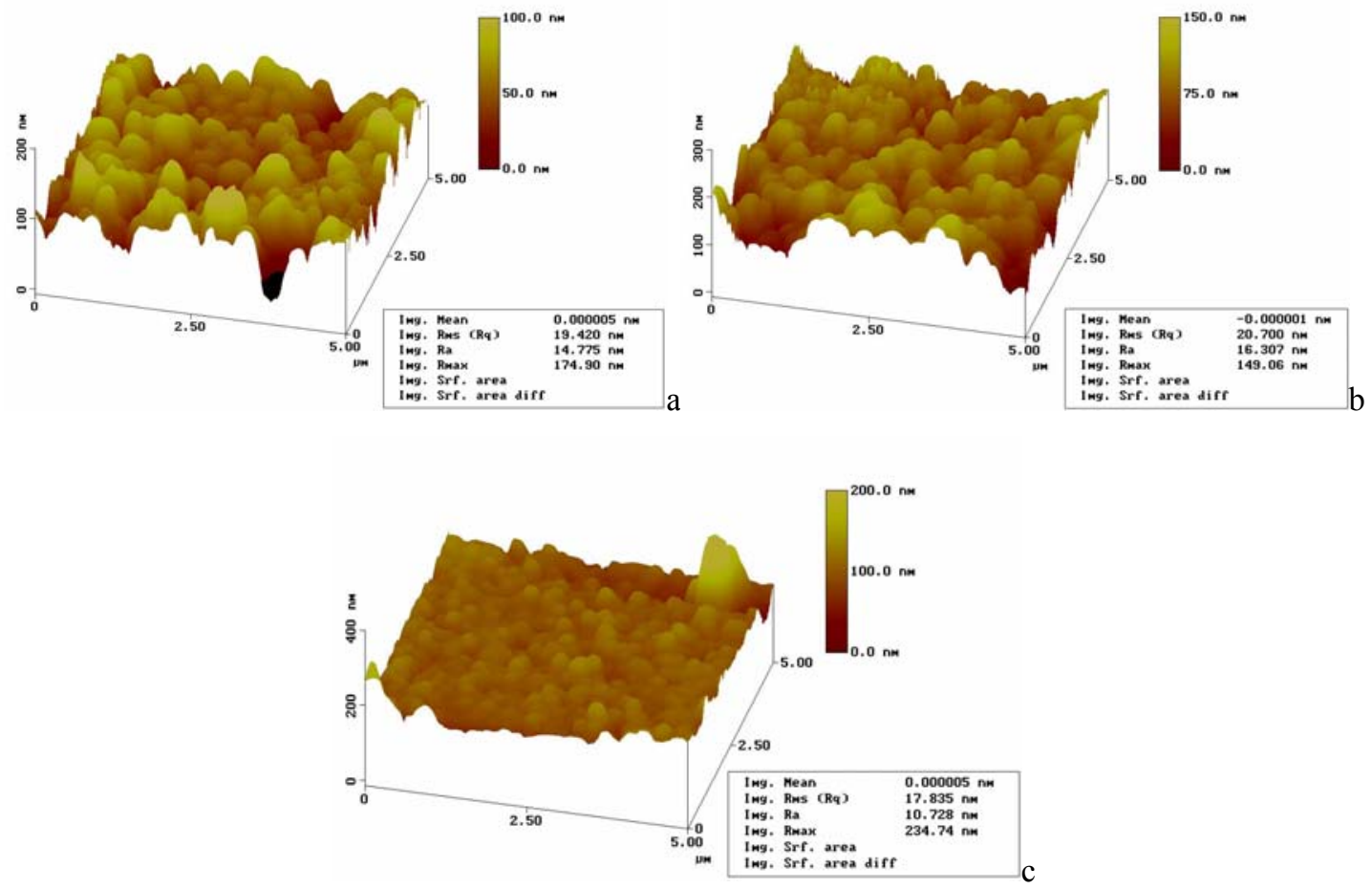

Fig. 41 Microscopia de Força Atômica das amostras processadas com a) amostra $250 \mathrm{~W}, \mathrm{~b})$ amostra $350 \mathrm{~W}$ e c) amostra $400 \mathrm{~W}$

A amostra cujos parametros de processo de corrosão foram 100 mTorr e $400 \mathrm{~W}$ de potência, é a que apresenta uma distribuição mais uniforme de picos menos íngremes e com pontas mais arredondadas. Todas amostras apresentaram valores de rugosidade RMS menores que o valor limite de $63,3 \mathrm{~nm}$, tendo em vista que o maior resultado apresentado foi $20,7 \mathrm{~nm}$.

\subsubsection{Microanálise das amostras de vidro corroídas por plasma - Porcentagem atômica das amostras processadas com 250 W, 350 W e 400 W}

$\mathrm{Na}$ Tabela VI pode ser observado que existe uma grande porcentagem de carbono nas amostras, parte desta proveniente do gás $\mathrm{CF}_{4}$ do plasma. Isso indica que existe formação de polímeros sobre a superfície do material, principalmente do vidro óptico. Infelizmente isso é um problema, já que tal polímero acaba funcionando 
como máscara, impedindo a corrosão da região e diminuindo o valor de taxa de corrosão estimado, o que prejudica muito a reprodutibilidade de um dado processo.

Tabela VI - Resultados obtidos pela microanálise de porcentagem atômica

\begin{tabular}{|c|c|c|c|c|c|c|c|c|c|c|c|}
\hline Amostra & Material & $\mathrm{C}$ & $\mathrm{O}$ & $\mathrm{F}$ & $\mathrm{Na}$ & $\mathrm{Al}$ & $\mathrm{Si}$ & $\mathrm{K}$ & $\mathrm{Ca}$ & $\mathrm{Ni}$ & $\mathrm{Ba}$ \\
\hline Virgem & vidro & 30.76 & 53.44 & --- & 5.00 & 0.30 & 8.97 & 0.57 & 0.78 & 0.19 & --- \\
\hline \multirow{2}{*}{$\mathbf{2 5 0} \mathbf{W}$} & vidro & 32.51 & 55.82 & --- & 4.68 & 0.39 & 5.53 & 0.24 & 0.31 & 0.49 & 0.03 \\
\cline { 2 - 12 } & silica & 22.80 & 59.57 & --- & --- & 0.20 & 17.44 & --- & --- & --- & --- \\
\hline \multirow{2}{*}{$\mathbf{3 5 0} \mathbf{W}$} & vidro & 33.55 & 33.80 & 14.99 & 5.53 & 0.66 & 9.28 & 0.64 & 1.44 & --- & 0.10 \\
\hline \multirow{4}{*}{$\mathbf{0 0 0} \mathbf{W}$} & vidro & 44.09 & 45.82 & --- & 3.51 & 0.56 & 4.95 & 0.29 & 0.37 & 0.41 & --- \\
\cline { 2 - 10 } & silica & 34.47 & 61.18 & --- & --- & 0.76 & 2.87 & 0.72 & --- & --- & --- \\
\hline
\end{tabular}

A grande quantidade de oxigênio observada é devido à própria composição do vidro B270. A sílica fundida possui normalmente o dobro desse elemento em relação ao silício, no entanto, o vidro utilizado no trabalho é contaminado com muitos óxidos, o que eleva a porcentagem de $\mathrm{O}_{2}$ detectada na microanálise. Mesmo o vidro virgem que não sofreu nenhum processo chega a ter 6 vezes mais oxigênio do que silício. $\mathrm{E}$ isso prejudica em muito o a corrosão por plasma, já que durante o processo, são formados óxidos não voláteis que mascaram a superfície do vidro e impedem que a taxa de corrosão seja maior.

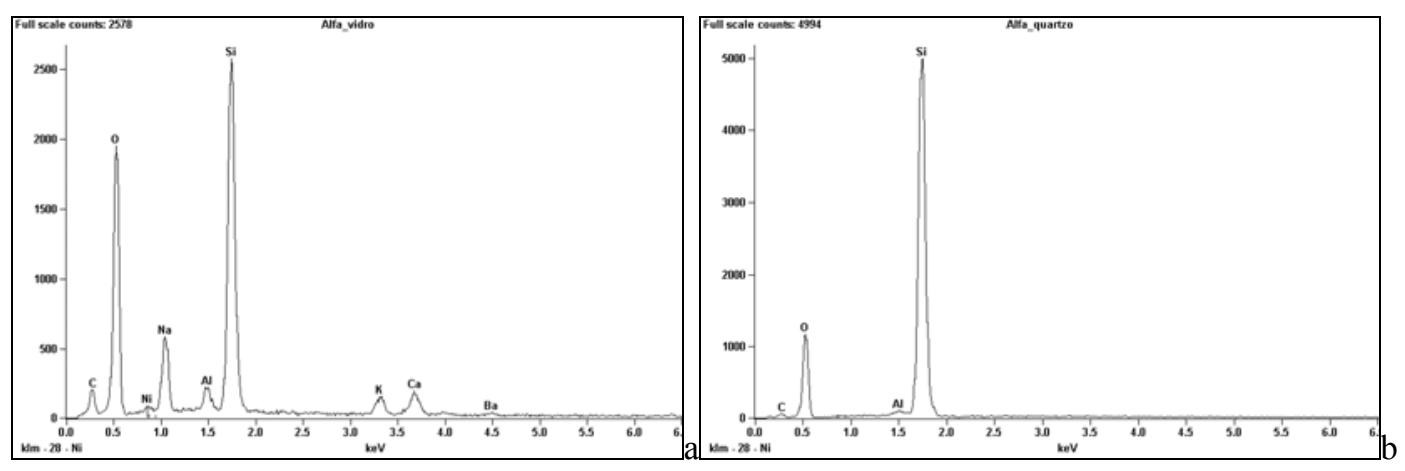

Fig. 42 Espectro da amostra processada com $250 \mathrm{~W}$ com contagem dos elementos presentes para a) vidro e b) sílica fundida

Nos espectros (Figura 42) acima são mostradas as diferenças de composição de cada tipo de material e também quais elementos o compõe. $O$ vidro óptico de fato é rico em impurezas e contém mais elemento carbono do que a silica, indicando que no processo de corrosão, polímeros são formados em maior quantidade sobre tal material. 


\subsubsection{EODs de dois níveis de fase obtidos através de corrosão de vidro óptico}

Foram fabricados 22 diferentes tipos de EODs sobre substrato de vidro pelo processo de corrosão por plasma de $\mathrm{CF}_{4}$ em 4 processos com tempos diferentes ( 5 minutos, 6 minutos, 6,5 minutos e 7 minutos). O objetivo era fazer um estudo do tempo adequado ao processo de corrosão (cuja pressão e potência de RF foram 100 mTorr e $400 \mathrm{~W}$ respectivamente) com a finalidade de se obter o dispositivo com melhor desempenho.

\subsubsection{Análise ópticas dos dispositivos ópticos difrativos de dois níveis de fase}

As imagens reconstruidas pelos dispositivos dispositivos são apresentadas a seguir (Figuras 43 e 44) e o aparato montado para medição pode ser obsevado na Figura 23:
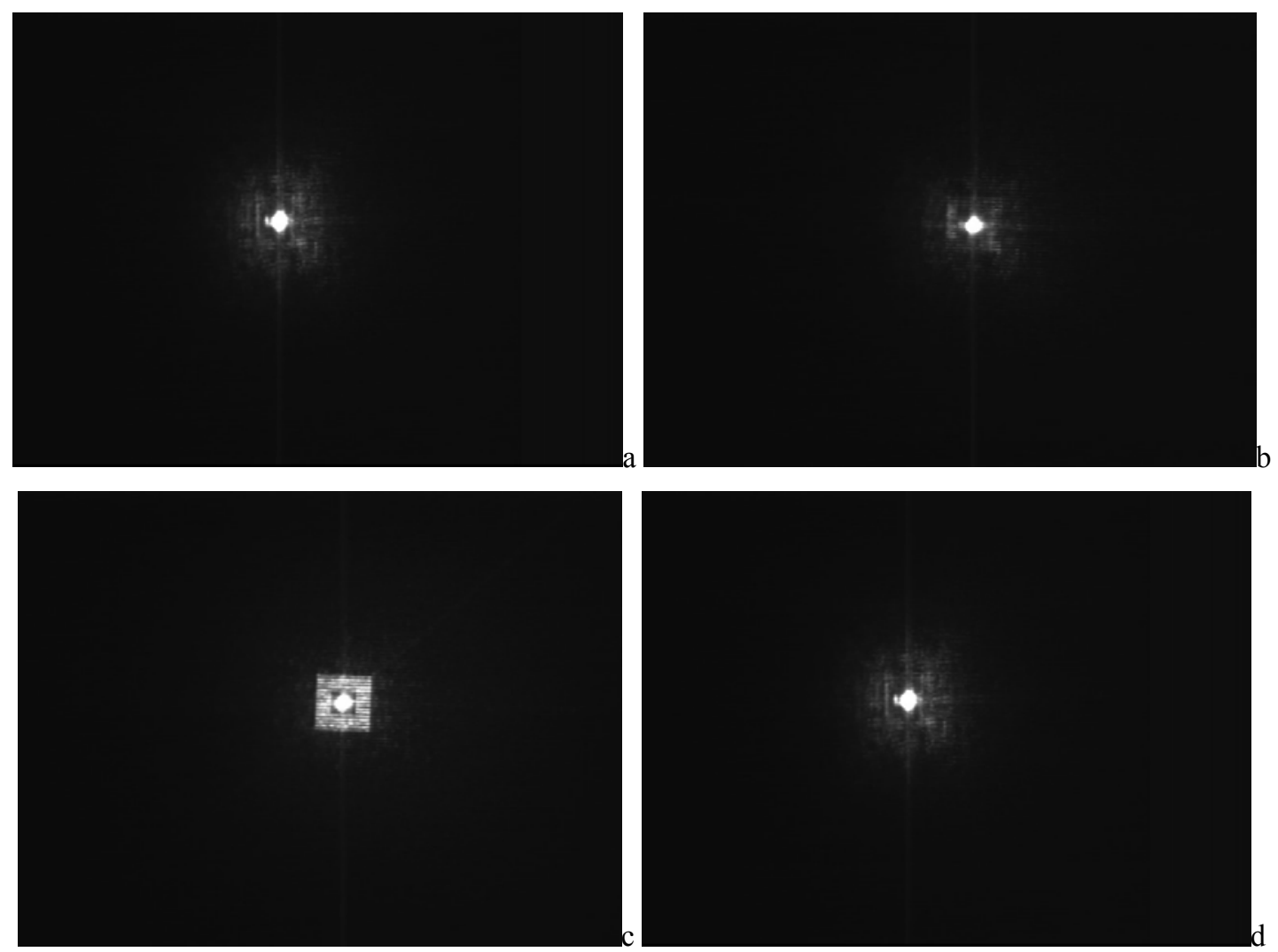

Fig. 43 EODs "quadrado" corroídos por a) 5 minutos, b) 6 minutos, c) 6,5 minutos e

d) 7 minutos 
Quando comparadas as imagens (Figura 43) obtidas para o dispositivo "quadrado", nota-se que a que apresenta maior qualidade é a amostra cujo processo de corrosão durou 6,5 minutos, pois o ponto de ordem zero aparenta ter quase a mesma intensidade que os demais pontos pertencentes ao quadrado. Quando a imagem da amostra cujo processo durou 6,5 minutos é comparada com a imagem das demais amostras, a diferença é bastante percepitível: elas apresentam um ponto central demasiadamente intenso e a imagem do quadrado que deveria ser formada está com intensidade fraca e disforme.
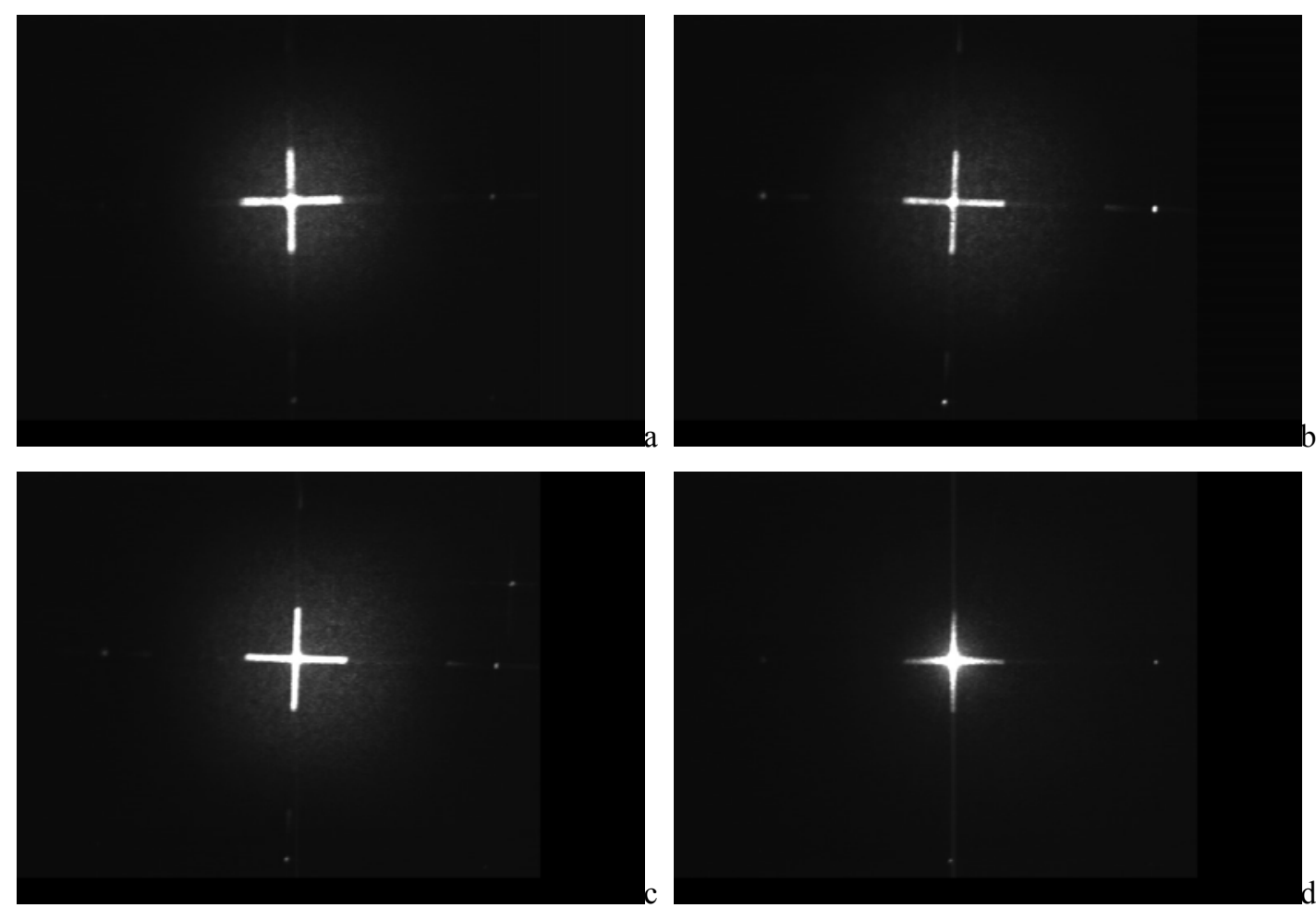

Fig. 44 EODs “cruz” corroídos por a) 5 minutos, b) 6 minutos, c) 6,5 minutos e d) 7 minutos

As diferenças nas imagens (Figura 44) resultantes são ainda mais visíveis para o dispositivo "cruz". A homogeneidade de intensidade para os pontos da imagem pertencente à amostra cujo processo durou 6,5 minutos, indicou que tal tempo é o mais próximo do ideal. 
Para uma análise mais detalhada da resolução dos dispositivos, foram obtidos gráficos de intensidade luminosa das amostras (Figura 45). Os gráficos abaixo foram obtidos a partir dos pontos da linha vertical da cruz.
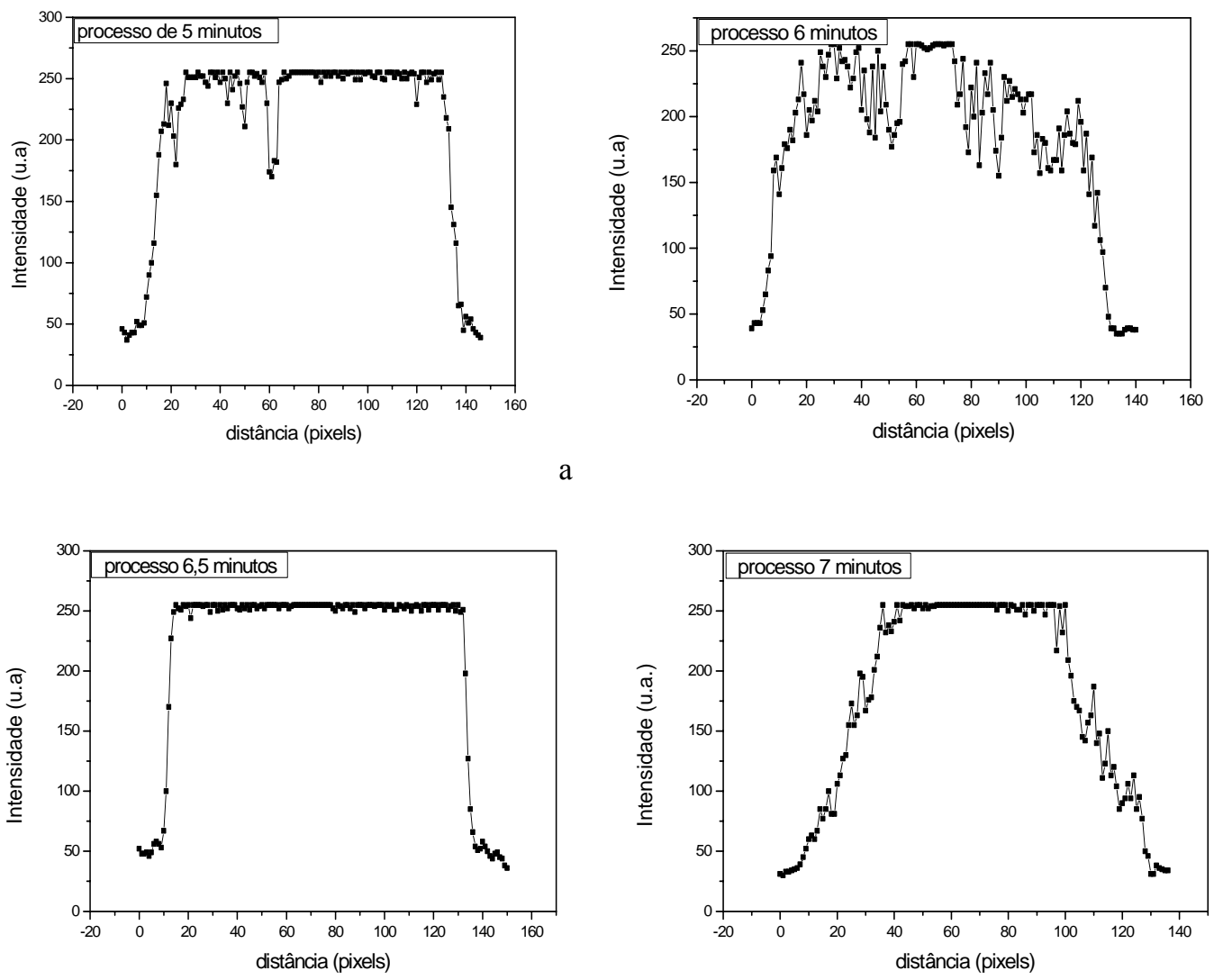

c

d

Fig. 45 Análise da intensidade de luz dos EODs "cruz" corroídos por a) 5 minutos, b) 6 minutos, c) 6,5 minutos e d) 7 minutos

Quando tais gráficos são observados, fica evidente a influência do tempo de processo sobre os dispositivos. Novamente o melhor resultado é o visto para a lâmina cujo processo foi de 6,5 minutos de corrosão.

Também fora feitos gráficos de intensidade em 3 dimensões de toda a imagem obtida. Os resultados são mostrados na Figura 46. 

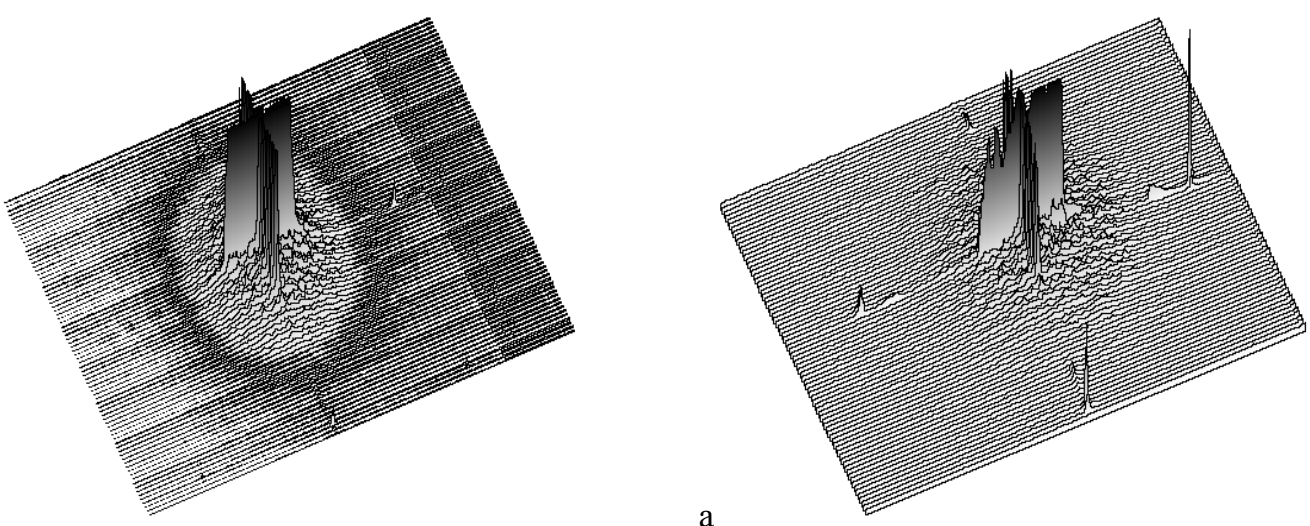

b
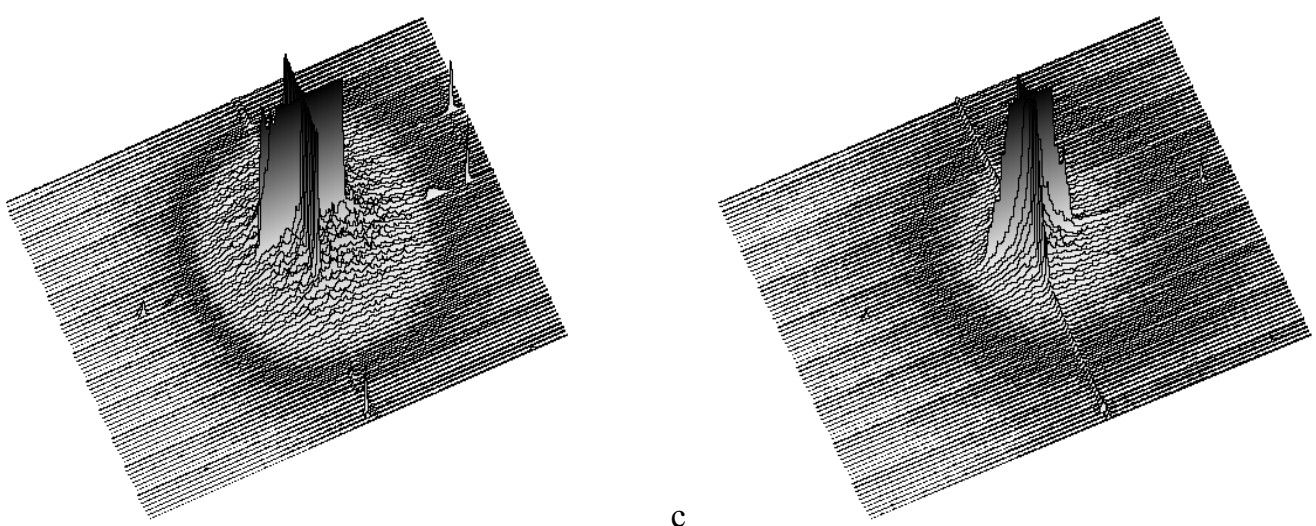

d

Fig. 46 Análise de intensidade de luz 3D dos EODs "cruz" corroídos por a) 5 minutos, b) 6 minutos, c) 6,5 minutos e d) 7 minutos

Pela análise das figuras nota-se de fato as diferenças que existem entre uma amostra e outra. É possível também verificar que existem pequenos ruídos em torno da imagem de todas as amostras, ruídos estes causados pelo fenômeno de speckle, cujo maior responsável é a rugosidade superficial do material.

Apesar do tempo estimado em 5 minutos do processo ideal de corrosão para fabricação do dispositivo ter sido calculado em função do valor da taxa de corrosão com parâmetros de $400 \mathrm{~W}$ de potência RF e pressão 100 mTorr, os melhores resultados foram obtidos para um tempo maior do que este. Os dispositivos que apresentaram melhor performance foram fabricados para um processo de corrosão que durou 6 minutos e 30 segundos. O motivo deste fato é que durante o processo de corrosão, existe a formação de polímero sobre o vidro, provocando um 
mascaramento e diminuindo assim a corrosão, portanto, o tempo calculado corresponde à um processo de corrosão ideal, livre da formação de polímero.

\subsubsection{Análise da altura do degrau dos dispositivos fabricados}

Para a análise da espessura dos elementos ópticos difrativos, foram escolhidos os mesmos dois dispositivos da análise óptica: um que forma uma imagem de um quadrado e um que forma a imagem de uma cruz. Tal análise é importante para se obter a espessura dos perfis da estruturas e através dos resultados, verificar se a espessura calculada teoricamente foi atingida. Tal medida foi obtida através de perfilometria.

Tabela VII - Altura dos dispositivos obtidos por corrosão por plasma

\begin{tabular}{|c|c|c|}
\hline $\begin{array}{c}\text { Tempo de processo } \\
\text { de corrosão }\end{array}$ & \multicolumn{2}{|c|}{ dispositivo } \\
\cline { 2 - 3 } & quadrado & cruz \\
\hline $\mathbf{5}$ minutos & $555 \mathrm{~nm}$ & $516 \mathrm{~nm}$ \\
\hline $\mathbf{6}$ minutos & $704 \mathrm{~nm}$ & $697 \mathrm{~nm}$ \\
\hline $\mathbf{6 , 5}$ minutos & $806 \mathrm{~nm}$ & $788 \mathrm{~nm}$ \\
\hline 7 minutos & $850 \mathrm{~nm}$ & $879 \mathrm{~nm}$ \\
\hline
\end{tabular}

A espessura desejada calculada foi de $770 \mathrm{~nm}$ e o dispositivo que apresentou uma espessura do perfil da estrutura mais próxima deste valor foi o que gera uma imagem de cruz e que sofreu processo de corrosão em um tempo de 6,5 minutos. Na análise óptica ficou evidente que este foi o dispositivo com melhor desempenho devido à uniformidade da intensidade da luz projetada na imagem e da baixa intensidade do ponto de ordem zero, além da imagem estar bem focada e definida. A análise perfilométrica só comprova tais resultados, e ainda mostrou que pouco (quase nenhum) polímero ou elementos não voláteis ficaram acumulados entre as paredes das estruturas.

O que mais chamou a atenção nesta análise foi que as amostras que sofreram processo de corrosão por 6 minutos apresentaram perfís também próximos do valor desejado, mas na análise óptica, as imagens de ambos dispositivos se apresentaram 
um tanto desuniformes e desfocadas. Isto tem como explicação o fato de entre as estruturas de ambos dispositivos ter se acumulado muito material, talvez polímero formado durante o processo de corrosão e impurezas não voláteis que fazem parte da estrutura do vidro e que durante a corrosão, mascararam a região entre as estruturas.

As amostras corroídas para tempos de 5 e 7 minutos de fato não poderiam apresentar bons reultados na análise óptica pelo fato dos perfís corroídos apresentarem uma espessura com valor longe do estimado. Para estas amostras, foi verificado através da perfilometria que pouco material ficou acumulado entre as estruturas.

\subsubsection{EODs de quatro níveis de fase obtidos através de corrosão de vidro óptico}

Foram fabricados 10 diferentes tipos de elementos ópticos difrativos sobre substrato de vidro pelo processo de corrosão por plasma. Tais dispositivos foram fabricados com 4 níveis de fase através de 2 processos de corrosão com 2 máscaras diferentes ( $\pi$ e $\pi / 2$ ), seguindo a seqüência apresentada na Figura 17 .

\subsubsection{Análise óptica dos dispositivos ópticos difrativos de quatro níveis de fase}

Nas figuras 47 e 48 são apresentadas algumas imagens reconstruídas a partir de elementos ópticos difrativos apenas de fase, implementados em vidro óptico, com quatro níveis de modulação de fase. $\mathrm{O}$ aparato utilizado para medição pode ser obsevado na Figura 24:

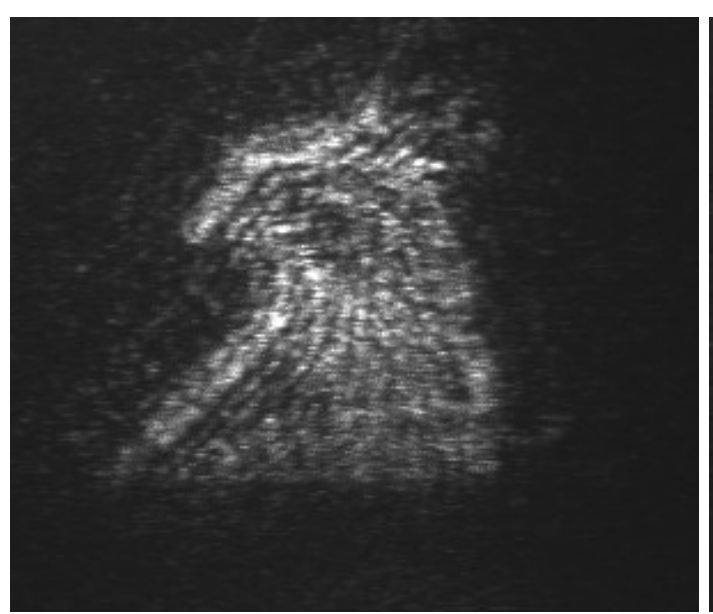

Fig. 47 EOD de Fresnel Águia

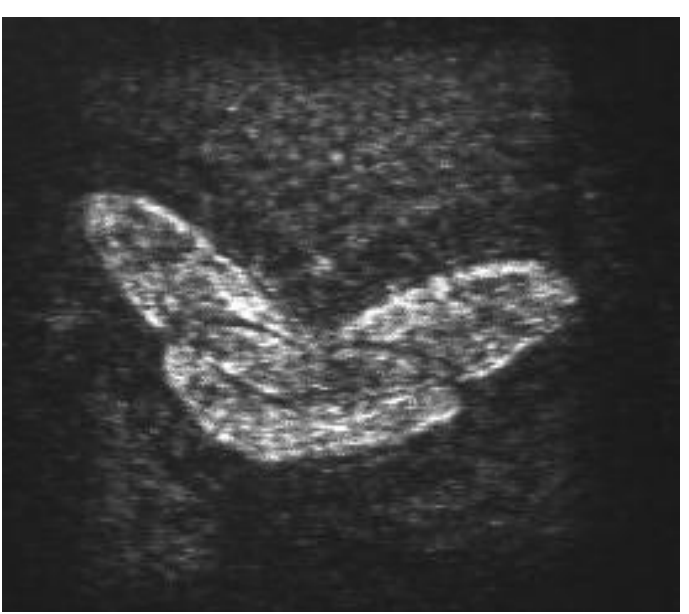

Fig. 48 EOD de Fresnel Borboleta 
Nas Figuras 47 e 48 são apresentadas uma reconstrução típica a partir de elementos ópticos difrativos de fase binária, tipo Fresnel. Pode-se observar que não existe a presença de ponto de ordem zero de difração nas imagens que foram reconstruídas com relativa fidelidade, mas com excessivo ruído speckle.

Para uma análise qualitativa da superfície dos dispositivos, foram obtidas micrografias de topografia através de Microscopia Eletrônica de Varredura (Figura 49).
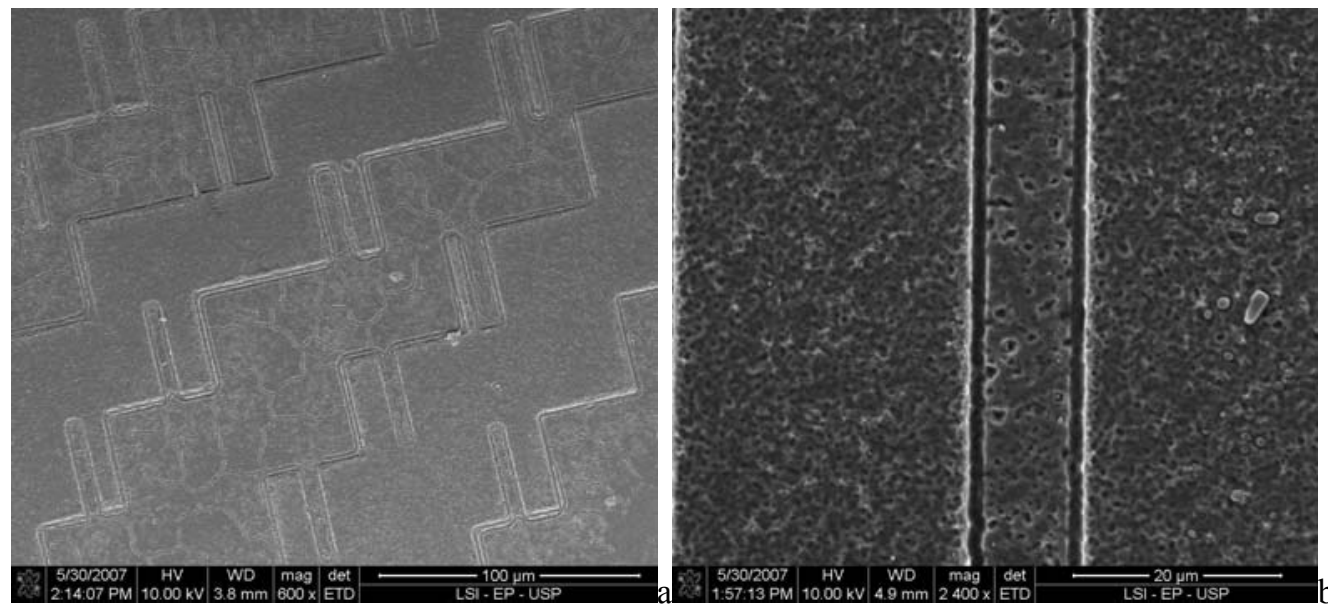

Fig. 49 a) Estutura da borboleta e b) Rugosidade 


\subsubsection{Análise óptica da superfície dos dispositivos}

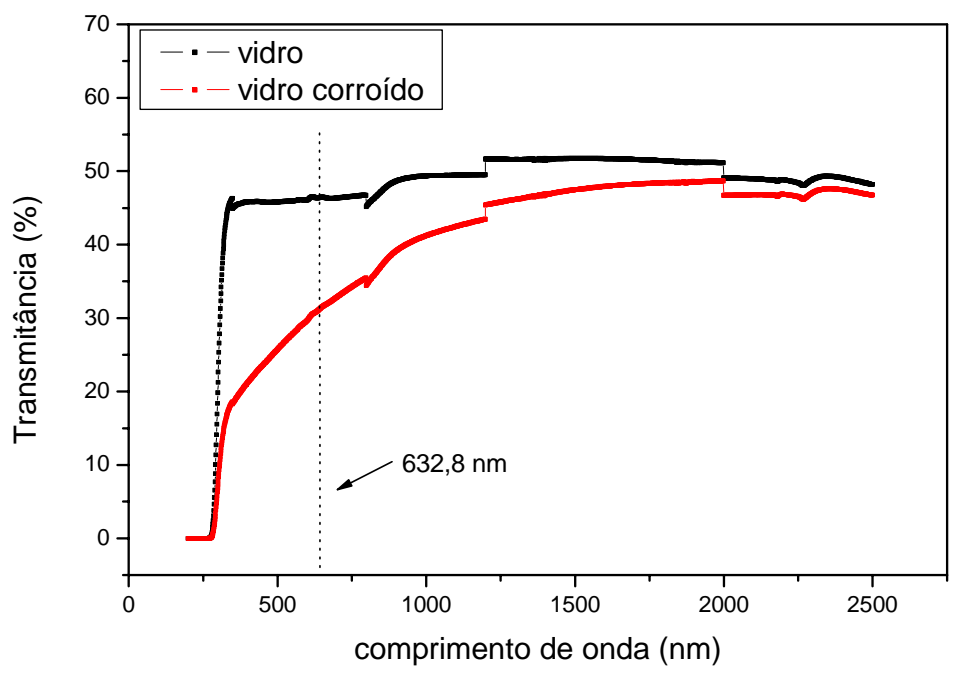

Fig. 50 Curvas de transmitância do vidro virgem e do vidro corroído

Para o comprimento de onda do laser $\mathrm{HeNe}(632,8 \mathrm{~nm})$, há uma transmitância (Figura 50) de aproximadamente $31 \%$ da luz incidida para o vidro já corroído, enquanto que o vidro virgem possui uma transmitância de $46 \%$. Isto indica que o dispositivo fabricado através de processo de corrosão por plasma possui menos eficiência em transmitir a luz do que o substrato que não sofreu nenhum processo. $\mathrm{O}$ processo de corrosão em si deixa a superfície do substrato opaca, interferindo assim na transmissão de qualquer onda que incida nela. Apesar da diferença nos valores de transmitância das duas amostras, é observado que ambas deixam de transmitir em valores de comprimento de onda inferiores a $277 \mathrm{~nm}$ (limite de transmitância do vidro óptico). 

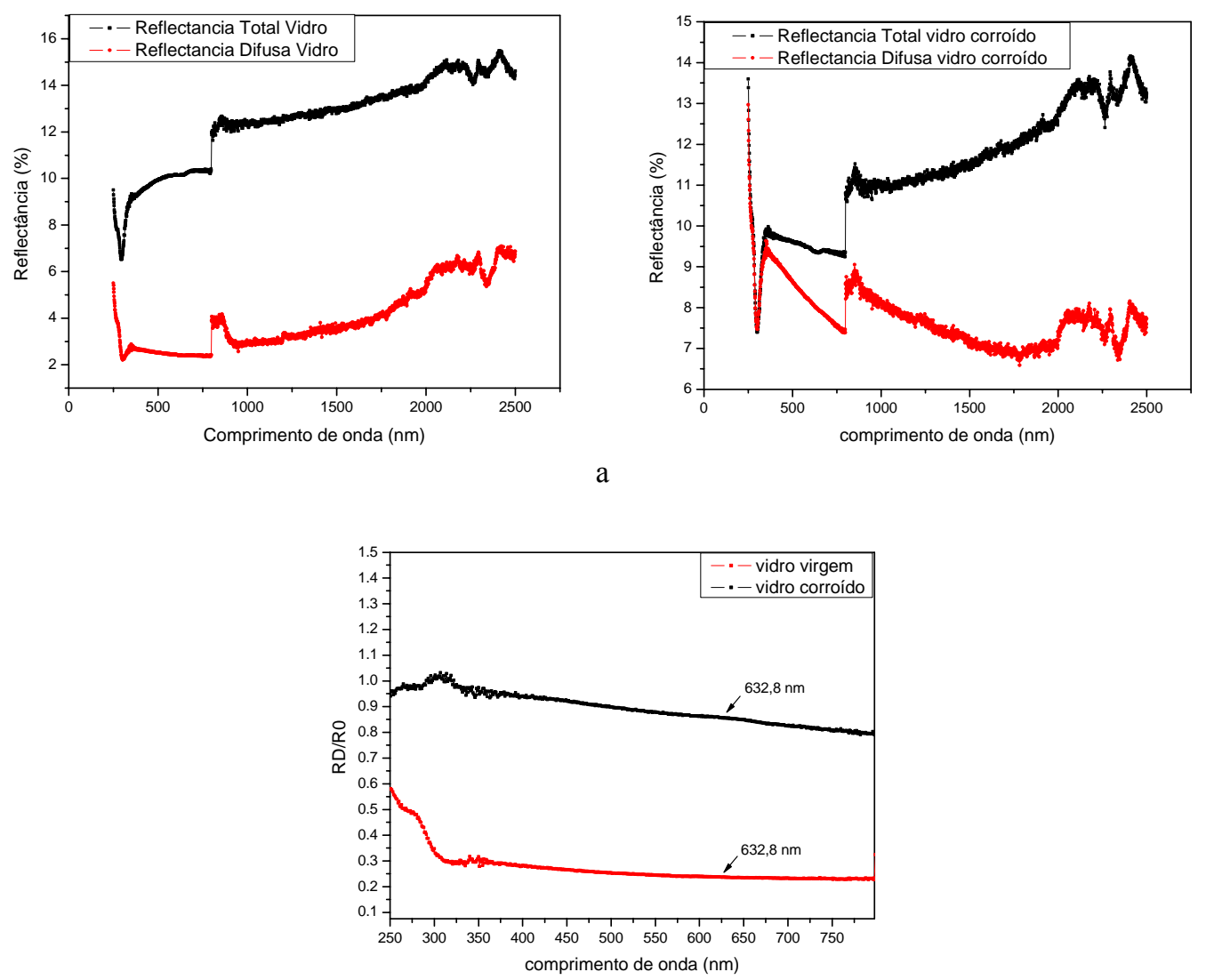

Fig. 51 a) Reflectância difusa e total do vidro virgem, b) Reflectância difusa e total do vidro corroído e c) Reflectância difusa dividida pela total do vidro virgem e corroído para cálculo de rugosidade RMS

Foi realizado um estudo de reflectância dos materiais empregados na fabricação dos dispositivos. Para o vidro corroído por plasma (em um processo cujos parâmetros foram 100 mTorr de pressão e $400 \mathrm{~W}$ de potência, os mesmos utilizados para confecção dos dispositivos difrativos), a diferença entre os valores das curvas de reflectância total $\mathrm{R} 0$ e reflectância difusa $\mathrm{RD}$ ficou inferior a 1,4\% (no comprimento de onda de $632,8 \mathrm{~nm}$ ), enquanto que para o vidro virgem, tal diferença ultrapassou $7,8 \%$. Estes valores são refletidos nas curvas RD/R0 (mostradas na Figura 51) para o vidro virgem e para o corroído. Consequentemente, a rugosidade vista para o vidro corroído é maior. Neste trabalho, para confecção de EODs de vidro que operam com o laser de HeNe, o que realmente importa são os valores para o comprimento de onda de $632,8 \mathrm{~nm}$. Para tal $\lambda$, tem-se: 
Tabela VIII - Comparação entre vidro virgem e vidro corroído

\begin{tabular}{|c|c|c|}
\hline & Vidro Virgem & Vidro Corroído \\
\hline R0 - RD & $7,8 \%$ & $1,4 \%$. \\
\hline RD/R0 & 0,24 & 0,86 \\
\hline Rugosidade & $24,7 \mathrm{~nm}$ & $46,6 \mathrm{~nm}$ \\
\hline
\end{tabular}

Os valores obtidos para a rugosidade pela eq. (11) [85-90] indicam que tanto o vidro que sofreu processo quanto o vidro virgem apresentam um valor alto de rugosidade, mas que ainda estão dentro do limite de $63 \mathrm{~nm}$, assim, não interferindo no bom desempenho dos elementos ópticos difrativos fabricados.

$$
\frac{R D}{R 0}=\left(\frac{4 \pi \Delta}{\lambda}\right)^{2}
$$

De fato, o vidro corroído apresenta um valor maior de rugosidade RMS $(\Delta)$ e isto pode ser explicado pelo fato de que o bombardeamento da superfície por íons durante a corrosão tornou-a esbranquiçada e levemente opaca e isto afetou a reflectância do substrato. 


\subsection{Dispositivos difrativos binários fabricados em DLC}

\subsubsection{Perfilometria e Elipsometria da amostra de filme fino de DLC sobre substrato de silício}

Para se calcular a taxa de deposição do DLC, o índice de refração e a espessura do filme que foi depositado, foi obtida a amostra "DLC" com um tempo de deposição de filme fino de DLC por sputtering de 140 minutos. Teve-se o cuidado de manter uma parte da lâmina encoberta durante a deposição do filme para se fabricar um degrau e se medir a espessura. A média das espessuras obtidas foi de 1994,3 nm ( $\pm 61,8 \mathrm{~nm})$ e a média do índice de refração foi de $1,78( \pm 0,03 \mathrm{~nm})$. A partir da média das espessuras obtidas, pôde-se calcular a taxa de deposição do filme (média espessura/tempo de deposição) cujo valor foi de 14,24 nm/minuto $( \pm 0,41$ $\mathrm{nm} /$ minuto).

\subsubsection{Perfilometria das amostras de filme fino sobre substrato de silício}

\subsubsection{Perfilometria antes do processo de corrosão}

Esta medida foi realizada antes de se fazer os processos de corrosão do DLC e obteve-se o valor médio $h_{\text {rnc }}=1319,8 \mathrm{~nm}$ que é a altura do fotorresiste depositado.

\subsubsection{Perfilometria após processo de corrosão}

Após o processo de corrosão foi medida a altura das camadas de DLC, alumínio e fotorresiste juntamente. Em seguida, foi removido o fotorresiste e foi medida a espessura das duas camadas restantes. A máscara de alumínio foi retirada e a espessura do DLC corroído pôde ser averiguada. Feito isto, pôde-se fazer o cálculo da espessura de fotorresiste efetivamente corroída, em função da qual foi calculada a taxa de corrosão. Pela técnica de perfilometria também foram medidas as rugosidades do fotorresiste. 


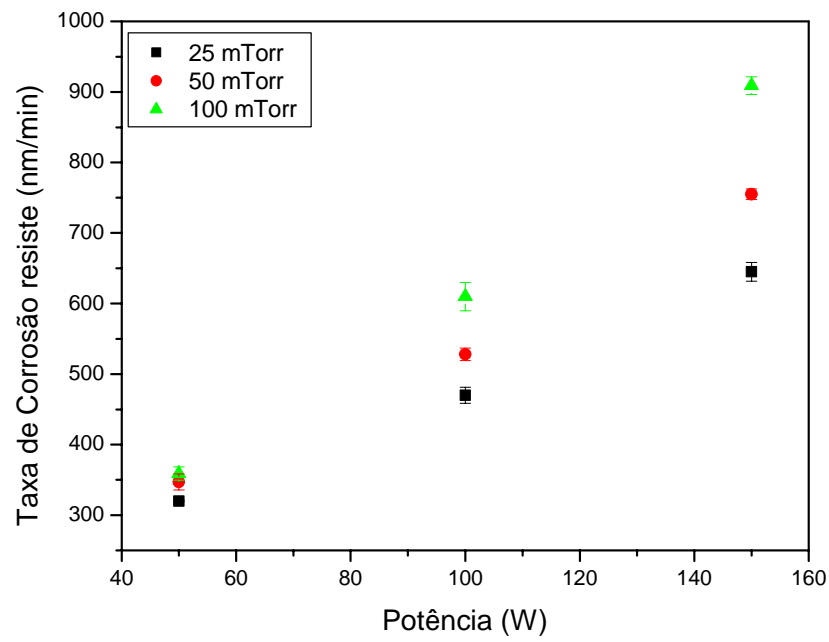

Fig. 52 Taxa de corrosão do fotorresiste em função dos parâmetros de processo da corrosão por plasma e média das rugosidades das amostras

Na Figura 52 é apresentado o gráfico de taxa de corrosão em função dos parâmetros de processo. As curvas apresentam comportamento linear e crescente, além de indicar que quanto maior a pressão, maior a inclinação da curva.

Na Figura 53 é apresentada a rugosidade normalisada para as diferentes amostras, e as curvas apresentam caráter crescente da mesma forma que as curvas da taxa de corrosão. Isto indica que houve uma corrosão de uma profundidade cada vez maior com o aumento da energia do processo, no entanto, a rugosidade RMS ficou próxima do valor médio para as amostras, com exceção da amostra cujos parâmetros de corrosão foram pressão de 50 mTorr e potência RF de $50 \mathrm{~W}$. 


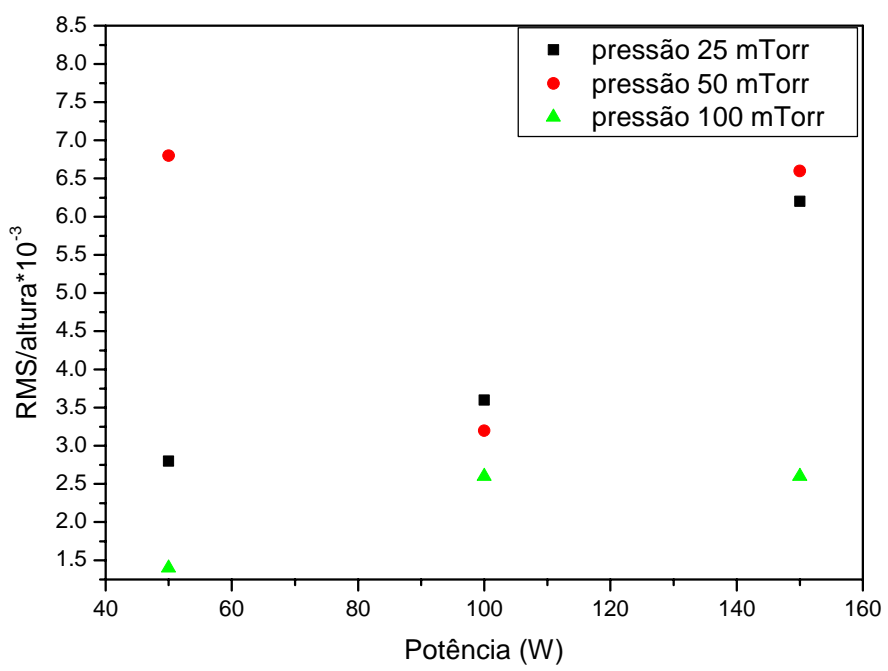

Fig. 53 Rugosidade normalizada em função da variação dos parâmetros de processo de corrosão por plasma do fotorresiste

\begin{tabular}{|c|c|c|}
\hline \multicolumn{3}{|c|}{ Tabela X - Médias das rugosidades do } \\
DLC \\
\hline p.p.(nm) & RMS(nm) & $\mathbf{R}_{\mathbf{A}}(\mathbf{n m})$ \\
\hline 17 & 3,16 & 2,7 \\
\hline
\end{tabular}

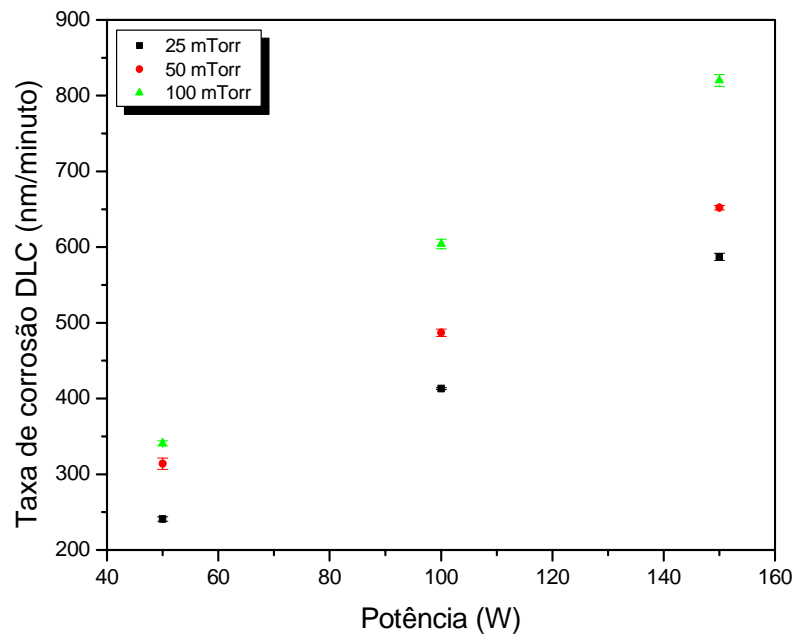

Fig. 54 Taxa de corrosão do DLC em função dos parâmetros de processo da corrosão por plasma e média das rugosidades das amostras

Na Figura 54 é apresentado o gráfico de taxa de corrosão do DLC em função de potência. É visto que o crescimento da taxa de corrosão em funçao da potência é praticamente linear. A curva para a pressão de 100 mTorr é a que apresenta crescimento mais acentuado e isto provavelmente ocorre porque em tal pressão existe maior livre caminho médio, maior concentração de íons e maior ataque iônico da superfície. A taxa de corrosão do filme fino de carbono amorfo foi obtida após 
remoção do fotorresiste e medição da espessura do DLC. O processo de corrosão do DLC é um processo de fácil controle e reprodutível. Além da taxa de corrosão, foram obtidas as 3 rugosidades que se encontram com um valor abaixo do limite.

No reator de corrosão utilizado, foi encontrado o ponto otimizado onde ocorre a mais alta taxa de corrosão, portanto maior ataque iônico, para uma pressão de $100 \mathrm{mT}$ orr e potência RF $150 \mathrm{~W}$, entretanto este ponto não é o melhor para processos de corrosão de dispositivos em filme de DLC porque amostras corroídas com tais parâmetros não requerem muito tempo de processo. Para melhor controle da espessura obtida no processo, foram requeridos parâmetros que resultavam menor taxa de corrosão e mais tempo de processo; isto foi apresentado para pressão de 25 mTorr e potência RF $50 \mathrm{~W}$.

A rugosidade normalisada é apresentada na Figura 55. Os valores para todas amostras se apresentaram baixos.

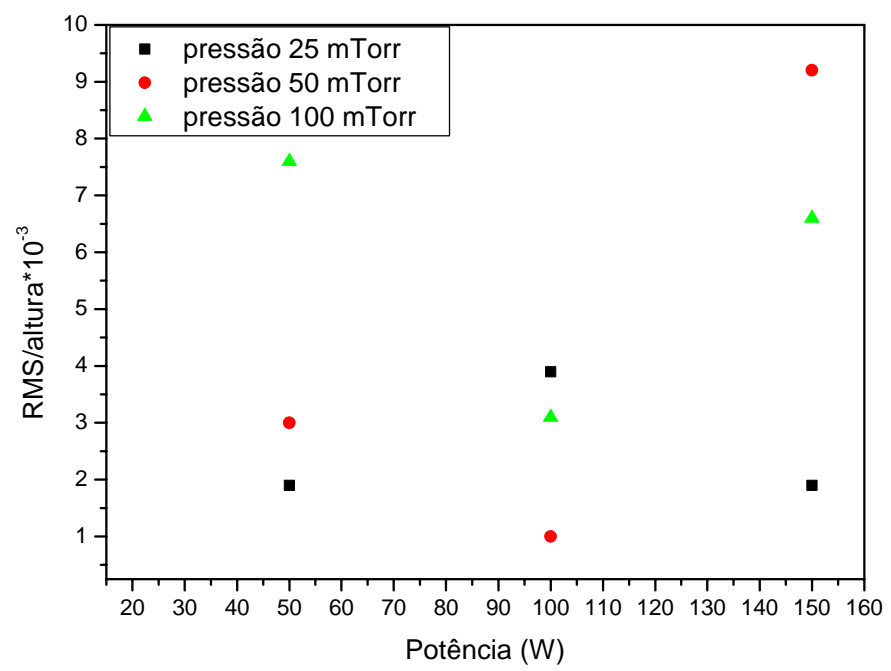

Fig. 55 Rugosidade normalizada em função da variação dos parâmetros de processo de corrosão por plasma do DLC

Com base nos resultados referentes ao índice de refração obtido pela técnica de elipsometria, tem-se eq. (12): 


$$
D_{\max } \approx \frac{\lambda}{2(n-1))} \approx \frac{632,8}{2(1,78-1)} \approx 0,41 \mu m
$$

A partir deste valor e tendo os resultados das taxas de corrosão do DLC para cada processo, pode-se estimar em minutos o tempo necessário para se obter a amplitude $\mathrm{d}_{\max }$ em cada processo de corrosão do carbono amorfo. Para o processo (pressão 25 mTorr e $50 \mathrm{~W}$ de potência) escolhido para ser feito o dipositivo, o tempo estimado para se obter $410 \mathrm{~nm}$ é 1 minuto e 42 segundos.

\subsubsection{Análise por Microscopia de Força Atômica (AFM - Atomic Force Microscopy) das amostras de DLC}

Foi feita análise por Microscopia de Força Atômica as 9 amostras de DLC com a finalidade de se obter resultados quantitativos de rugosidade.

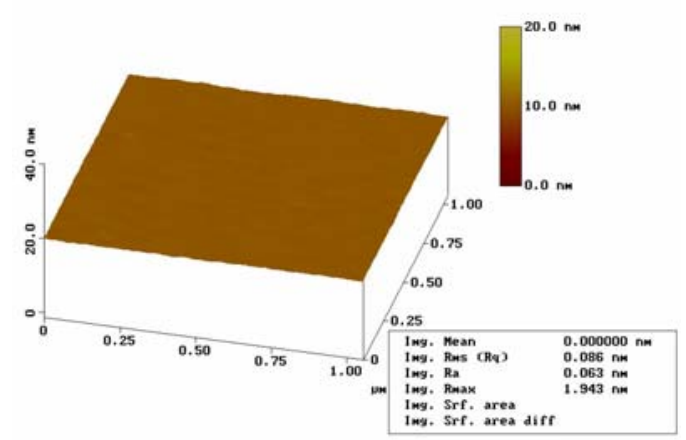

Fig. 56 AFM amostra 25 mTorr e 50W

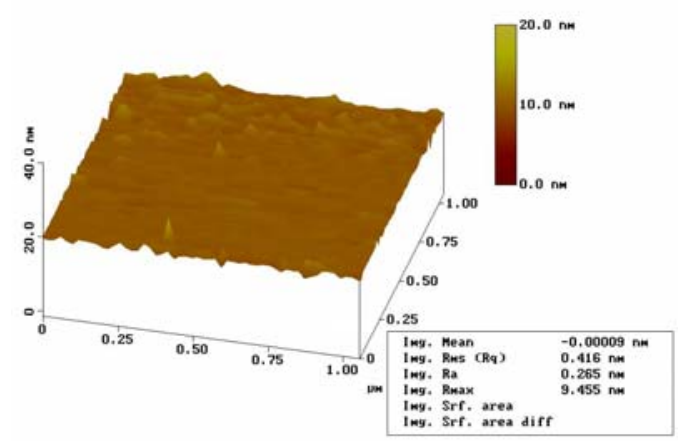

Fig. 57 AFM amostra 100 mTorr e 150W

Observando-se os valores de rugosidades pico-a-pico, RMS e $\mathrm{R}_{\mathrm{A}}$ para as amostras analisadas (Figuras 56 e 57), é perceptível que elas não tiveram uma variação muito grande. Considerando-se que o valor mínimo limite que a rugosidade RMS pode atingir é $63 \mathrm{~nm}$, têm-se valores otimizados para todas amostras. A amostra que apresentou os menores valores de rugosidade é justamente aquela cujos parâmetros de corrosão foram escolhidos para se fazer os processos para fabricação dos EODs (25 mTorr e $50 \mathrm{~W})$. 


\subsection{3 dispositivos de 2 níveis de fase obtidos pela corrosão de filme fino de DLC}

Foram fabricados 22 diferentes tipos de elementos ópticos difrativos sobre filme fino de carbono amorfo pelo processo de corrosão por plasma.

\subsubsection{Análise óptica}

Para a análise do funcionamento dos elementos ópticos difrativos, foram escolhidos 3 dispositivos: um que forma a imagem de uma cruz, um que forma um quadrado e outro que forma a palavra "LSI". Utilizou-se o aparato visto na Figura 25.
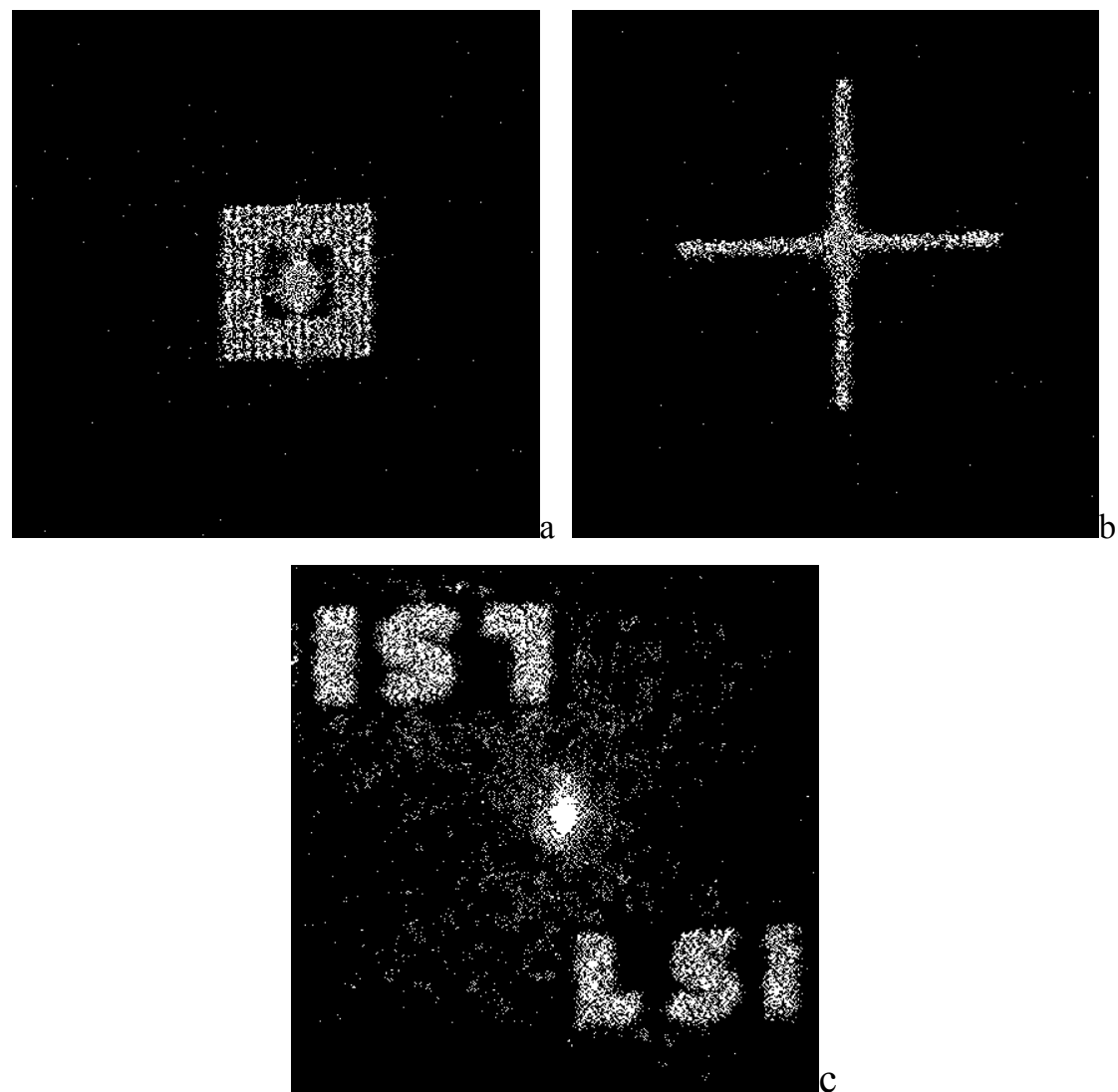

Fig. 58 Imagem formada pelo dispositivo fabricado sobre filme fino de DLC a) “quadrado", b) “cruz" e c) "LSI"

As imagens formadas pelos dispositivos apresentam uma boa definição em seus contornos e as imagens formadas pelas estruturas está bem focada, indicando que houve um bom processo de fabricação. 


\subsubsection{Análise óptica da superfície dos dispositivos}

Para os dispositivos fabricados em filme fino de DLC também foi feita uma análise mais qualitativa por Microscópio Eletrônico de Varredura.

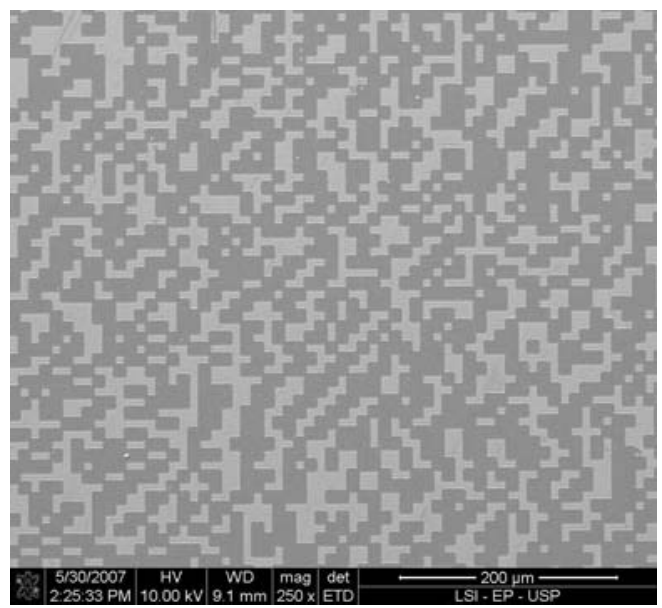

Fig. 59 Micrografia da estrutura do dispositivo "cruz"

A micrografia do elemento óptico difrativo "cruz" obtida apresenta a imagem de estruturas bem delineadas e definidas, indicando que o processo de fabricação dos dispositivos foi bastante otimizada.

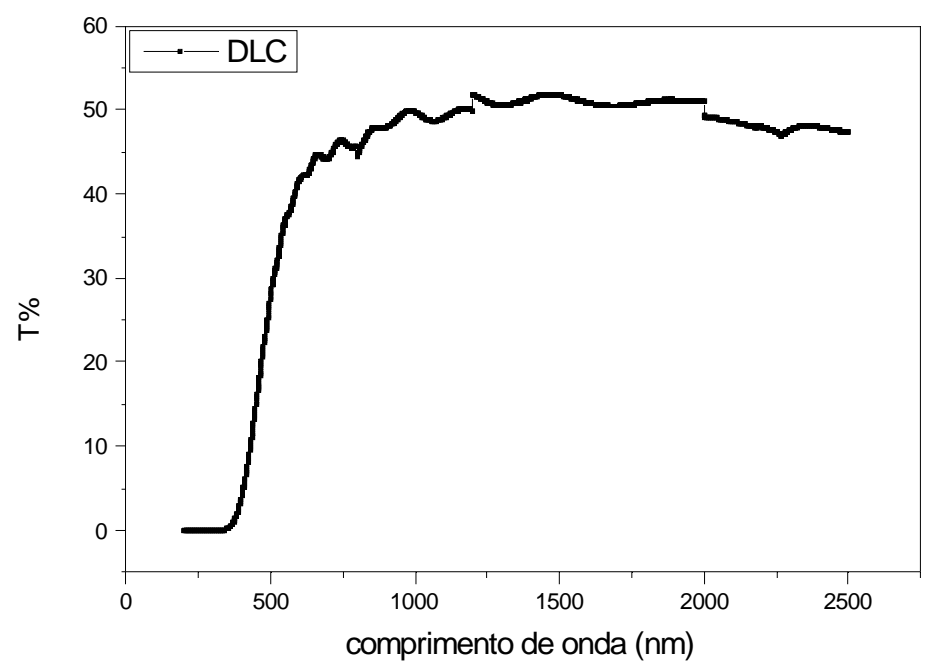

Fig. 60 Curva de transmitância do filme fino de DLC sobre vidro óptico 
Há uma transmitância de aproximadamente $42,6 \%$ da luz incidida para o vidro no comprimento de onda do Laser de HeNe (Figura 60). O DLC é um material que começa a transmitir a partir do comprimento de onda de $330 \mathrm{~nm}$ e seu ponto máximo ocorre em $1459 \mathrm{~nm}$ com uma transmitância de 51,9\%.
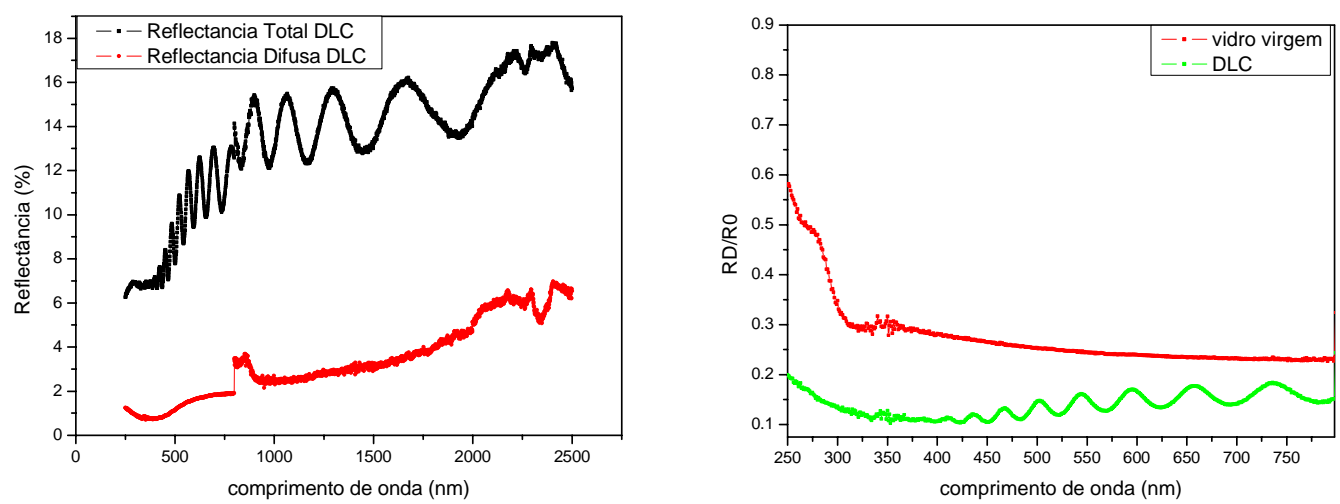

Fig. 61 a) Reflectância difusa e total do DLC e b) Reflectância difusa dividida pela total do vidro virgem e DLC para cálculo de rugosidade RMS

O valor de R0 para o comprimento de onda $632,8 \mathrm{~nm}$ é aproximadamente $12,12 \%$, enquanto que o valor de RD é 1,7\% (Figura 61). A rugosidade encontrada para o DLC foi de 18,8 nm para o comprimento de onda do laser de $\mathrm{HeNe}$, ou seja, um valor muito próximo do vidro virgem. Isto indica que utilizar o vidro como substrato impede que dispositivos feitos em DLC apresentem uma rugosidade mais baixa, já que a superfície destes componentes difrativos apresentaram rugosidade próxima da do o vidro. Conclui-se que o substrato pode ser um limitante na construção de EODs com filmes finos de DLC. 


\subsection{Estudo de corrosão de silício para fabricação de dispositivos difrativos binários}

\subsubsection{Perfilometria das amostras de silício}

\subsubsection{Medida da altura de degrau antes do processo de corrosão}

Esta medida foi realizada antes de se fazer os processos de corrosão tanto do alumínio quanto do silício e obteve-se o valor médio $\mathrm{h}_{\mathrm{rnc}}=1319,8 \mathrm{~nm}$ que é a altura do fotorresiste depositado.

\subsubsection{Medidade de altura de degrau e rugosidades após processo de corrosão}

Após o processo de corrosão foi medida a altura das camadas de silício, alumínio e fotorresiste juntamente. Em seguida, foi removido o fotorresiste e foi medida a espessura das duas camadas restantes. Por fim, a espessura do silício corroído pôde ser averiguada. A espessura de fotorresiste efetivamente corroída, em função da qual foi calculada a taxa de corrosão, foi calculada após a obtenção da altura do silício e também da espessura da máscara de alumínio. Pela técnica de perfilometria também foi medida a rugosidade do fotorresiste.

Observa-se que os valores de rugosidade do fotorresiste para as amostras se apresentam muito altos, com valores médios de 73,6 nm para rugosidade pico-a-pico; 15,9 $\mathrm{nm}$ para rugosidade $\mathrm{RMS} ; 13,6 \mathrm{~nm}$ para rugosidade $\mathrm{R}_{\mathrm{A}}$. Mesmo altos, os valores de rugosidade RMS (que é a rugosidade mais importante no caso deste estudo) estão longe do limite máximo que elas podem atingir, que seria 1/10 do comprimento de onda do laser utilizado no funcionamento dos dispositivos. 


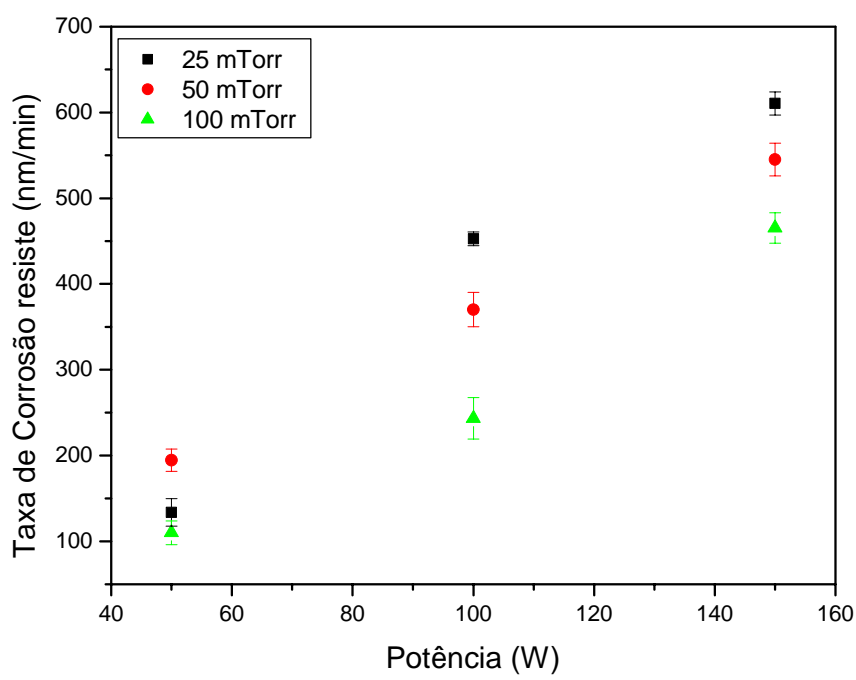

Fig. 62 Taxa de corrosão do fotorresiste em função da variação dos parâmetros de processo de plasma

Na Figura 62 é apresentado o gráfico de taxa de corrosão do fotorresiste em função dos parâmetros de plasma. O processo onde ocorre a maior taxa de corrosão foi feito com 100 mTorr de pressão e $150 \mathrm{~W}$ de potência RF.

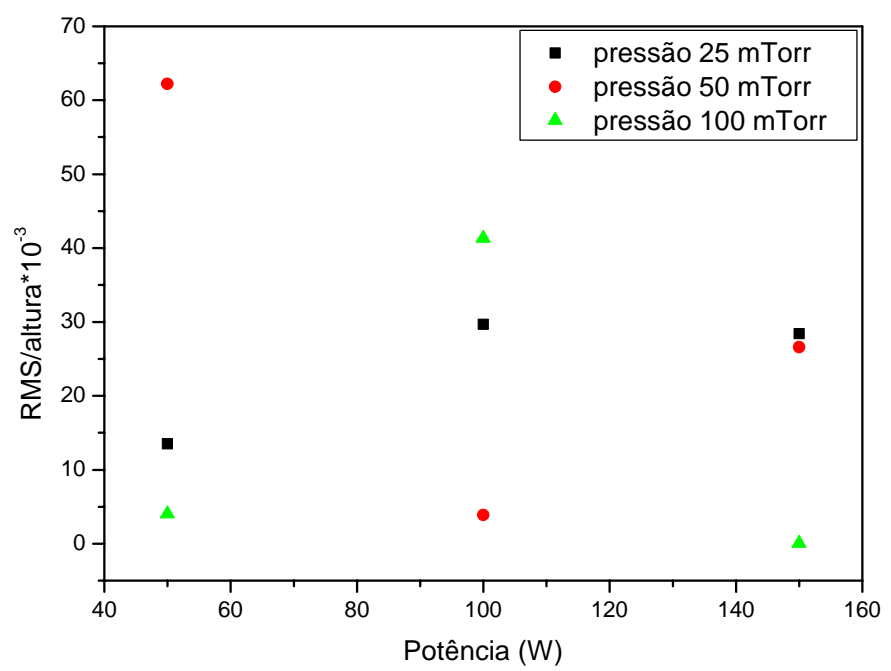

Fig. 63 Rugosidade normalizada em função da variação dos parâmetros de processo de corrosão por plasma do fotorresiste 
Neste gráfico (Figura 63), os valores de rugosidade normalizada do fotorresiste corroído com plasma de $\mathrm{SF}_{6}$ puro se apresentaram baixos se comparados com os valores para a rugosidade normalizada do fotorresiste corroído com $\mathrm{CF}_{4}$. No entanto, os valores de rugosidade normalizada foram mais baixos para o fotorresiste corroído com $\mathrm{O}_{2}$ puro.

A taxa de corrosão do silício foi obtida após remoção do fotorresiste e máscara de alumínio e medição da espessura do Si. Além da taxa de corrosão, foram obtidas as rugosidades pico-a-pico, RMS e $\mathrm{R}_{\mathrm{A}}$ (Figura 69).

\begin{tabular}{|c|c|c|}
\hline \multicolumn{3}{|c|}{ Tabela XI - Médias das rugosidades do } \\
\multicolumn{3}{|c|}{ Silício } \\
\hline p.p. $(\mathrm{nm})$ & RMS $(\mathrm{nm})$ & $\mathrm{R}_{\mathrm{A}}(\mathrm{nm})$ \\
\hline $\mathbf{1 5 , 9}$ & $\mathbf{1 , 9 1}$ & $\mathbf{2 , 4}$ \\
\end{tabular}

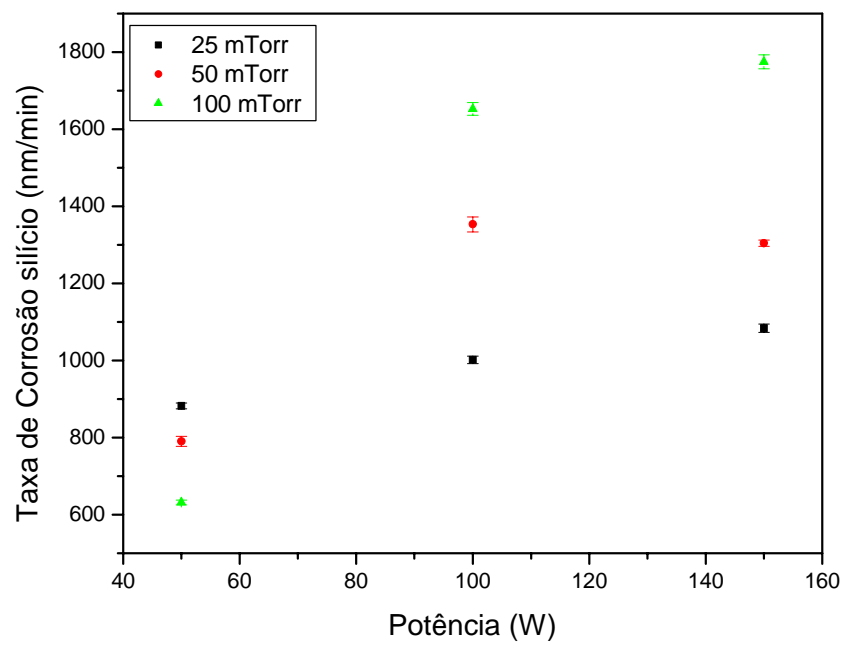

Fig. 64 Taxa de corrosão do silício em função da variação dos parâmetros de processo de corrosão por plasma

Na Figura 64 é apresentado o gráfico de taxa de corrosão do silício em função dos parâmetros de plasma. A curva para a pressão de 100 mTorr é a que apresenta crescimento mais acentuado. Foi encontrado o ponto otimizado onde ocorre a mais alta taxa de corrosão, portanto maior ataque iônico, para os parâmetros pressão 100 mTorr e potência RF $150 \mathrm{~W}$. 


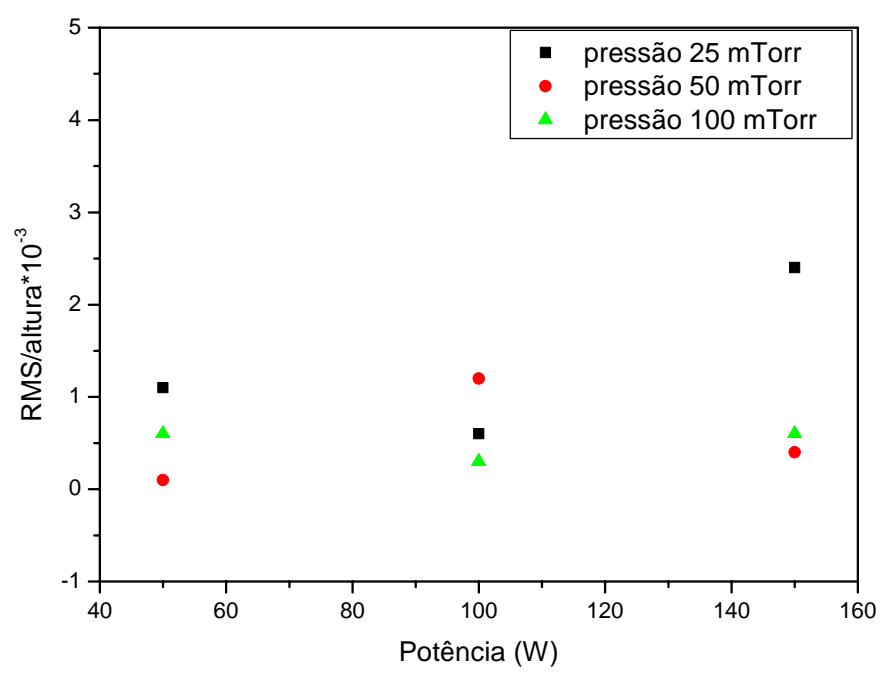

Fig. 65 Rugosidade normalizada em função da variação dos parâmetros de processo de corrosão por plasma do silício

A s curvas de rugosidade normalizada (Figura 65) novamente apresentaram pontos discrepantes para a potência de $100 \mathrm{~W}$. Indicado que os mesmos problemas de sputtering e redeposição do fotorresiste que ocorre para o vidro óptico, também ocorre para o substrato de silício. No entanto, os valores apresentados são muito baixos se comparados com os valores obtidos na corrosão por plasma de vidro ópticos.

Foram desenvolvidos elementos ópticos difrativos para dois comprimentos de onda diferentes: $\lambda=1550 \mathrm{~nm}$ e $10600 \mathrm{~nm}$. A equação utilizada para o cálculo da espessura, utilizando-se o índice de refração do silício de 3,5 é eq. (13):

$$
d_{\max } \approx \frac{\lambda}{2(n-1)}
$$

A partir da equação e tendo os resultados das taxas de corrosão do silício para cada processo, pode-se estimar em minutos o tempo necessário para se obter a amplitude $\mathrm{d}_{\text {max }}$ em cada processo de corrosão para o comprimento de onda desejado. Como o tempo para o processo cuja pressão é de 100 mTorr e potencia $150 \mathrm{~W}$ é muito baixo para obter tal espessura e, portanto ficaria difícil reproduzir tal processo com exatidão para várias amostras, o processo escolhido para ser feito o dipositivo foi 
aquele de pressão 100 mTorr e $50 \mathrm{~W}$ de poência, cujo tempo estimado para se obter $300 \mathrm{~nm}$ é 28,5 segundos para um comprimento de onda de $1550 \mathrm{~nm}$ utilizado. Já para o comprimento de onda de $10600 \mathrm{~nm}$ tem-se tempo de 3 minutos e 22 segundos para se obter um $d_{\max } 2120 \mathrm{~nm}$.

\subsubsection{Análise por Microscopia de Força Atômica (AFM - Atomic Force Microscopy) das amostras de silício}

Foi feita análise por Microscopia de Força Atômica as 9 amostras de silício com a finalidade de se obter resultados quantitativos de rugosidade (Figura 66).
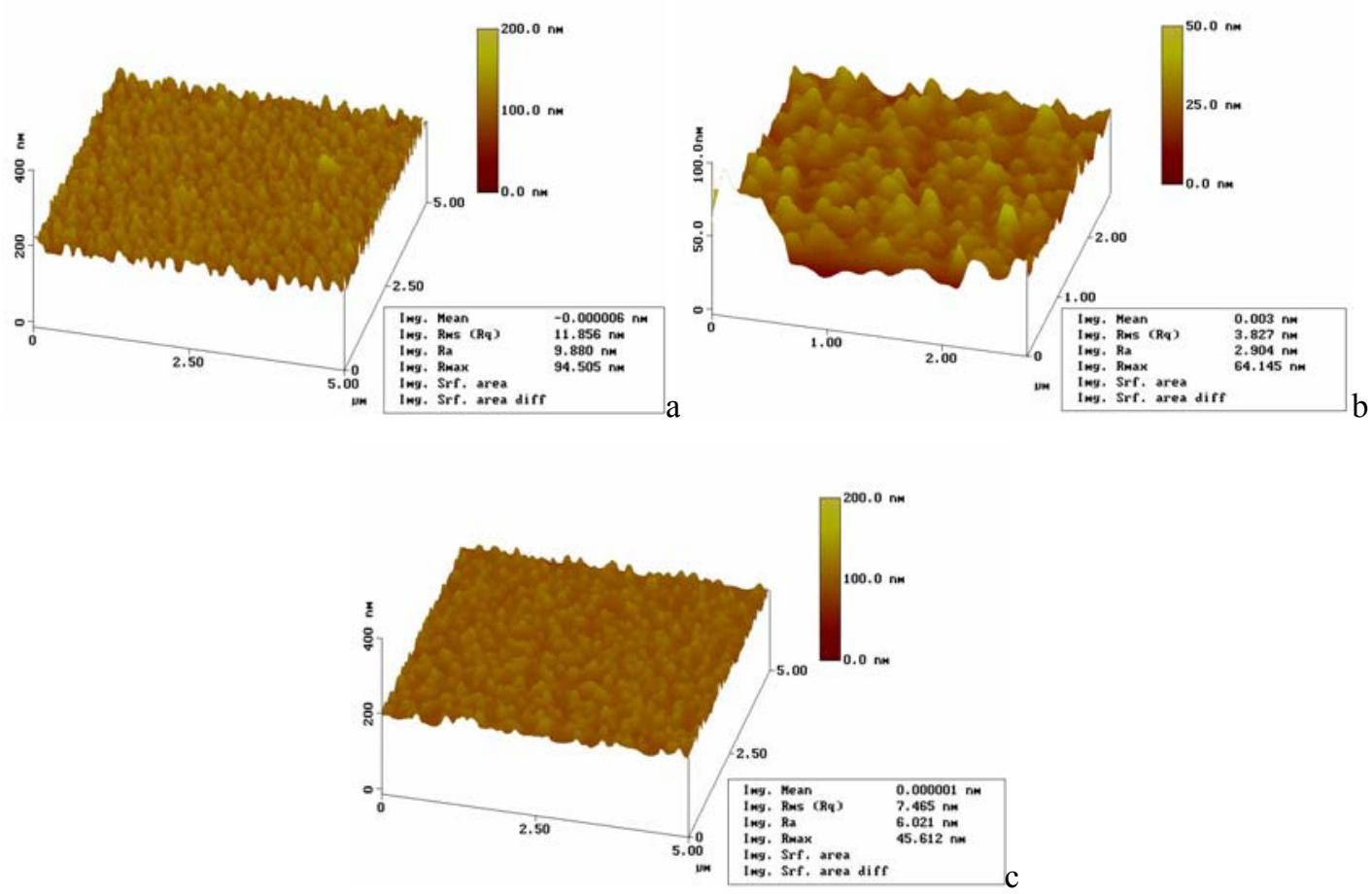

Fig. 66 Micrografia AFM das amostras de silício corroídas por plasma com os parâmetros a) 25 mTorr e $50 \mathrm{~W}$, b) 100 mTorr e $50 \mathrm{~W}$ e c) 100 mTorr e $150 \mathrm{~W}$

Observando-se os valores de rugosidades pico-a-pico, RMS e $\mathrm{R}_{\mathrm{A}}$ para as amostras analisadas, elas não tiveram uma variação muito grande. Considerando-se que o valor mínimo limite que a rugosidade RMS pode atingir (pertencente ao laser de comprimento de onda de $1550 \mathrm{~nm}$ ou $10600 \mathrm{~nm}$ ) é $155 \mathrm{~nm}$ ou $1060 \mathrm{~nm}$, têm-se valores otimizados para todas amostras. O processo (pressão de 100 mTorr e 
potência RF de $50 \mathrm{~W}$ ) que resultou na amostra com menor rugosidade foi escolhido para fabricação de EODs.

\subsubsection{Análise óptica da superfície dos dispositivos de $\mathbf{2}$ níveis de fase obtidos pela} corrosão do silício

Foram fabricados 22 diferentes tipos de elementos ópticos difrativos sobre silício pelo processo de corrosão por plasma. Nas Figuras 67, 68, 69 e 70 são apresentados alguns exemplos fotografados através de microscopia óptica (aumento de 100 vezes):

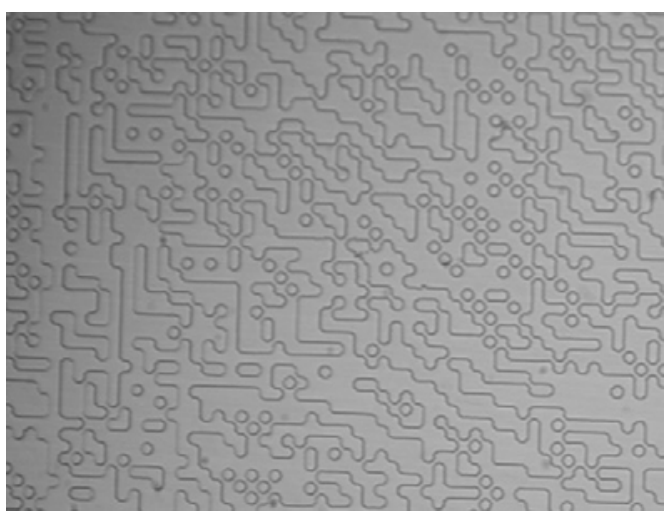

Fig.67 Estrutura do dispositivo Cruz

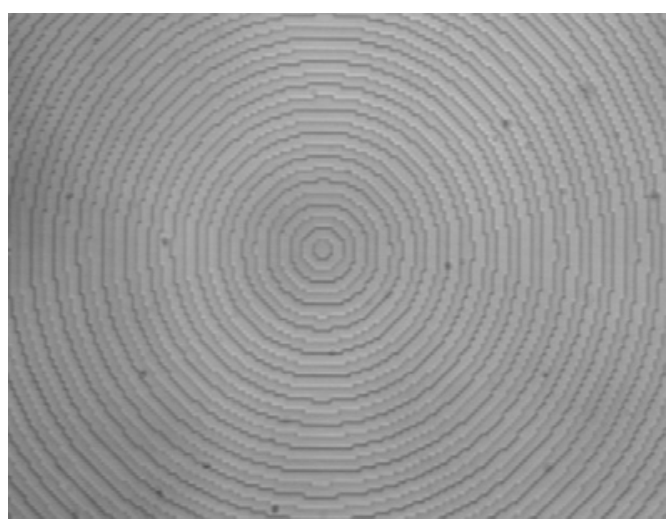

Fig.69 Estrutura do dispositivo Círculo

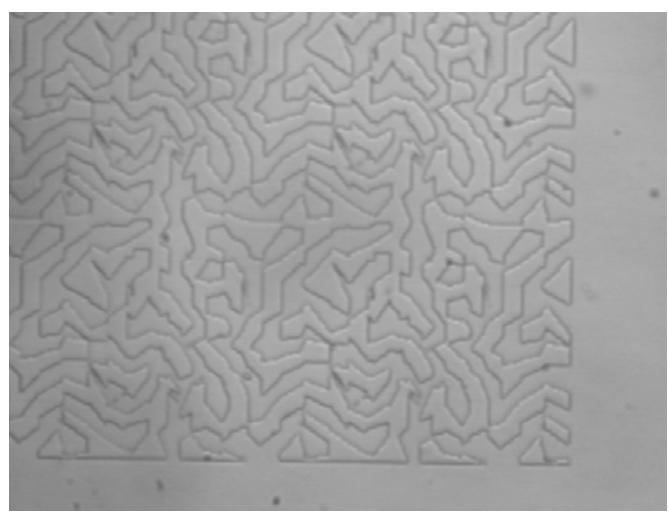

Fig. 68 Estrutura do dispositivo Quadrado

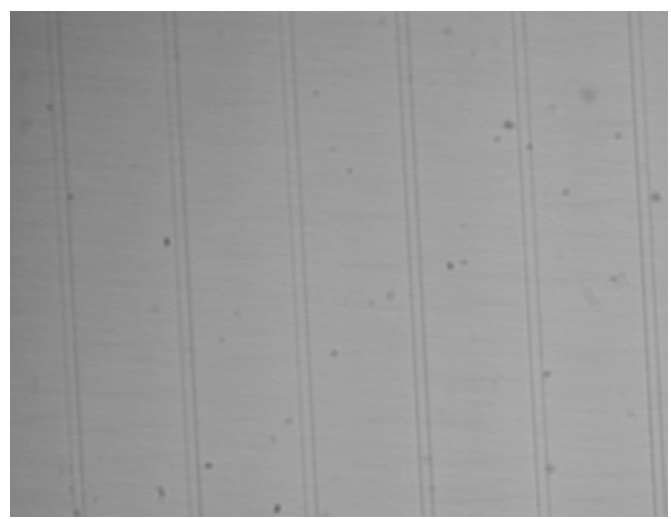

Fig. 70 Estrutura da Rede Difrativa

Para se ter um melhor detalhamento das estruturas, foram feitas também micrografias do elemento óptico difrativo “cruz"através da técnica de Microscopia Eletrônica de Varredura (SEM - Scanning Electronic Microscopy). 

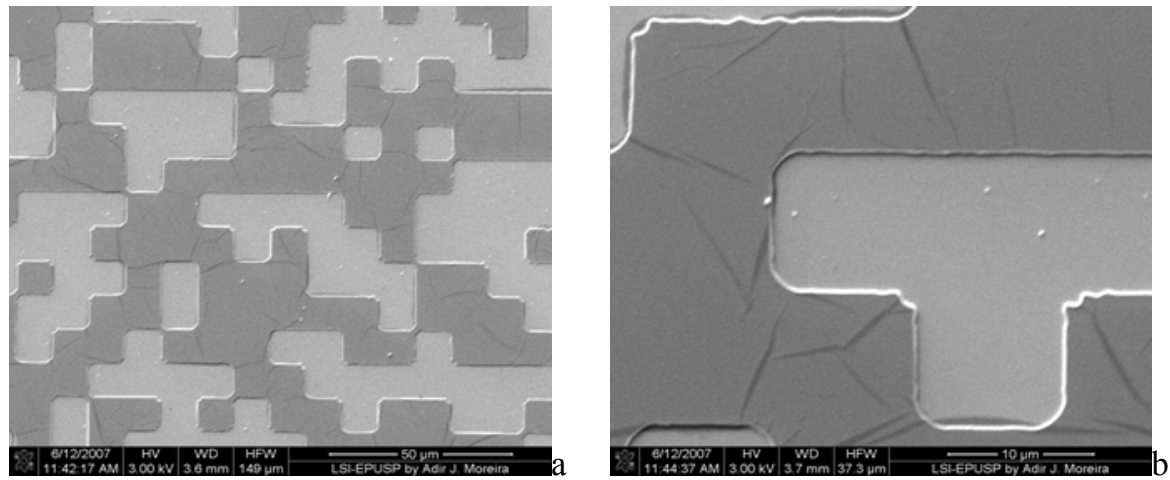

Fig. 71 Micrografias do mesmo elemento óptico difrativo com detalhes em a) $50 \mu \mathrm{m}$ e b) $10 \mu \mathrm{m}$

Na Figura 71 é mostrada a estrutura do dispositivo "cruz" em uma escala de $50 \mu \mathrm{m}$ e $10 \mu \mathrm{m}$. Tais micrografias foram feitas para se observar com maior detalhamento o dispositivo. Tais EODs foram fabricados com a finalidade de se construir dispositivos que atuem em comprimentos de ondas diferentes dos vistos atualmente. Os elementos construídos atualmente operam na faixa do visível, no entanto, EODs de silício atuam para comprimentos de onda no infravermelho próximo e médio.

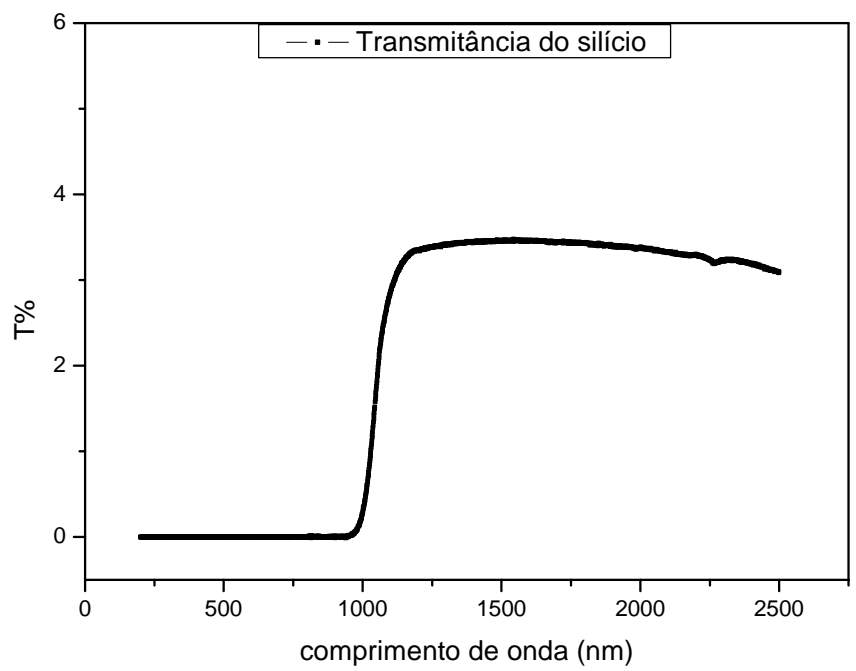

Fig. 72 Curva de Transmitância do silício

O silício é um material que possui uma transmitância muito baixa, começa a transmitir a partir do comprimento de onda de $980 \mathrm{~nm}$ e seu ponto máximo ocorre em $1551 \mathrm{~nm}$ com uma transmitância de 3,47\%. Comparado com o vidro e o DLC 
possui uma transmitância máxima de valor muito inferior, no entanto a transmitância do DLC permanece até $16000 \mathrm{~nm}$, segundo consultado na literatura [91]. 


\section{CONCLUSÕES}

O objetivo principal deste trabalho é a fabricação de elementos ópticos difrativos com modulação de fase e amplitude e, paralelamente, a otimização das etapas de processos utilizadas na fabricação de dispositivos ópticos difrativos. Para isso foram desenvolvidas e caracterizadas as principais etapas para a fabricação deste componentes, nesta etapa do trabalho foi estudada a corrosão por plasma do substrato de vidro óptico e feita uma análise óptica de dispositivos fabricados em vidro e DLC. Também foi feito um estudo de taxa de corrosão e rugosidade de silício após processos de corrosão com diferentes parâmetros para desenvolvimento de EODs baseados neste material.

O processo de corrosão do vidro com máscara de fotorresiste não apresentou bons resultados com relação à taxa de corrosão do fotorresiste que foi demasiadamente alta, então foi feito um segundo processo utilizando uma máscara de alumínio. Após o processo e remoção do alumínio, foi medida a altura e a rugosidade do trecho corroído do vidro pela técnica de perfilometria. Em todos os casos de amostra, a rugosidade RMS foi inferior a 1/10 do comprimento de onda $632,8 \mathrm{~nm}$ do laser de $\mathrm{HeNe}$, indicando que esta rugosidade superfícial não influenciará no desempenho do dispositivo. Temos como confirmação qualitativa para as rugosidades RMS os resultados da Microscopia Eletrônica de Varredura e como confirmação quantitativa, os resultados de Microscopia de Força Atômica para as amostras com pressão fixa em 100 mTorr e potências $50 \mathrm{~W}, 150 \mathrm{~W}$ e $200 \mathrm{~W}$ cujos resultados são respectivamente $1,447 \mathrm{~nm}, 3,542 \mathrm{~nm}$ e $14,026 \mathrm{~nm}$.

Quando comparadas as imagens formadas pelas lâminas produzidas com processos de corrosão por plasma (100 mTorr de pressão e $400 \mathrm{~W}$ de potência) feitos por diferentes tempos para o dispositivo "quadrado", nota-se que a que apresenta maior qualidade é a pertencente à lâmina corroída por 6 minutos e 30 segundos, pois o ponto de ordem zero aparenta ter a mesma intensidade que os demais pontos pertencentes ao quadrado. Quando a imagem da lâmina 6,5 minutos é comparada com a imagem da lâmina corroída por um tempo de 7 minutos, a diferença é bastante 
percepitível: tal lâmina apresenta um ponto central demasiadamente intenso e a imagem do quadrado que deveria ser formada está com intensidade fraca e disforme. Portanto o tempo influi muito na imagem final que o dispositivo apresentará. As diferenças nas imagens resultantes são ainda mais visíveis para o dispositivo "cruz". A homogeneidade de intensidade para os pontos da imagem pertencente à lâmina 6,5 minutos é ainda mais percepitível, indicando que o tempo do processo de corrosão com o qual o dispositivo foi fabricado é o mais próximo do ideal. Observando-se a imagem formada pela mesma lâmina antes do processo de limpeza, verifica-se que de fato existe diferença entre as duas imagens e isso é devido ao polímero que foi formado durante o processo de corrosão estar presente sobre o dispositivo, atrapalhando a boa formação da imagem quando o laser incide sobre o elemento óptico difrativo.

A espessura desejada calculada foi de $770 \mathrm{~nm}$ e o dispositivo que apresentou uma altura do perfil da estrutura mais próxima deste valor foi o que gera uma imagem de cruz e que sofreu processo de corrosão em um tempo de 6,5 minutos. Na análise óptica ficou evidente que este foi o dispositivo com melhor desempenho devido à uniformidade da intensidade da luz projetada na imagem e da baixa intensidade do ponto de ordem zero, além da imagem estar bem focada e definida. A análise perfilométrica só comprova tais resultados, e ainda mostrou que pouco (quase nenhum) polímero ou elementos não voláteis ficaram acumulados entre as paredes das estruturas. O que mais chamou a atenção nesta análise foi que as amostras que sofreram processo de corrosão por 6 minutos apresentaram perfís também próximos do valor desejado, mas na análise óptica, as imagens de ambos dispositivos se apresentaram um tanto desuniformes e desfocadas. Isto tem como explicação o fato de entre as estruturas de ambos dispositivos ter se acumulado muito material, talvez polímero formado durante o processo de corrosão e impurezas não voláteis que fazem parte da estrutura do vidro e que durante a corrosão, mascararam a região entre as estruturas.

Foram apresentadas algumas imagens (uma borboleta e uma águia) reconstruídas a partir de elementos ópticos difrativos apenas de fase, implementados em vidro 
óptico, com quatro níveis de modulação de fase fabricados por corrosão por plasma. As figuras mostram uma reconstrução típica a partir de elementos ópticos difrativos de fase binária, tipo Fresnel. Pode-se notar que não existe a presença de ponto de ordem zero de difração nas imagens que foram reconstruídas com relativa fidelidade, mas com excessivo ruído speckle (devido ao processo de corrosão do vidro que é problemático).

Antes de se fabricar EODs sobre filmes de DLC, foram feitos processos de corrosão com diferentes parâmetros, tendo por finalidade o estudo de taxa de corrosão e rugosidade. Nos processos corrosão utilizados, foi encontrado o ponto otimizado onde ocorre a mais alta taxa de corrosão, portanto maior ataque iônico, para uma pressão de 100 mTorr e potência RF $150 \mathrm{~W}$, entretanto este ponto não é o melhor para processos de corrosão de dispositivos, pois as amostras corroídas com tais parâmetros não requerem muito tempo de processo, dificultando o controle do mesmo. Para melhor controle da espessura obtida no processo, foram requeridos parâmetros que resultavam menor taxa de corrosão e mais tempo de processo; isto foi obtido para pressão de 25 mTorr e potência RF de $50 \mathrm{~W}$.

Após finalizado o estudo, os elementos ópticos difrativos foram fabricados. Para a análise do funcionamento dos elementos ópticos difrativos, foram escolhidos três dispositivos: um que forma a imagem de uma cruz, outro que forma a imagem de uma cruz e um último que mostra a palavra "LSI". Os dispositivos formam imagens bem definidas e focadas. Em uma análise óptica da rugosidade RMS do DLC através da obtenção da Reflectância Total e da Reflectância Difusa, foi encontrado um valor de $18,8 \mathrm{~nm}$, o qual se encontra bem abaixo do limite de $63 \mathrm{~nm}$, mas é uma rugosidade com um valor muito próximo do vidro virgem. Isto indica que utilizar o vidro como substrato impede que dispositivos feitos em DLC apresentem uma rugosidade mais baixa, já que a superfície destes componentes difrativos apresentaram rugosidade próxima à do o vidro. Conclui-se que o substrato pode ser um limitante na construção de EODs com filmes finos. 
Para fabricação de elementos ópticos difrativos baseados em substrato de silício fezse um estudo de taxa de corrosão e rugosidade resultantes de processos de corrosão por plasma com diferentes parâmetros de pressão e potência RF. Foi encontrado o ponto otimizado onde ocorre a mais alta taxa de corrosão, portanto maior ataque iônico, para os parâmetros pressão de 100 mTorr e potência de RF 150W. Foram desenvolvidos elementos ópticos difrativos para dois comprimentos de onda diferentes: $\lambda=1550 \mathrm{~nm}$ e $10600 \mathrm{~nm}$.

Em uma análise comparativa entre os diferentes tipos de EODs, é possível concluirse:

\begin{tabular}{|c|c|c|c|}
\hline Tipo & EOD vidro & EOD DLC & EOD silício \\
\hline $\begin{array}{c}\text { Rugosidade RMS } \\
\text { (Perfilometria) }\end{array}$ & $5,4 \mathrm{~nm}$ & $3,16 \mathrm{~nm}$ & $1,9 \mathrm{~nm}$ \\
\hline $\begin{array}{c}\text { Rugosidade RMS } \\
\text { (AFM) }\end{array}$ & $10,3 \mathrm{~nm}$ & $0,1 \mathrm{~nm}$ & $3,8 \mathrm{~nm}$ \\
\hline $\begin{array}{c}\text { Rugosidade RMS } \\
\text { (Espectrofotometria) }\end{array}$ & $\begin{array}{c}\text { Transparência no } \\
\text { visível; substrato } \\
\text { barato. }\end{array}$ & $\begin{array}{c}\text { Pode ser utilizado } \\
\text { como dispositivo } \\
\text { modulador de } \\
\text { amplitude na } \\
\text { faixa do UV; fácil } \\
\text { reprodutibilidade. }\end{array}$ & $\begin{array}{c}\text { Transparência no } \\
\text { infra vermelho } \\
\text { próximo e } \\
\text { distante; fácil } \\
\text { reprodutibilidade. }\end{array}$ \\
\hline Desvantagens & $\begin{array}{c}\text { Processo de } \\
\text { fabricação de } \\
\text { difícil controle e } \\
\text { reprodutibilidade. }\end{array}$ & $\begin{array}{c}\text { Alto custo de } \\
\text { produção dos } \\
\text { filmes finos. }\end{array}$ & $\begin{array}{c}\text { Porcentagem de } \\
\text { transmitância } \\
\text { muito baixa. }\end{array}$ \\
\hline \multicolumn{2}{|c}{} \\
\hline
\end{tabular}




\section{PROPOSTAS PARA NOVOS TRABALHOS}

No presente trabalho Foram fabricados e caracterizados Elementos Ópticos Difrativos fabricados em diferentes materiais e foram otimizadas as etapas de fabricação destes dispositivos. Como continuidade deste trabalho são apresentadas algumas propostas.

Os materiais utilizados foram adequados para a fabricação de EODs, portanto pretende-se utilizar os resultados para fabricação de EODs com mais níveis de fase e amplitude.

Os processos de corrosão do vidro utilizando $\mathrm{CF}_{4}$ apresentaram excesso de redeposição e micromascaramento devido aos óxidos não voláteis. Assim, uma proposta seria a utilização de outras fontes de flúor tais como $\mathrm{SF}_{6}$ e plasmas de alta densidade para eliminar estes efeitos. A redução destes efeitos reduz o ruído de speckle.

Outra possibilidade para a redução desta rugosidade é a utilização de corrosão por plasma e polimento químico visando a remoção dos óxidos não voláteis.

Os processos desenvolvidos neste trabalho podem ser integrados gerando uma nova classe de dispositivos difrativos para vários comprimentos de onda, abrangendo desde o UV ao infravermelho.

Os elementos baseados em silício podem ser empregados em sensores de infravermelho e para fabricação de dispositivos passivos integrados que operam na faixa de 1 a $16 \mu \mathrm{m}$.

Os testes realizados nos dispositivos de silício foram preliminares. Futuramente serão feitos análises ópticas mais apuradas e também mais testes da rugosidade superficial. Tais EODs operam na faixa do infravermelho, por isso requerem um aparato de análise especial. 


\section{ANEXO 1 - PUBLICAÇÕES}

1a Trabalhos gerados durante o período do projeto

Sparvoli, M.; Mansano, R.D.; Mousinho, A.P.; Verdonck, P.B.; apresentação intitulada "New photoelectric device using nanostructured amorphous carbon films", Carbono - 2005, Rio de Janeiro, Rio de Janeiro, Brasil, Novembro de 2005. (Artigo completo publicado em anais de congresso).

> Sparvoli, M.; Mansano, R.D., apresentação intitulada "Desenvolvimento de um espectrofotômetro de baixo custo”, XXIX ENFMC ( $29^{\circ}$ Encontro Nacional de Física da Matéria Condensada), São Lourenço, Minas Gerais, Brasil, Maio de 2006. (Resumo publicado em anais de congresso).

> Sparvoli, M.; Mansano, R.D., apresentação intitulada "Novo componente fotoelétrico baseado em filmes finos de carbono nanoestruturado", MOMAG - 2006 ( $12^{\circ}$ SBMO - Simpósio Brasileiro de Microondas e Optoeletrônica e $7^{\circ}$ CBMAG - Congresso Brasileiro de Eletromagnetismo ), Belo Horizonte, Minas Gerais, Brasil, Agosto de 2006. (Artigo completo publicado em anais de congresso).

Sparvoli, M.; Mansano, R.D., apresentação intitulada "New photoelectric device based in amorphous hydrogenated carbon”, X Jorge André Swieca School on Quantum Optics and Nonlinear Optics, São Miguel dos Milagres, Alagoas, Março de 2007. (Resumo publicado em anais de congresso).

1b Trabalhos gerados a partir dos resultados deste trabalho

Sparvoli, M.; Mansano, R.D.; Lopera, S.A., apresentação intitulada "Elementos Ópticos Difrativos baseados em polímeros", X EBEE ( $10^{\circ}$ Escola Brasileira de Estrutura Eletrônica), Niterói, Rio de Janeiro, Brasil, Julho de 2006. (Resumo publicado em anais de congresso).

> Sparvoli, M.; Mansano, R.D.; Moreira, A., apresentação intitulada "Processos de corrosão por plasma de vidro óptico para fabricação de elementos ópticos difrativos", XXVII CBRAVIC ( $27^{\circ}$ Congresso Brasileiro de Aplicações do 
Vácuo na Índustria e na Ciência ), Itatiba, São Paulo, Brasil, Julho de 2006. (Resumo publicado em anais de congresso).

> Sparvoli, M.; Mansano, R.D.; Moreira, A., artigo intitulado "Processos de corrosão por plasma de vidro óptico para fabricação de elementos ópticos difrativos", aceito para publicação na Revista Brasileira de Aplicações de Vácuo.

> Sparvoli, M.; Mansano, R.D., apresentação intitulada "Desenvolvimento de elementos opticos difrativos para a região do infra vermelho", XXX ENFMC (30 Encontro Nacional de Física da Matéria Condensada), São Lourenço, Minas Gerais, maio de 2007. (Resumo publicado em anais de congresso).

> Sparvoli, M.; Mansano, R.D., apresentação intitulada "Obtenção de elementos ópticos difrativos baseados em filme de carbono amorfo", XXX ENFMC ( $30^{\circ}$ Encontro Nacional de Física da Matéria Condensada), São Lourenço, Minas Gerais, maio de 2007. (Resumo publicado em anais de congresso).

A.R., Mascaro ; MEDEIROS, Marina Sparvoli de ; L. C. D. Gonçalvez ; N. I. Morimoto, apresentação intitulada "Application of Ni2Si masks for optical devices on Si”, XXX ENFMC ( $30^{\circ}$ Encontro Nacional de Física da Matéria Condensada), São Lourenço, Minas Gerais, maio de 2007. (Resumo publicado em anais de congresso).

> Sparvoli, M.; Mansano, R.D., apresentação intitulada "DIFFRACTIVE OPTICAL ELEMENTS BASED IN DIAMOND LIKE CARBON (DLC) FILMS”, trabalho aceito para apresentação na conferência Iberoamerican Conference on Optics (RIAO) Latinamerican meeting on Optics, Lasers and Applications (OPTILAS), Campinas, outubro de 2007. (Resumo será publicado em anais de congresso). 


\section{REFERÊNCIAS}

[1] Rivera, N. I. R.. Imagens por dupla difração com luz branca usando redes de difração e uma fenda. 2003. Dissertação (Mestrado) - UNICAMP. Campinas, Brasil, 2003.

[2] Toma, S.N.; Alexandrescu, A.; Cristea, D.; Muller, R.; Kusko, M.; Dumbravescu, N.; Nascov, V.; Cojoc, D.. Binary phase reflective diffractive optical elements design and fabrication. IEEE, p.401-404, 2004.

[3] Kusko, M.; Cojoc, D.; Apostol, D.; Muller, R.; Manea, E.; Podaru, C.; Design and fabrication of Diffractive Optical Elements, IEEE, p. 167-170, 2003.

[4] Daschner, W.; Larsson, M.; Lee, S. H.; Design and Fabrication of Low Noise High Diffraction Efficiency Diffractive Optical Elements, IEEE, p. 1283-1285, 1995.

[5] Giuseppe Schirripa Spagnolo, Carla Simonetti, Lorenzo Cozzella. Designing of Diffractive Optical Element for the generation of uniform arrays of beams. IEEE, $p$. 355-359, 2005.

[6] Gallagher, N. C.; Diffractive Optical Elements, IEEE, p. 440-444, 1989.

[7] Nascov, V.; Apostol, D.; Damian, V.; Kusko, M.; Dumbrivescu, N.; Muller, R.; Podaru, C.; Cojoc, D.; Toma, S. N.; On a diffractive optical element, IEEE, p. 513$516,2004$.

[8] Kuroiwa, Y.; Takeshima,N.; Narita, Y.; Tanaka, S.; Hiraob, K. Arbitrary micropatterning method in femtosecond laser microprocessing using diffractive optical elements. Optics Express, v. 12, n. 9, p. 1908 - 1915, 2004.

[9] Apresenta tutorial sobre elementos ópticos difrativos. Disponível em http://www.xmission.com/ ralcon/tutorial/tutorial.html . Acesso em Agosto de 2005. 
[10] Apresenta um exemplo de elemento óptico difrativo e suas aplicações. Disponível em http://www.xmission.com/ ralcon/hoes.html. Acesso em Setembro de 2005.

[11] Zhou, G., Tay , F. E. H. , Chau, F. S.; Design of the diffractive optical elements for synthetic spectra; Optics Express, v. 11, n. 12, p. 1392, 2003.

[12] Apresenta uma empresa que fabrica elementos ópticos difrativos. Disponível em www.laseroptical.co.uk. Acesso em Janeiro de 2006.

[13] Apresenta exemplos de elementos ópticos difrativos. Disponível em http://www.hololight.net/hoe.html\#section5. Acesso em Janeiro de 2006.

[14] Fu, Y.; Bryan, N. K. A.; One-step fabrication of hybrid micro-diffractivereffractive lens with continuous relief using focused beam milling, OSA Technical Digest, p. 30-32, 2002. / Apresentado em OSA Trends in Diffractive Optics and Micro-Optics, Tucson, Arizona, 2002/.

[15] Kitchen, S. R. Optical Sensors Based on Dedicated Diffractive Optical Elements. 2003. 134p. Tese (Ph.D.) - Technical University of Denmark.Dinamarca, 2003.

[16] Rossi, M.; Gale, M. T. Technology fulfills its promise, Laser Focus World, p. 76-80.

[17] Golub, M.; Grossinger, I. Diffractive optical elements for biomedical applications. Holo-Or, p. 1051.

[18] Herzig, H. P. Micro-optics. Taylor \&Francis, 1997. v.1. 
[19] Fabrizio, E. D.; Cojoc, D.; Cabrin, S. ; Diffractive optical elements for differential interference contrast x-ray microscopy. Optics Express, v. 11, n. 19, p. $2278,2003$.

[20] Yong-Qi, F.; Bryan, N. K. A.; Shing, O. N.; Diffractive optical elements with continuous relief fabricated by focused ion beam for monomode fiber coupling. Optics Express, v. 7, n. 3, 2000.

[21] Apresenta uma empresa que fabrica elementos ópticos difrativo. Disponível em http://www.heptagon.fi/products/diffractive_microlens.html. Acesso em Fevereiro de 2006.

[22] Apresenta uma empresa que fabrica elementos ópticos difrativo. Disponível em http://www.heptagon.fi/products/nanoperiod_gratings.html. Acesso em Fevereiro de 2006.

[23] Apresenta uma empresa que fabrica elementos ópticos difrativo. Disponível em http://www.leister.com/microsystems/microoptics/products. Acesso em Fevereiro de 2006.

[24] M. Rossi et al. Diffractive Optical Elements for Passive Infrared Detectors, in OSA Trends in Diffractive Optics and Micro-Optics, OSA Technical Digest, p. 288290, 2000.

[25] Futhey, J. A. Diffractive bifocal intraocular lensin holographic Optics: Optical and computer generated. Proc. SPIE, n. 1052, p. 142-149, 1989.

[26] Morrison, R. L.; Walker, S. L.; Cloonan, T. J. Bean array generation and holographic interconnection in a free-space optical switching network. Appl. Opt., n. 32, p. 2512-2518, 1993. 
[27] Zhao, B.; Asundi, A. Strain microscope with grating diffraction method. Opt. Eng., n. 38, p. 170-174, 1999.

[28] Schertler, D. J.; George, N. Uniform scattering patterns from gratting-diffuser cascades for display applications. Appl. Opt., n. 38, p. 291-303, 1999.

[29] Spagnolo, G. S.; Ambrosini, N.; Diffractive optical element-based profilometer for surface inspection, Opt. Eng., n.40, p. 44-51, 2001.

[30] Veldkamp, W.B; "Wireless focal planes: on the road to amacronic sensors, IEEE Journal of Quantuum Electronics, v.29, n.2, p.801-813, 1993.

[31] Stern, M.B.; Medeiros, S.S.; Deep three-dimentional microstructure fabrication for infrared binary optics, Journal of Vacuum Science and Technology B, v.10, n.6, p.2520-2525, 1992.

[32] Rajkumar, N.; McMullin, J.N.; V-groove gratings on silicon for infrared beam splitting, Applied Optics, v.34, n.14, p.2556-2559, 1995.

[33] Tooley, F.A.P.; S.M. Prince; Taghizadeh, M.R.; McCornick, F.B.; Derstine, M.W.; Wakelin, S.; Implementation of a hibrid lens. Applied Optics, v.34, n.28, p.6471-6480, 1995.

[34] Rotich, S.; Smith, J.G.; Evans, A.G.R.; Brunnschweiler, A.; Photoresist parabolas for curved micromirrors, J. Micromechanical Engineering, v.8, p.108-110, 1998.

[35] Li, Q.; Gao, H.; Dong, Y.; Shen, Z.; Wang, Q.; Investigation of diffractive optical element for shaping a gaussian beam into a ring shaped pattern. Optics \& Laser Technology, v.30, p.511-514, 1998. 
[36] Silvennoinen, R. et al; Diffractive element in optical inspection of paper, Optical Engineering, v.37, n.5, p.1482-1487, 1998.

[37] Apresenta explicação sobre a teoria da óptica difrativa. Disponível em http://www.cepa.if.usp.br/e-fisica/otica/universitario/cap09/cap9_01.php. Acesso em Dezembro de 2005.

[38] Volkel, R.; Herzig, H.P.; Nussbaum, P.; Dandliker, R.; Hugle, W.B.; Microlens array imaging system for photolithography. Optical Engineering, v.35, n.11, p.33233330, 1996.

[39] Kasai, I.; Tanijiri, Y.; Endo, T.; Ueda, H.; A practical see-through head mouted display using holographic optical element, Optical Review, v.8, n.4, p.241- 244, 2001.

[40] Hendriks, B.H.W.; Schneipen, J.; Stallinga, S.; van Houten, H.; Optical pick-up for blue optical recording at NA=0.85. Optical Review, v.8, n.4, p.211-213, 2001.

[41] Ference, M.; Lemon, H. B.; Stephenson, R. J.. Curso de física. São Paulo: Ed. Edgard Blücher.

[42] Baker, B. B.; Copson, E.T. Huygen's Principle. Oxford: Oxford University Press.

[43] Ditchburn, R.W. Light. Academic Press. Vol. 1

[44] Apresenta teorias ópticas sobre o princípio de Huygens. Disponível em http://www.cepa.if.usp.br/e-fisica/otica/universitario/cap09/cap9_01.php. Acesso em Outubro de 2005.

[45] BREAULT RESEARCH ORGANIZATION. ASAP Technical Guide. Estados Unidos da América, 2005. 
[46] Apresenta definição do conceito de fase. Disponível em http://pt.wikipedia.org/wiki/Fase_\%28f\%C3\%ADsica\%29. Acesso em Agosto de 2005.

[47] Apresenta definição do conceito de amplitude. Disponível em http://pt.wikipedia.org/wiki/Amplitude. Acesso em Agosto de 2005.

[48] Salmeron, R. A. Introdução à óptica. Centro brasileiro de pesquisas físicas e o instituto de eletrônica da universidade do Brasil.

[49] Blaker, J.W.; Rosenblum, W.M.. Optics. Macmillan Publishing Company.

[50] Halliday, D.; Resnick, R. Física. São Paulo: Livros técnicos e científicos editora. v. 4.

[51] Young, M. Óptica e lasers. São Paulo: Edusp.

[52] Mckelvey, J. P.; Grotch, H. Física. São Paulo:Ed. Harpen \& Row do Brasil. v. 4.

[53] Sears, F. W. Física. São Paulo: Ed. Gertum Carneiro. v. 3.

[54] Tipler, P. A. Física. Rio de Janeiro: Ed. Guanabara Koogan. v. 4.

[55] Amako, J.; Sonehara, T.; Kinoform using an eletrically controlled birefringent liquid-crystal spatial light modulator. Applied Optics, v.30, n.32,p.4622-4628,1991.

[56] . Neto, L.G; Roberge, D.; Sheng, Y. Programmable Optical Kinoforms and aomplex-amplitude hologram with coupled-mode modulation LCTV. OE Reports, p. 9-12, 1995. 
[57] Neto, L.G.; D. Roberge, Y. S. Proglammable optical phase mostly holograms with coupled mode modulation liquid crystal television. Applied Optics, v. 34, n. 11, p.1944-1950, 1995.

[58] Salmio, R.P.; Saarikoski, H., Wsterholm, J.; Turunen, J. three dimensionaly modulated graded index diffractive elements by thermal ion exchange in glass. Optic Letters, v,22, n.9, p. 591-593, 1997.

[59] Davis, J.A.; Mcnamara, D.E.; Cottrell, D.M.; Campos, J. M.; Ysuel, J.; Moreno, I.; Encoding complex diffractive elements onto a phase-only liquid crystal spatial light modulator. Optical Engineering, v. 40, n.2, p. 327-329, 2001.

[60] Neto, L.G. Optical Real-time holograms using liquid crystal television and computer iterative design. 1995, Tese (Doutorado) - Facultè de Ciences et Gènie, Universite Laval, Quebec,1995.

[61] Apresenta conteudo teórico sobre o efeito da difração. Disponível em http://www.diptech.com.br/seminars/difracao/diffraction.html. Acesso em outubro de 2005.

[62] Herzig, H. P. Micro-optics. Taylor \&Francis, 1997. v.1.

[63] BREAULT RESEARCH ORGANIZATION. ASAP Technical Guide. Estados Unidos da América, 2005.

[64] O'Shea, D.; Suleski, T.; Kathman, A. Tutorial de óptica difrativa. SPIE.

[65] Gale, M. T. Diffractive optics and micro-optics production technology in Europe. Technical Digest, p. 18-20, 2002.

[66] Gale, M. T. Replicated diffractive optics and micro-optics. Optics \& Photonics News, p. 24-29, 2003. 
[67] Saarinen, J.; Rossi, M. Current Trends of Fabrication Technologies of DOE's and New Applications. Heptagon, Espoo Office.

[68] Apresenta Breve introdução sobre o polímero policarbonato. Disponível em http://pt.wikipedia.org/wiki/Policarbonato. Acesso em Agosto de 2005.

[69] Cirino, G. A. Fabricação de elementos ópticos difrativos empregando processos de microusinagem.2002. Tese (Doutorado) - Escola Politécnica, Universidade de SãoPaulo. São Paulo, 2002.

[70] Kluepefel, B.; Ross, F. Holography Market Place. Berkely: Ross Books, 1991.

[71] Gale, M. T.; Replication techniques for diffractive optical elements. Microeletronic engineering, p. 321-339, 1997.

[72] Herzig, H.P. Micro-optics: Elements, systems and applications. Bristol: Taylor and Francis, 1997.

[73] Pasco, I.K.; Everest, J.H. Plastics optics for opto electronics. Optics and Laser Technology, v.10, p.71-76, 1978.

[74] Brenner, K.H.; Kufner, M.; Kufner, S.; Moisel, J.; Sinzinger, S.; Testorf, M.; Gottert, J.; Mohr, J. Application of three-dimensional micro-optical components formed by lithography, electroforming, and plastic moulding. Applied Optics, v.32, p.6464-6469, 1993.

[75] Tomas, T. R. Rough Surfaces. Segunda Edição. Imperial college press.

[76] Bennett, J. M, Mattson, L. Introduction to Surface Roughness and Scattering. Washington: Optical Society of America, 1989. 
[77] Campbell, P.D.Q. An introduction to measuration and calibration. Industrial press.

[78] Apresenta teoria sobre rugosidade e como é feito seu cálculo. Disponível em http://myspace.eng.br/eng/rugosid.asp. Acesso em Fevereiro de 2006.

[79] Verdonck, P. B. Estudo sobre danos induzidos por plasma. 1998. 147p. Tese (Livre Docência) - Escola Politécnica, Universidade de São Paulo. São Paulo, 1998.

[80] Leech, P. W. Reactive ion etching of quartz and silica-based glasses in CF4/CHF3 plasmas. Vacuum, n. 55, p. 191-196, 1999.

[81] Thiénot, E.; F. Domingo, E.; Cambril, Gosse, C. Reactive ion etching of glass for bioship applications: Composition effects and surfaces damages. Microelectronic Engineering, n. 83, p. 1155-1158, 2006.

[82] Metwalli, E.; Pantano, C. G. Reactive ion etching of glasses: Composition dependence. Nuclear Instruments and Methods in Physics Research B, n. 207, p. 2127, 2003.

[83] Liu , J.; Nemchuk, N.I.; Ast, D.G.; Couillard, G. Etch rate and surface morphology of plasma etched glass and glass ceramic substrates. Journal of noncrystalline solids, n. 342, p. 110-115, 2004.

[84] Goyal, A.; Hood, V.; Tadigadapa, S. High speed anisotropic etching of Pyrex for microsystems applications. Journal of non-crystalline solids, n. 352, p. $657-663$, 2006.

[85] Bennett, J. M.; Dancy, J. H. Stylus profiling instrument for measuring statistical properties of smooth optical surfaces. APPLIED OPTICS, n. 10, p.1785-1802, 1981. 
[86] Duparre, A.; Ferre-Borrull, J.; Gliech, S.; Notni, G.; Steinert, J.; Bennett, J. M. Surface characterization techniques for determining the root-mean-square roughness and

power spectral densities of optical components. APPLIED OPTICS, n. 1, p.154-171, 2001.

[87] Guenther, K. H.; Wierer, P. G.; Bennett, J. M. Surface roughness measurements of low-scatter mirrors and roughness standards. APPLIED OPTICS, n. 21, p.3820$3836,1984$.

[88] Elson, J. M.; Rahn, J. P.; Bennett, J. M. Relationship of the total integrated scattering from multilayer-coated optics to angle of incidence, polarization, correlation length, and roughness cross-correlation properties. APPLIED OPTICS, $\mathrm{n}$. 20, p.3207-3219, 1983.

[89] Bennett, J. M. Recent developments in surface roughness characterization. Meas. Sci. Technol., n.3, p.1119-1127, 1992.

[90] Bennett, J. M.; Mattsson, L. Introduction to Surface Roughness and Scatering. Washington. DC, Optical Society of America, 1989.

[91] Apresenta conteúdo de um manual sobre as características do silício. Disponível em http://www.tydex.ru. Acesso em Dezembro de 2006. 